University of Louisville

ThinkIR: The University of Louisville's Institutional Repository

8-2009

\title{
Application of acousto-ultrasonic technique in evaluation of bond strength between composites and concrete substrates.
}

Stanley C. Stoll

University of Louisville

Follow this and additional works at: https://ir.library.louisville.edu/etd

\section{Recommended Citation}

Stoll, Stanley C., "Application of acousto-ultrasonic technique in evaluation of bond strength between composites and concrete substrates." (2009). Electronic Theses and Dissertations. Paper 1390.

https://doi.org/10.18297/etd/1390

This Master's Thesis is brought to you for free and open access by ThinkIR: The University of Louisville's Institutional Repository. It has been accepted for inclusion in Electronic Theses and Dissertations by an authorized administrator of ThinkIR: The University of Louisville's Institutional Repository. This title appears here courtesy of the author, who has retained all other copyrights. For more information, please contact thinkir@louisville.edu. 


\title{
APPLICATION OF ACOUSTO-ULTRASONIC TECHNIQUE IN EVALUATION OF BOND STRENGTH BETWEEN COMPOSITES AND CONCRETE SUBSTRATES
}

\author{
By \\ Stanley C. Stoll \\ B.S., University of Louisville, 2009

\begin{abstract}
A Thesis
Submitted to the Faculty of the

University of Louisville

J.B. Speed School of Engineering

as Partial Fulfillment of the Requirements

for the Professional Degree
\end{abstract}

\section{MASTER OF ENGINEERING}

Department of Civil \& Environmental Engineering

August 2009 



\section{APPLICATION OF ACOUSTO-ULTRASONIC TECHNIQUE IN EVALUATION OF BOND STRENGTH BETWEEN COMPOSITES AND CONCRETE SUBSTRATES}

Submitted By:

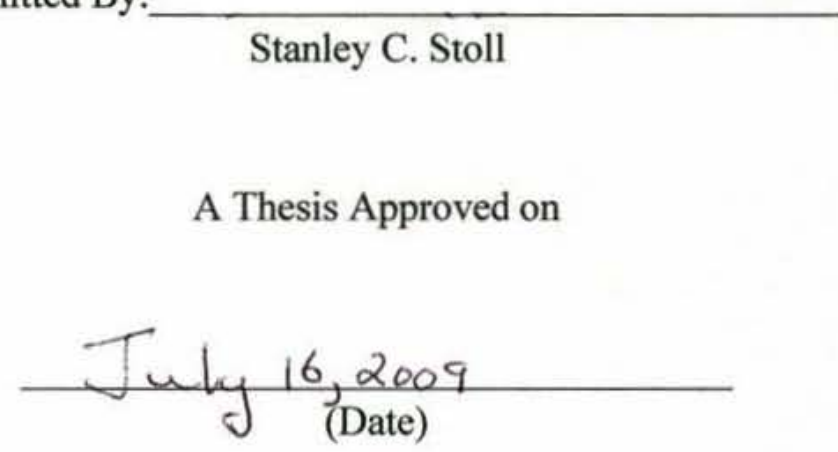

by the Following Reading and Examination Committee:

Dr. W. Mark McGinley, $\overparen{\text { P.E., Thesis Director }}$

Dr. Zhihui Sun

Dr. Roger D. Bradshaw 


\section{ACKNOWLEDGEMENTS}

I would like to give thanks and show my appreciation to the people who have provided invaluable assistance to me in pursuing my Master of Engineering Degree. First and foremost, I would like to thank my wonderful wife. Without your love, blessings, and unwavering support, this degree would not have been possible. I want to thank my graduate committee for their guidance and suggestions. A special thanks goes to Matt Cupps for his vast knowledge of programming. You provided the basis for the programs used to run all of the data within this thesis. I also owe Sean Gallegher and Sika Corporation thanks for their material donations and financial assistance.

Lastly, I owe my deepest gratitude to Dr. Mark McGinley. Your encouragement, guidance, and incredible engineering knowledge have made this thesis possible. You are a great educator and mentor. 


\begin{abstract}
APPLICATION OF ACOUSTO-ULTRASONIC TECHNIQUE IN EVALUATION OF BOND STRENGTH BETWEEN COMPOSITES AND CONCRETE SUBSTRATES
\end{abstract}

Stanley C. Stoll

July 10, 2009

The use of fiber reinforced polymer materials (composite FRP materials) to strengthen existing concrete structures continues to expand as our current infrastructure ages. However, one of the concerns when using FRP systems in this manner is the difficulty in determining the quality and strength of the bond between the concrete and FRP overlays. There appears to be a need for a reliable non-destructive testing (NDT) method that can directly determine the strength of this bond to ensure the structural performance of FRP-strengthened concrete systems.

The goal of this research was to evaluate whether a non-destructive acoustoultrasonic parameters (AUP) evaluation method could be used to determine the shear strength of the bond between FRP systems and concrete substrates. Eighteen concrete beams were externally reinforced flexurally with carbon fiber reinforced polymers (CFRP) and glass fiber reinforced polymers (GFRP) and then non-destructively tested using the AUP procedures. The test beam specimens were then placed in a simply supported configuration and loaded to failure. Interfacial shear strengths obtained from the destructive testing were compared against AUP analysis results to determine if a correlation could be established. 
Both longitudinal and shear transducers were utilized to collect propagating stress waves; however, only the longitudinal transducer provided consistent correlations to interfacial shear strength values. The investigation concluded that the (AUP) analysis procedure can be used to determine the interfacial shear bond strength of both glass and carbon fiber reinforced concrete beam specimens with relatively good correlation to actual strength data. 


\section{TABLE OF CONTENTS}

$\underline{\text { Page }}$

APPROVAL PAGE....................................................... ii

ACKNOWLEDGEMENTS .................................................. ii

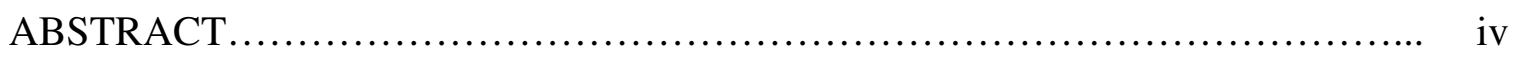

NOMENCLATURE....................................................... viii

LIST OF TABLES ..................................................... ix

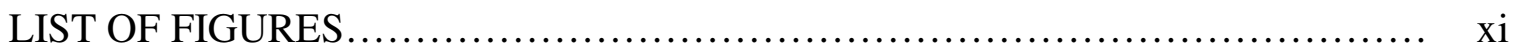

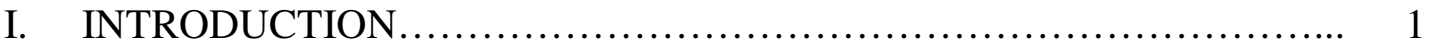

II. LITERATURE REVIEW .......................................... 4

A. Introduction............................................... 4

B. Concrete and FRP Shear Bond Strength Research.................. 5

C. Non-Destructive Evaluation Technologies........................ 6

D. Non-Destructive Evaluation of Concrete and Concrete/FRP Systems. 13

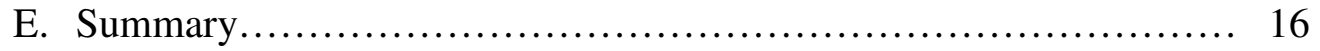

III. TEST PROGRAM................................................ 17

A. Introduction................................................. 17

B. Specimen Construction...................................... 17

C. Acousto-Ultrasonic Evaluations............................... 25

D. Testing Procedure Evaluation and Optimization.................. 30

E. Destructive Beam Tests..................................... 31

F. FRP Design Calculations ................................. 35

1. General Design Calculations.............................. 35

2. Carbon Reinforced Specimen Calculations................... 36

3. Glass Reinforced Specimen Calculations.................... 38

IV. TEST RESULTS ............................................... 41

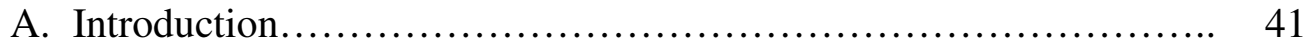

B. Acousto-Ultrasonic Parameter Calculation Procedures.............. 41

C. Acoustic Test Results....................................... 44

D. AUP and Energy Test Results................................ 54

E. Destructive Beam Test Results.............................. 67

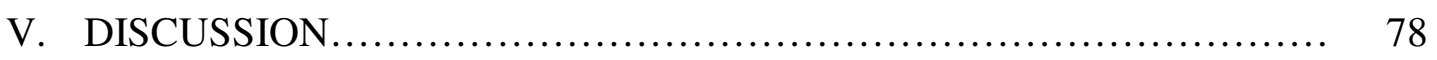

A. Introduction.................................................. 78

B. Received Signals........................................ 78

C. Destructive Beam Tests........................................ 79

D. AUP vs. CFRP Test Specimen Shear Bond Capacity............... 86

1. Longitudinal Receiving Transducer......................... 86 
2. Shear Receiving Transducer............................ 89

E. Energy vs. CFRP Test Specimen Shear Bond Capacity............. 92

1. Longitudinal Receiving Transducer....................... 92

2. Shear Receiving Transducer............................. 95

F. AUP vs. GFRP Test Specimen Shear Bond Capacity............... 97

1. Longitudinal Receiving Transducer......................... 97

G. Energy vs. GFRP Test Specimen Shear Bond Capacity............. 101

1. Longitudinal Receiving Transducer....................... 101

2. Shear Receiving Transducer............................ 102

H. AUP and Energy Transducer Distance Correlations................ 103

I. Summary of the Effectiveness of the NDT Procedures............. 105

VI. CONCLUSIONS AND RECOMMENDTIONS........................ 110

A. Conclusions.................................................. 110

B. Recommendations........................................ 111

REFERENCES ......................................................... 113

APPENDIX - AUP AND ENERGY TEST RESULTS .......................... 116

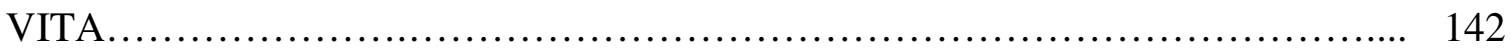




\section{NOMENCLATURE}

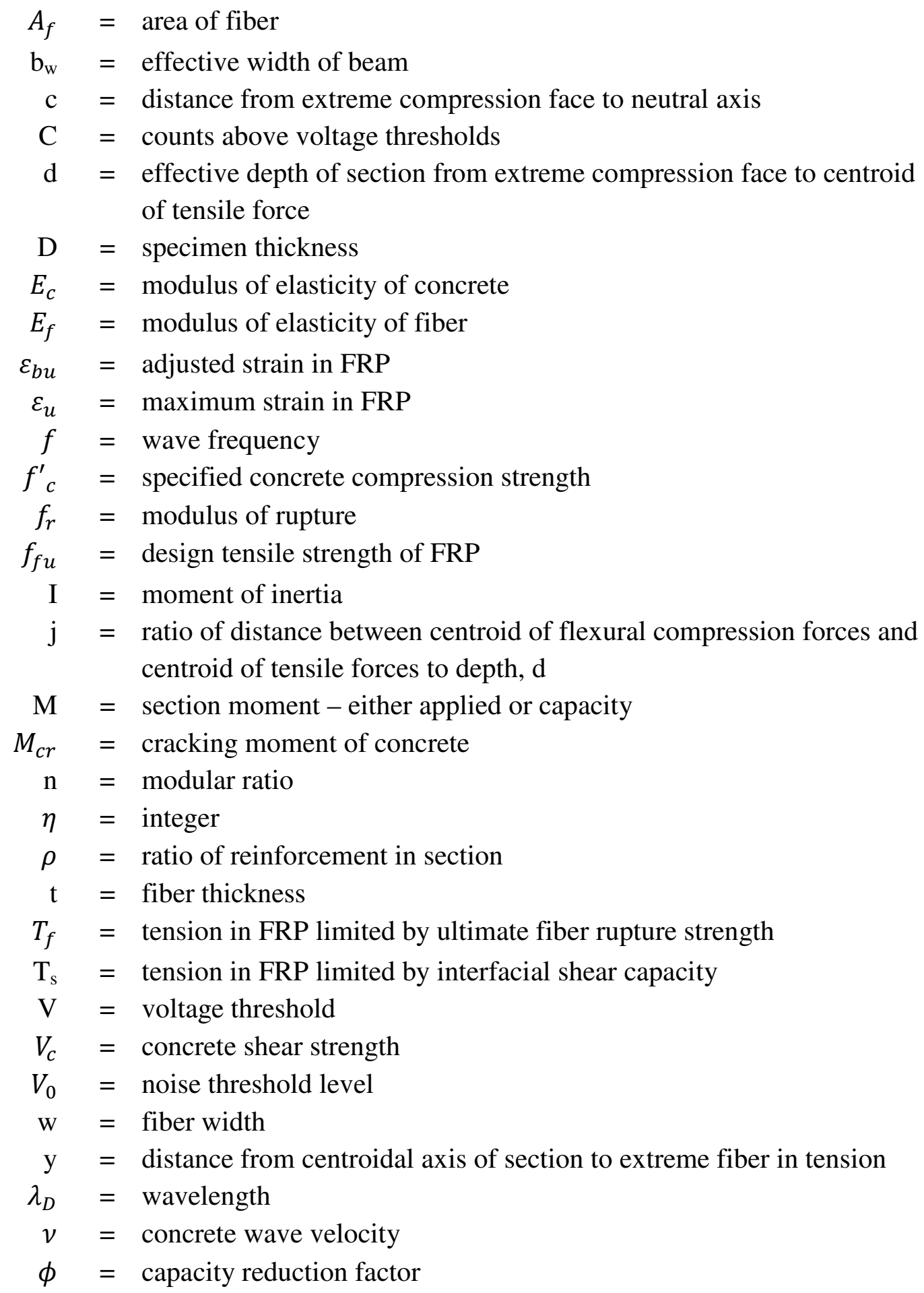




\section{LIST OF TABLES}

$\underline{\text { Page }}$

I. TEST SPECIMEN BOND DIMENSIONS AND FRP TYPE............... 23

II. SPECIMEN CONFIGURATION ................................... 24

III. CARBON SPECIMENS TESTED IN THE NEAR TO NEAR CONFIGURATION WITH LONGITUDINAL RECEIVING

TRANSDUCER .................................................... 55

IV. CFRP BEAM DESTRUCTIVE LOAD TEST RESULTS .................... 68

V. GFRP BEAM DESTRUCTIVE LOAD TEST RESULTS................... 69

VI. ESTIMATION OF GLASS TEST SPECIMEN DEBONDED AREA........ 74

VII. COMPANION CONCRETE CYLINDER COMPRESSION TEST RESULTS................................................... 77

VIII. CFRP REINFORCED TEST SPECIMEN LOADING VALUES AND FAILURE TYPE ................................................... 82

IX. GFRP REINFORCED TEST SPECIMEN LOADING VALUES AND

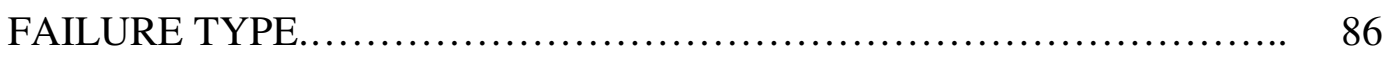

X. CORRELATION FACTORS BETWEEN NDT AND INTERFACIAL SHEAR LOADS ..................................................... 107

XI. CARBON SPECIMENS TESTED IN THE NEAR TO NEAR CONFIGURATION WITH LONGITUDINAL RECEIVING TRANSDUCER.

XII. GLASS SPECIMENS TESTED IN THE NEAR TO NEAR CONFIGURATION WITH LONGITUDINAL RECEIVING TRANSDUCER. 
XIII. CARBON SPECIMENS TESTED IN THE FAR TO NEAR CONFIGURATION WITH LONGITUDINAL RECEIVING TRANSDUCER

XIV. GLASS SPECIMENS TESTED IN THE FAR TO NEAR CONFIGURATION WITH LONGITUDINAL RECEIVING

TRANSDUCER

XV. CARBON SPECIMENS TESTED IN THE NEAR TO FAR CONFIGURATION WITH LONGITUDINAL RECEIVING TRANSDUCER

XVI. CARBON SPECIMENS TESTED IN THE NEAR TO NEAR CONFIGURATION WITH SHEAR RECEIVING TRANSDUCER

XVII. GLASS SPECIMENS TESTED IN THE NEAR TO NEAR CONFIGURATION WITH SHEAR RECEIVING

TRANSDUCER

XVIII. CARBON SPECIMENS TESTED IN THE FAR TO NEAR CONFIGURATION WITH SHEAR RECEIVING TRANSDUCER

XIX. GLASS SPECIMENS TESTED IN THE FAR TO NEAR CONFIGURATION WITH SHEAR RECEIVING TRANSDUCER. 


\section{LIST OF FIGURES}

$\underline{\text { Page }}$

1. Wooden Forms Used to Construct Concrete Beam Test Specimens............. 18

2A. Schematic Illustration of the Tensile Face of the ASTM-C78 Concrete Beam with $100 \%$ (Good) Bond Area.................................................................. 20

2B. Photo of ASTM-C78 Concrete Beam with 100\% (Good) Bond Area........ 20

3A. Schematic Illustration of the Tensile Face of the ASTM-C78 Concrete Beam with $75 \%$ (Medium) Bond Area................................ 21

3B. Photo of ASTM-C78 Concrete Beam with 75\% (Medium) Bond Area...... 21

4A. Schematic Illustration of the Tensile Face of the ASTM-C78 Concrete Beam with $50 \%$ (Poor) Bond Area...................................... 22

4B. Photo of ASTM-C78 Concrete Beam with 50\% (Poor) Bond Area.......... 22

5. Schematic Side Elevation of AUP NDT Set-up and Dimensions........... 27

6. Schematic Top Elevation of AUP NDT Set-up and Dimensions............ 27

7. Typical Near to Near Transducer Set-up........................... 28

8. Schematic of AUP NDT System................................ 29

9. Schematic Side Elevation of Third Point Load Test Set-up.............. 32

10. Schematic Side Elevation of Single Point Load Test Set-up............. 33

11. Side Elevation of Third Point Load Test Set-up...................... 33

12. Side Elevation of Single Point Load Test Set-up..................... 34

13. Strain Gage Configuration...................................... 34 
14. Beam Specimen Cross Section \& Stress Diagram.........................

15. Schematic Illustration of the AUP Calculation Process [Modified from

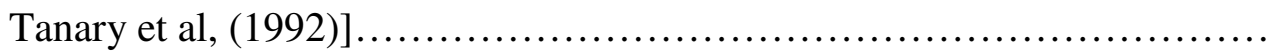

16. Received Wave Signal Collected from Specimen C-1 (Carbon Reinforced 100\% Bond Area) using a Longitudinal Receiving Transducer With a Gain of $20 \mathrm{~dB}$ in the Near to Near Transducer Configuration

17. Received Wave Signal Collected from Specimen C-3 (Carbon Reinforced 75\% Bond Area) using a Longitudinal Receiving Transducer With a Gain of $20 \mathrm{~dB}$ in the Near to Near Transducer Configuration.......................

18. Received Wave Signal Collected from Specimen C-5 (Carbon Reinforced 50\% Bond Area) using a Longitudinal Receiving Transducer With a Gain of $20 \mathrm{~dB}$ in the Near to Near Transducer Configuration....

19. Received Wave Signal Collected from Specimen C-1 (Carbon Reinforced 100\% Bond Area) using a Longitudinal Receiving Transducer With a Gain of $20 \mathrm{~dB}$ in the Far to Near Transducer Configuration

20. Received Wave Signal Collected from Specimen C-1 (Carbon Reinforced 100\% Bond Area) using a Longitudinal Receiving Transducer With a Gain of $20 \mathrm{~dB}$ in the Near to Far Transducer Configuration

21. Received Wave Signal Collected from Specimen C-2 (Glass Reinforced 100\% Bond Area) using a Longitudinal Receiving Transducer With a Gain of $20 \mathrm{~dB}$ in the Near to Near Transducer Configuration

22. Received Wave Signal Collected from Specimen C-2 (Glass Reinforced 100\% Bond Area) using a Longitudinal Receiving Transducer With a Gain of $20 \mathrm{~dB}$ in the Far to Near Transducer Configuration.....

23. Received Wave Signal Collected from Specimen B-1 (Carbon Reinforced 100\% Bond Area) using a Shear Receiving Transducer With a Gain of 40dB in the Near to Near Transducer Configuration

24. Received Wave Signal Collected from Specimen B-1 (Carbon Reinforced 100\% Bond Area) using a Shear Receiving Transducer With a Gain of 40dB in the Far to Near Transducer Configuration 
25. Received Wave Signal Collected from Specimen C-1 (Carbon Reinforced $100 \%$ Bond Area) using a Shear Receiving Transducer With a Gain of 40dB in the Near to Far Transducer Configuration......................... 54

26. Average AUP Test Results for Carbon Specimens Tested in the Near to Near Configuration with Longitudinal Receiving Transducer............. 56

27. Average Total Energy Test Results for Carbon Specimens Tested in the Near to Near Configuration with Longitudinal Receiving Transducer........

28. Average AUP Test Results for Glass Specimens Tested in the Near to Near Configuration with Longitudinal Receiving Transducer.

29. Average Total Energy Test Results for Glass Specimens Tested in the Near to Near Configuration with Longitudinal Receiving Transducer..............

30. Average AUP Test Results for Carbon Specimens Tested in the Far to Near Configuration with Longitudinal Receiving Transducer.

31. Average Total Energy Test Results for Carbon Specimens Tested in the Far to Near Configuration with Longitudinal Receiving Transducer.

32. Average AUP Test Results for Glass Specimens Tested in the Far to Near Configuration with Longitudinal Receiving Transducer.

33. Average Total Energy Test Results for Glass Specimens Tested in the Far to Near Configuration with Longitudinal Receiving Transducer.............. 60

34. Average AUP Test Results for Carbon Specimens Tested in the Near to Far Configuration with Longitudinal Receiving Transducer.

35. Average Total Energy Test Results for Carbon Specimens Tested in the Near to Far Configuration with Longitudinal Receiving Transducer.........

36. Average AUP Test Results for Carbon Specimens Tested in the Near to Near Configuration with Shear Receiving Transducer.

37. Average Total Energy Test Results for Carbon Specimens Tested in the Near to Near Configuration with Shear Receiving Transducer.............. 
38. Average AUP Test Results for Glass Specimens Tested in the Near to Near Configuration with Longitudinal Shear Transducer.

39. Average Total Energy Test Results for Glass Specimens Tested in the Near to Near Configuration with Longitudinal Shear Transducer.

40. Average AUP Test Results for Carbon Specimens Tested in the Far to Near Configuration with Shear Receiving Transducer.

41. Average Total Energy Test Results for Carbon Specimens Tested in the Far to Near Configuration with Shear Receiving Transducer.

42. Average AUP Test Results for Glass Specimens Tested in the Far to Near Configuration with Shear Receiving Transducer.

43. Average Total Energy Test Results for Glass Specimens Tested in the Far to Near Configuration with Shear Receiving Transducer.

44. Typical Cracking Moment Type Failure at the end of FRP Reinforcement.. $\quad 70$

45. Typical Cracking Moment Type Failure at the end of the CFRP Reinforcement (Bottom Side)

46. Carbon Interfacial Shear Debond (Specimen C-1, a 100\% Bond Area Specimen) with the Largest Amount of Fractured Concrete Material........

47. Typical Carbon Interfacial Shear Debond (Specimen B-3 a 75\% Bond Area Specimen) with Same Fractured Concrete Material...

48. Typical Carbon Interfacial Shear Debond (Specimen C-5, a 50\% Bond Area Specimen) with a Small Amount of Fractured Concrete Material.

49. Test Specimen C-4 Shows the Contrast in Color of the Bonded and Debonded FRP

50. Typical Glass Fiber Rupture Failure

51. Typical Glass Interfacial Shear Debond Failure. 
52. Interfacial Shear Load of Carbon Reinforced Test Specimen (Including Moment Failures) vs. Near to Near Longitudinal Normalized AUP Evaluations.

53. Interfacial Shear Load of Carbon Reinforced Test Specimen (Excluding Moment Failures) vs. Near to Near Longitudinal Normalized AUP Evaluations.

54. Interfacial Shear Load of Carbon Reinforced Test Specimen (Excluding Moment Failures) vs. Far to Near Longitudinal Normalized AUP Evaluations

55. Interfacial Shear Load of Carbon Reinforced Test Specimen (Including Moment Failures) vs. Near to Near Shear Normalized AUP Evaluations....

56. Interfacial Shear Load of Carbon Reinforced Test Specimen (Excluding Moment Failures) vs. Near to Near Shear Normalized AUP Evaluations.....

57. Interfacial Shear Load of Carbon Reinforced Test Specimen (Including Moment Failures) vs. Near to Near Longitudinal Normalized Energy Evaluations.

58. Interfacial Shear Load of Carbon Reinforced Test Specimen (Excluding Moment Failures) vs. Near to Near Longitudinal Normalized Energy Evaluations.

59. Interfacial Shear Load of Carbon Reinforced Test Specimen (Excluding Moment Failures) vs. Far to Near Longitudinal Normalized Energy Evaluations.

60. Interfacial Shear Load of Carbon Reinforced Test Specimen (Including Moment Failures) vs. Near to Near Shear Normalized Energy Evaluations..

61. Interfacial Shear Load of Glass Reinforced Test Specimen (Including Interfacial Shear Loads Above 5.0 kips) vs. Near to Near Longitudinal Normalized AUP Evaluations.

62. Interfacial Shear Load of Glass Reinforced Test Specimen (Excluding Interfacial Shear Loads Above 5.0 kips) vs. Near to Near Longitudinal Normalized AUP Evaluations. 
63. Interfacial Shear Load of Glass Reinforced Test Specimen (Excluding Interfacial Shear Loads Above 5.0 kips) vs. Far to Near Longitudinal Normalized AUP Evaluations...

64. Interfacial Shear Load of Glass Reinforced Test Specimen (Excluding Shear Loads Above 5.0 kips) vs. Near to Near Longitudinal Normalized Energy Evaluations.

65. Interfacial Shear Load of Glass Reinforced Test Specimen (Excluding Shear Loads Above 5.0 kips) vs. Far to Near Longitudinal Normalized Energy Evaluations.

66. Interfacial Shear Load of Carbon Reinforced Test Specimen (Including Moment Failures) vs. Averaged Near to Near and Far to Near Longitudinal Normalized AUP Evaluations...

67. Interfacial Shear Load of Carbon Reinforced Test Specimen (Excluding Moment Failures) vs. Averaged Near to Near and Far to Near Longitudinal Normalized AUP Evaluations. 


\section{INTRODUCTION}

The use of fiber reinforced polymer materials (composite FRP materials) to strengthening existing concrete structures continues to expand as our infrastructure ages. In many cases, these FRP overlay systems provide a relatively low cost and effective method to repair and strengthen reinforced concrete structural elements (Alkhrdaji and Thomas 2004). These systems have become more appealing as an increased number of these structures need repair and maintenance budgets dwindle. However, one of the concerns in the use of FRP system is the difficulty in determining the quality and strength of the bond between the concrete and FRP overlays and, ultimately, the performance of the strengthened member. In addition, after the application of the FRP materials, environmental conditions may later affect the strength and performance of the composite systems. This change in system performance characteristics is currently difficult to assess.

To ensure adequate bond between the FRP systems and concrete substrates, the provisions in ACI 440.2R-02, Guide for the Design and Construction of External Bonded FRP System for Strengthening Concrete Structures (ACI 440 2002), explicitly describes surface preparation and FRP application techniques. In addition, this document has provisions that require field inspection of the fiber application and final patch configuration in an effort to identify voids and other defects in the system. To accomplish this, it is suggested that visual inspection, sounding, and ultrasonic methods 
be used to identify voids and delaminations in the FRP overlay. In critical shear bond applications, ACI 440R.02 also recommends pull-off tests be conducted (ASTM C1583 2004). However, these pull-off tests are destructive, are applied to a limited area, and impact the integrity of the FRP overlay.

Over the past few years, a number of non-destructive techniques have been developed and used to evaluate the integrity of structures, inspect materials and evaluate the strength of repairs in metal and composite construction. When non-destructive evaluation (NDE) methods have been successfully used to evaluate FRP composite overlays, most have focused on the identification of voids and defects in the FRP materials. The presence of a void however, does not necessarily correspond to a significant reduction in strength (Rao \& Daniel 1999; Tanary et al. 1992). In addition, the ultrasonic NDE methods that have been applied to FRP and concrete composite systems do not appear to be able to identify areas in the FRP matrix that may have lower strengths due to improper manufacturing, construction, or environmental factors. Thus, these methods do not address the fundamental question of degree (strength) of bond, which is critical in the estimate of the performance of the joined materials. Thus, there is a need for a reliable NDT method that can be used to directly determine the strength of the interface bond to ensure the structural performance of FRP strengthened concrete systems.

The goal of this thesis was to evaluate whether NDE methods could be developed to determine the shear bond strength between composite FRP and concrete systems. Specifically, this investigation evaluated whether an acousto-ultrasonic method could be 
used to evaluate the shear strength of the bond between CFRP, or GFRP, and concrete substrates.

This thesis summarizes the investigation of 18 concrete beams flexurally reinforced with CFRP and GFRP and non-destructively tested with an acousto-ultrasonic procedure. Chapter II summarizes materials reviewed that were related to this research. Chapter III describes the design calculations, analysis procedures and testing program. Test results are presented in Chapter IV. Chapter V discusses the results and evaluates the validity of the NDT procedures. Chapter VI presents the conclusions and recommendations of this investigation. 


\title{
II. LITERATURE REVIEW
}

\author{
$\underline{\text { A. Introduction }}$
}

Reinforced concrete members must be strengthened for a variety of reasons, including change of occupancy, concrete deterioration, insufficient reinforcement, corrosive damage, structural damage and seismic upgrade. Experimental work using fiber reinforced polymer (FRP) materials on concrete structures was reported as early as 1978 in Germany and FRP systems have been used to strengthen concrete and masonry structures world-wide since the 1980's (ACI 440 2002). Today, structural elements such as beams, columns, slabs, walls, domes, tunnels, silos and other concrete and masonry structures are being routinely strengthened with FRP (ACI 440 2002).

The successful application of external FRP systems is highly dependent upon the strength of the bond developed between the FRP and the substrate since this bond affects the composite action developed. Engineers must ensure the FRP is bonded securely to the concrete substrate without significant defects in order to ensure the composite action assumed in design calculations. Delaminations and other weaknesses can cause premature failure of FRP strengthened concrete beams.

ACI Committee 440.2R currently requires the use of pull-off tests (ASTM C1583 2004) and visual observations to assess concrete/FRP bond quality. However, this 
quality assurance test only provides localized data on the concrete/FRP bond quality, and does not assess the overall shear bond, nor the effective strength of the composite beam.

As the current infrastructure continues to degrade, use of FRP systems will continue to increase as viable solutions to improving and restoring the strength of concrete elements and a more quantitative measure of bond performance will be needed.

\section{B. Concrete and FRP Shear Bond Strength Research}

Lorenzis et al. (2001) examined the bond and force transfer mechanism in FRP plates bonded to concrete by using single-lap beam specimens. Test specimens consisted of 48-inch long plain concrete beams with an inverted $\mathrm{T}$ shape and a-42 inch span. A steel hinge was placed in the top of the beam at mid-span and a vertical saw cut was placed in the bottom of the beam at the same location. The FRP system used to provide tensile strength to the beam consisted of a two-inch wide CFRP strip running longitudinally on the bottom of the concrete beam. A transverse strip of CFRP was lapped over the top of the longitudinal strip on one side of the saw cut to force the debonding to occur on the opposite side of the specimen. Three CFRP bond lengths were used to create variation in testing specimens. Additional parameters investigated included the effect of surface preparation, type of adhesive, the effect of concrete strength on the interfacial bond strength, force transfer mechanism between the composite plates and the concrete substrate and the width of the FRP sheet.

Lorenzis et al. concluded that there appeared to be two common types of failure mechanisms between the concrete and the FRP overlay, and which occurred depended on 
the type of adhesive used. The first failure mechanism was direct concrete shearing beneath the concrete surface and the second was a cohesion failure between the FRP matrix and the concrete substrate. They predicted that when the failure mode is governed by the shearing of the concrete, the ultimate bond strength will be proportional to the square root of the concrete's compressive strength. The investigation also indicated that there is an effective bond length in which no further increase in failure load can be achieved. The researchers finally noted that an increase in the number of fiber plies is not directly proportional to the increase in a beam's flexural strength. They showed that the addition of a second ply only produced one and a half times the ultimate load resistance of a single ply. They also concluded that surface preparation can influence the bond strength.

\section{Non-Destructive Evaluation (NDE) Technologies}

Vary and Bowles (1979) investigated acousto-ultrasonic waves and the use of a stress wave factor (SWF) NDE process. In their investigation, Vary and Bowles performed evaluations of 15 AS-graphite PMR-15 polyimide panels where only the curing pressure was varied. In performing the SWF measurements, a sending transducer injected a longitudinal ultrasonic pulse into the specimen. The waves propagated through the material in a manner resembling actual acoustic emission events that would have arose if the materials were stressed and experienced local micro-cracking. The simulated stress waves mimicked the energy and frequency content of stress wave emissions produced by actual micro-cracking in the material. A receiving transducer intercepted 
some of the radiating energy waves injected into the material. The instrumentation used operated within a narrow frequency range between 0.1 and $2.5 \mathrm{MHz}$ to ensure that it was in the order of magnitude of the thickness of the specimen. In this research, pulses were injected with a $2.25 \mathrm{MHz}$ transducer because higher frequencies would not produce a good SWF for the full range of the material conditions, and the attenuation would be too high for the higher void concentrations. Frequencies approximately $0.1 \mathrm{MHz}$ would not produce wave interactions appropriate for the microstructure of the test specimens.

Vary and Bowles found that received wave signals were in a decaying sinusoidal form and simulated a stress wave footprint that varied with those material properties that might alter the stress waves traveling through the specimen. They also found that signal propagation through test materials parallel to the fiber directions better approximates loading stress waves, SWF and the cure pressure was proportional, and higher values of the SWF corresponded to greater values of inter-laminar shear strength. A composite with high values of SWF would exhibit higher strength because resistance to fracturing is enhanced by the same factors that increase the SWF. The researchers noted that since the received signal is a function of the material thickness, the effects of large thickness variations should be considered when performing SWF measurements. They also noted that the calculated SWF is a relative measure, will differ for various specimen geometries and requires calibration against a standard piece of material as a reference. The authors stated that the number of oscillations used in the SWF calculations can be related directly to wave energy content as measured by finding the root-mean-square amplitude of the burst waveform and the coupling media is an important factor in the transfer of energy to 
and from the test specimens. For graphite-polyimide composite specimens, an appropriate coupling media was determined to be water with a wetting agent.

Weston-Bartholomew (1981) sought to establish a NDT method capable of determining fatigue life of materials under service level loadings. Their investigation addressed the use of the Leaky-Rayleigh Wave methodology to perform the NDE tests. The procedure was performed by placing a homogeneous material under water and then sending a longitudinal wave through the water at various angles to the homogeneous material's surface. When the longitudinal waves strike the surface of the material, three waves are generated in the test specimen and propagated through the material: a longitudinal, a shear, and a Rayleigh wave. The values of these angles and propagation speeds were determined by Snell's Law, which describes the relationship between the angles and the velocities of the incident and refracted waves. By adjusting the angle of the initial longitudinal wave, a critical Rayleigh angle can be achieved so most of the energy propagates as a Rayleigh surface wave. This procedure of analyzing Rayleigh waves is referred to as the Leaky Rayleigh Wave because the fluid absorbs energy as the wave propagates across the surface. The data for their experiments were collected by varying the angle of incidence and simultaneously observing the reflected waves on the screen of an oscilloscope.

The specimens used by the researchers were made of titanium and mild steel. They were subjected to high stress levels and relatively low cycles. The author found it difficult to correlate any results with the performed fatigue tests and suggested that more testing be performed in the area to try to establish a correlation. 
Fahr et al. (1989) sought to utilize an acousto-ultrasonic parameter (AUP) methodology to evaluate the shear strength of steel/rubber adhesively bonded joints exposed to various temperatures. The researchers used a form of the SWF procedure that had been developed by Williams and Lampert (1980) (the AUP technique) to analyze temperature effects on single-lap shear specimens. The AUP evaluations were performed on the lap steel specimens by creating an input signal with an ultrasonic instrument, passing the signal through a repetition controller, a reset timer and then exciting a broadband transmitting transducer $(0.1 \mathrm{MHz}-2 \mathrm{MHz}$ with nominal central frequency of $.5 \mathrm{MHz})$. At a fixed distance, a receiving transducer (1 MHz nominal central frequency) intercepted the propagating ultrasonic waves. The received waves were amplified by 40 $\mathrm{dB}$, passed through a filter and processed in real time by a standard acoustical emissions instrument. A clamping device was used to minimize test variation by applying constant pressure to the transducers for each testing specimen. Mechanical tension testing was then performed on the steel single-lap specimens through direct shear tests performed in accordance with ASTM standard D1002-72. The mild steel strips were one-inch wide, 0.12-inch thick and cut to five-inch lengths. In addition, the researchers performed evaluations on test specimens exposed to cyclical temperature ranges.

Fahr et al. concluded that the AUP NDE procedure is sensitive to changes in strength of the epoxy adhesives at varying temperatures. The researchers noted the propagating waves were affected by the changes in the elastic modulus of the epoxies; and therefore, a good correlation between the shear strength and the AUP value for cyclical temperature exposures was shown. The researchers concluded this method can 
be used to non-destructively monitor and assess the strength degradations of adhesively bonded joints during and after exposures to varying temperatures.

Tanary et al. (1992) assessed the feasibility of using the AUP technique to nondestructively evaluate the bond strength of adhesively bonded graphite/epoxy composite joints. The researchers used single lap shear jointed specimens with three variations in the bond strength. The debonded specimens were created by applying grease to the center area of the bonding surface. The voided specimens were constructed by removing the center portion of the adhesive prior to joining the two specimens. An AUP testing procedure was performed on each specimen by applying a transmitting transducer directly on top of the lap splice and placing a receiving transducer two inches away on the same side of the specimen as the transmitting transducer.

An ultrasonic instrument was used to generate an input signal that passed through a repetition controller and reset timer into the transmitting transducer with a $500 \mathrm{KHz}$ central frequency. The ultrasonic waves were injected normal to the test specimen surface producing oblique reflections and shear waves that radiated through the test specimen. The shear waves were intercepted by the receiving transducer, amplified, passed through a $125-1000 \mathrm{KHz}$ filter, and then processed in real time by a standard acoustic emission instrument. In order to improve the data reliability, a fixture was utilized to hold the transducers against the test specimens. After completion of the acousto-ultrasonic testing procedure, the test specimens were loaded in tension to failure using a universal testing machine. The data obtained from the NDE procedure was analyzed using the AUP equations and compared to the actual shear strength determined from the direct tension test. 
Tanary et al. concluded the AUP methodology provides a good means of rating the efficiency of stress wave energy propagation through a material. The oblique and shear waves which propagate through the material interact with a significant portion of the bond line volume that lies in their path. Thus, the waves are affected by the microstructural and morphological properties, which also determine structural performance. The AUP technique can also be used to detect the presence of voids and unbonds by analyzing the frequency spectra of the acousto-ultrasonic waveform. The researchers also noted that large void areas do not necessarily correlate with low shear strengths. Therefore, void area alone cannot be used directly to establish shear strength values.

Rao and Daniel (1999) evaluated butt-jointed aluminum plates lapped with composite materials using a NDT method that measures an AUP value. Experiments were performed on both a symmetric patch specimen in which composite patches were applied to both sides of two butt-jointed aluminum plates and on an asymmetrical patch specimen in which only one patch was applied to the aluminum plates. All of the specimens were double lap butt joints consisting of two-inch wide by four-inch long by 0.2-inch thick aluminum plates joined together with composite patches. FM-73 film adhesive was used to bond the composite patches to the aluminum plates. Two 0.2inches wide by 0.002 -inch thick Teflon strips were inserted at the interface between the film adhesive and at the butt joint. Variation in specimen strengths were created by inserting controlled voids at the bond interface, creating debonds, and by altering the surface preparation treatment.

In this investigation, NDE used two transducers, the transmitting (1.0 Mhz) ultrasonic transducer was mounted on the surface of the aluminum plate near the patch, 
and the receiving transducer, with a central frequency of $150 \mathrm{kHz}$, was mounted on top of the composite patch. Both transducers were clamped to the material to improve reproducibility. The transmitting ultrasonic transducer was excited by a tone-burst pulse of five cycles of $150 \mathrm{kHz}$ at a repetition rate of $180 \mathrm{kHz}$. Each of the received signals were analyzed to determine total signal energy and an AUP parameter as defined.

1. Energy - as represented by the area under the rectified waveform signal as follows:

$$
\text { Energy }=\int f(t) d t
$$

2. Acousto-ultrasonic parameter (AUP) - The AUP is found to be approximately proportional to the area under the positive portion of the waveform and is therefore related to the energy and calculated by the following equation:

$$
A U P=\sum_{i=0}^{p}\left[V_{i}\left(C_{i}-C_{i+1}\right)\right]
$$

where, $\mathrm{V}_{\mathrm{i}}=$ voltage level, $\mathrm{V}_{0} \& \mathrm{~V}_{\mathrm{p}}$ are threshold and peak voltage level, respectively, and $\mathrm{C}_{\mathrm{i}}$ is the number of counts corresponding to voltage level $\mathrm{V}_{\mathrm{i}}$.

Rao and Daniel (1999) concluded that patch debonding and bond strength can be detected and correlated with various parameters from the AU evaluation process including strain, energy, AUP and the wave form correlation factor. 


\section{Non-Destructive Evaluation of Concrete and Concrete/FRP Systems}

An investigation performed by Bastianini et al. (2001) further pursued the idea of pulsed echo ultrasonics to establish the effectiveness of using ultrasonic testing methods on two different bonded materials, homogenous and non-homogeneous, to detect bonding defects. This ultrasonic NDE technique was intended to only measure the relative amplitude of the first recorded echo peak and use the phenomenon to detect the interface of the two different media. At the interface, the majority of the energy of the incident wave is refracted, while the remaining wave energy is reflected back. It was determined that the ratio between the energy of the refracted wave and the reflected wave is related to the acoustical impedance mismatch between the two different media. When a perfect bond is present between the FRP and the concrete substrate, the acoustical impedance mismatch is small. Therefore, the waves are transmitted almost entirely into the concrete and quickly refracted, reflecting little back to the origin. However, when discontinuities are present between the two media, a large acoustical impedance is created. This impedance leads to a great amount of energy reflected back to the origin, resulting in a notable echo peak. It was postulated that this phenomena could be used to detect and locate voids in the interface. Several experimental tests were performed on cylinders with known discontinuities.

The results from these tests clearly showed the known discontinuities by mapping them through a correlation between the first echo peak amplitude and using shades of light. They also found that when testing a relatively homogeneous FRP material, applied to a non-homogeneous material, like concrete or masonry, the non-homogeneous 
materials will scatter the ultrasonic wave reflection; thus, skewing the test results if any reflection is recorded at all.

Carino (2001) provided an overview of the impact-echo discontinuity detection method and discussed the parameters used for evaluation of this testing procedure. There were no evaluations performed by Carino for this reference article; however, the necessary parameters and the specifics of how to perform the test were discussed. The author noted that when a disturbance is created at a point on the surface of a homogenous material, energy waves are created. Two forms of these energy waves, pressure $(\mathrm{P})$ and shear $(\mathrm{S})$ waves, are associated with normal stresses and propagate radially through the material while the Rayleigh $(\mathrm{R})$ wave propagates only across the surface. All three energy wave forms travel through the material at speeds proportional to the Poisson's ratio for that material.

When used in a NDT procedure, the propagating waves will become incident on the interface of dissimilar materials and reflect off of that material at a specified angle. The amplitude of the reflected wave is a function of the incident angle and will be a maximum at 90 degrees (normal incidence). For normal incidence, the reflection coefficient is related to the impedance of the two materials. Since the specific acoustical impedances are known for various materials, this method can be used to identify discontinuities. It has been found that there is a relationship between the frequency, ' $\mathrm{P}$ ' wave speed, and thickness of the material. Carino stated that when using frequency analysis of the impact-echo method, the objective is to determine the dominant frequencies in the recorded waveform, typically using the Fast Fourier Transform technique to transform the recorded waveform into the frequency domain. The value of 
the peak frequency in the amplitude spectrum can be used to determine the depth of the interface. Thus, the frequency analysis can be used to determine plate thickness or the depth of the interface between two materials. For plate-like structures, it is assumed that the thickness frequency will be the dominant peak of the spectrum. This methodology has been developed into an ASTM standard test method.

Ekenel et al. (2005) investigated the use of an Acousto-Ultrasonics (AU) NDT method to detect and characterize surface defects in the form of delaminations of CFRP from concrete substrates. They also used NDT methodologies to examine defects in interfaces between layers of CFRP when more than one layer was applied. Testing was conducted on a Missouri bridge that was originally constructed in 1958. Fifteen CFRP overlays were applied to the bridge in various locations. Delaminations were created in the epoxy matrix. Ten of these sample locations were scanned using an acoustoultrasonic method to create C-scan images, a two-dimensional presentation of the data where color was used to represent the reflected acoustic energy. The C-scan images clearly showed the locations of delaminations in the CFRP through color contrasts and they concluded the acousto-ultrasonic NDT methodologies can detect delaminations between FRP and concrete substrates without being adversely influenced by interior reinforcement or aggregate. However, these experiments showed that this NDT method cannot establish whether the debonding was at the concrete-CFRP interface or between CFRP layers. 


\section{E. Summary}

Quality assurance test and evaluation procedures are critical in the use of FRP systems to reinforce structural concrete members. Current NDE research concerning concrete/FRP interfacial shear strength has been oriented to relate debonded and voided areas with total interfacial shear strength. Tanary et al.'s (1992) research determined that void area alone cannot be used directly to establish shear strength values. The SWF and AUP methodologies have provided direct relationships between the measured NDT parameters and interfacial shear strength for two homogeneous materials. Research is needed to determine whether the SWF and AUP methodologies are applicable to evaluate the interfacial shear strength of FRP overlays and concrete substrates. 


\title{
III. TEST PROGRAM
}

\author{
$\underline{\text { A. Introduction }}$
}

The following testing program was developed to investigate the use of AUP NDE methodology to directly assess the shear strength of composite overlays bonded to concrete substrates. The investigation described in the following section is the first phase of a planned three-phase research project to determine whether a relationship can be found between an acoustic emission (AE) wave characteristic and the interfacial shear strength developed between FRP overlays and concrete substrates.

In an effort to evaluate the AUP methodology on FRP/concrete bond interfaces, 18 standard plain concrete beam specimens were constructed and externally reinforced flexurally with either GFRP overlays, or CFRP overlays. The beams were first tested non-destructively using AUP procedures and then loaded to failure in a simply supported beam configuration using a universal testing machine.

\section{B. Specimen Construction}

Each of the six-inch wide by six-inch deep by 20-inch long ASTM-C78 plain concrete beam specimens were constructed with a $1 \frac{1}{2}$-inch wide gap in the bottom half of 
the beam at center span (see Figure 1). This gap was formed using a 1/2-inch thick piece of plywood, three inches high by six inches long. This specimen configuration ensured the flexural tension stresses were resisted primarily by the FRP overlays. The spacer placement also ensured beam cracking would initiate at mid span. The configuration allowed direct calculation of the interfacial shear stresses.

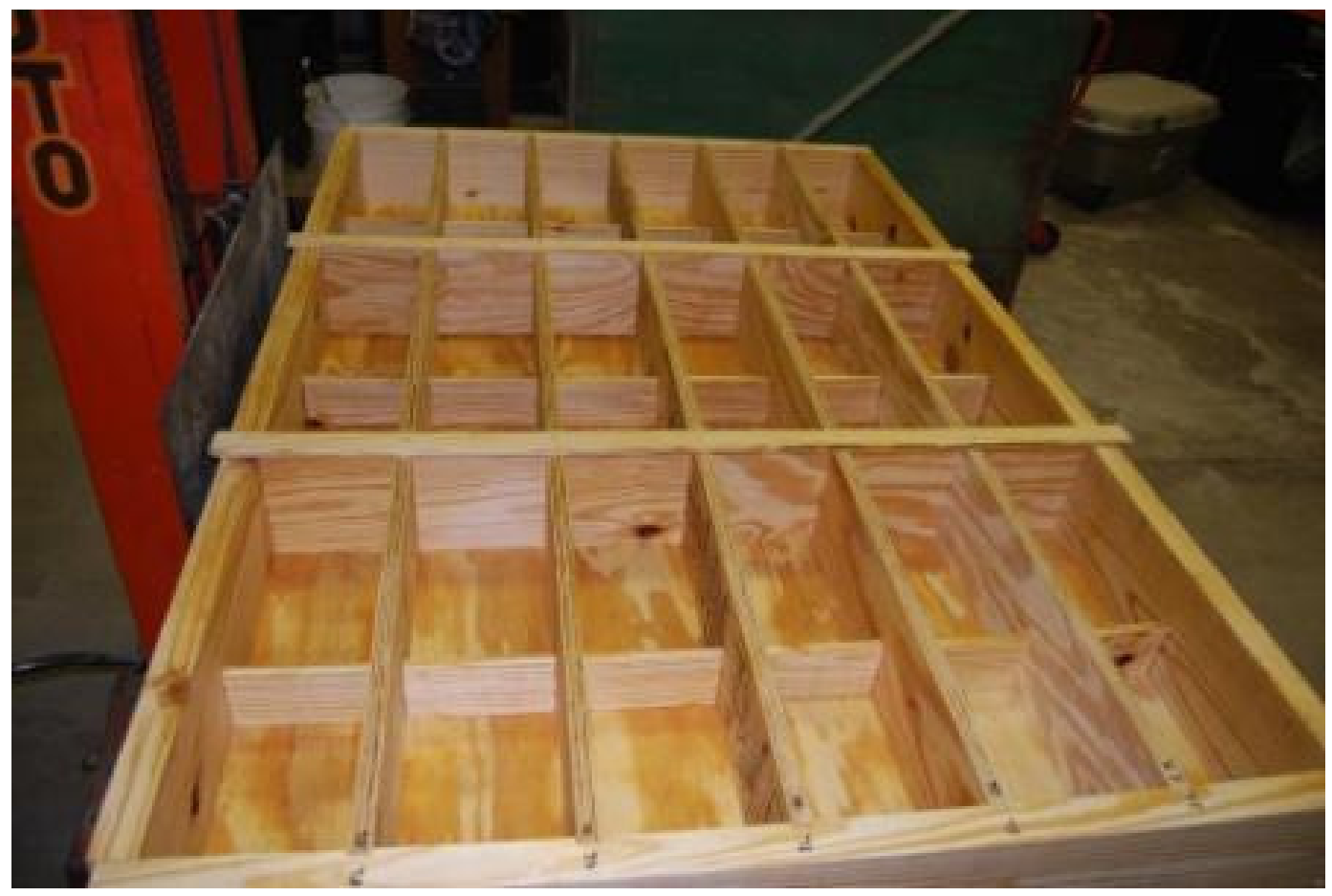

FIGURE 1. Wooden Forms Used to Construct Concrete Beam Test Specimens.

Three batches of Sikacrete ${ }^{\circledR} 211$ (specified strength - 5000psi) were used to construct the beam specimens. Cylindrical companion compression test specimens (three inch by six inch) were cast and cured with each of the beam specimens to verify the concrete's compressive strength. After the beam specimens were moist-cured for 28 days, they were removed from the forms and air dried before preparation for the FRP overlays. 
Preparation of the concrete specimen surface was performed in accordance with the manufacturer's recommendations using a diamond blade grinder to level the concrete surface and expose the aggregate. A vacuum was used to remove dust particles from the pours of the concrete surface.

One ply of SikaWrap ${ }^{\circledR}$ Hex $103 \mathrm{C}$ was used as the CFRP overlay and what was supposed to be one ply of Sika Hex 100G was used as the GFRP overlay. During construction it was not clear whether the furnished glass fibers were actually those specified, and a decision was made to apply three layers of glass fiber overlay. The expected performance of the beam specimens is described in Section E later in this chapter, and a discussion of the actual materials used and its effects on performance is presented in Chapter V. The overlays were three inches wide and 8.5 inches long, centered over the wooden spacer at the bottom of the beam specimen. Variation in FRP bond strength was established by varying the width of the surface bond area of both the glass and carbon overlays. One set of specimens used $100 \%$ of the surface area (approximately 12 square inches) and was defined as good bond. Other specimen sets limited surface area bond using tape that was placed on the concrete surface prior to epoxy application. This was done to limit epoxy bond as shown in Figures 2 through 4. Thus, specimen sets with $75 \%$ (medium, approximately eight square inches) and 50\% (poor, approximately five square inches) bond areas were constructed. Table 1 shows the as-built dimensions of each of the beam test specimens. 


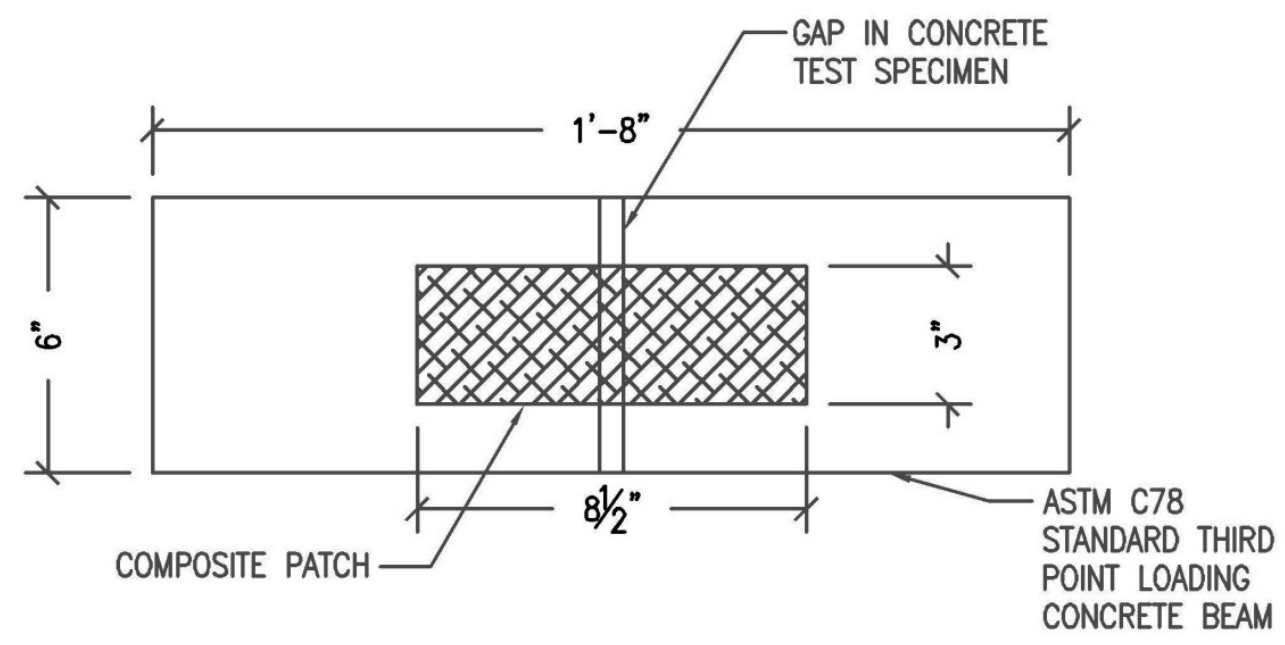

FIGURE 2A. Schematic Illustration of the Tensile Face of the ASTM-C78 Concrete Beam with 100\% (Good) Bond Area.

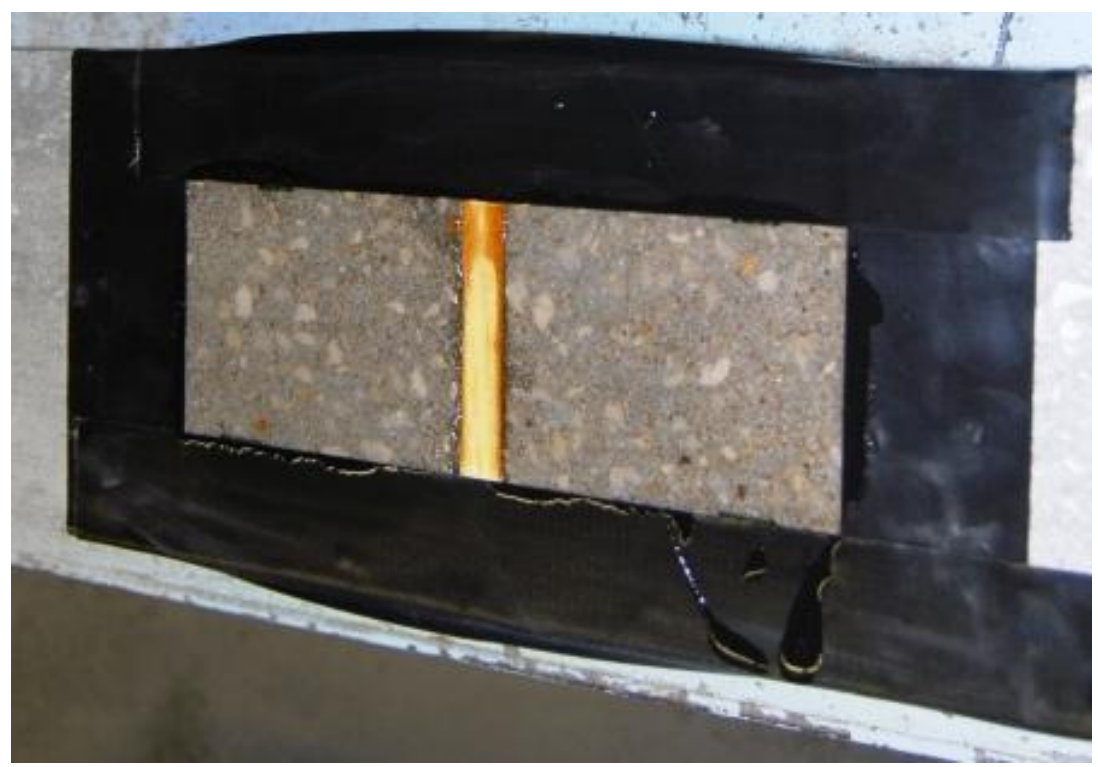

FIGURE 2B. Photo of ASTM-C78 Concrete Beam with 100\% (Good) Bond Area. 


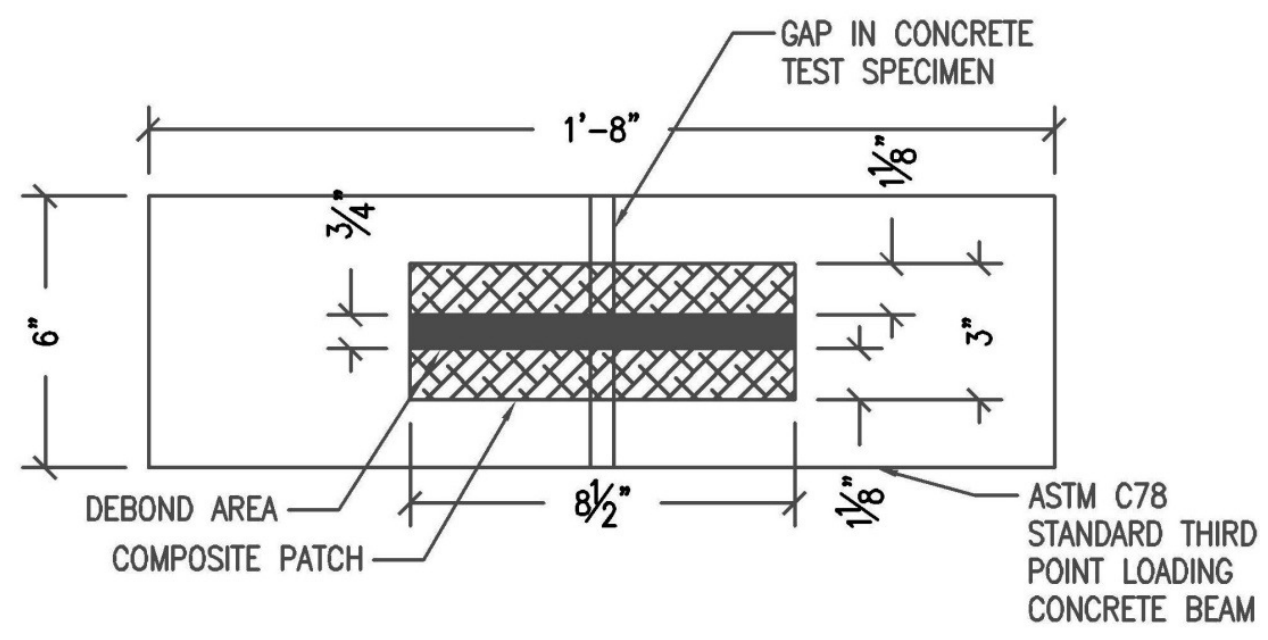

FIGURE 3A. Schematic Illustration of the Tensile Face of the ASTM-C78 Concrete Beam with 75\% (Medium) Bond Area.

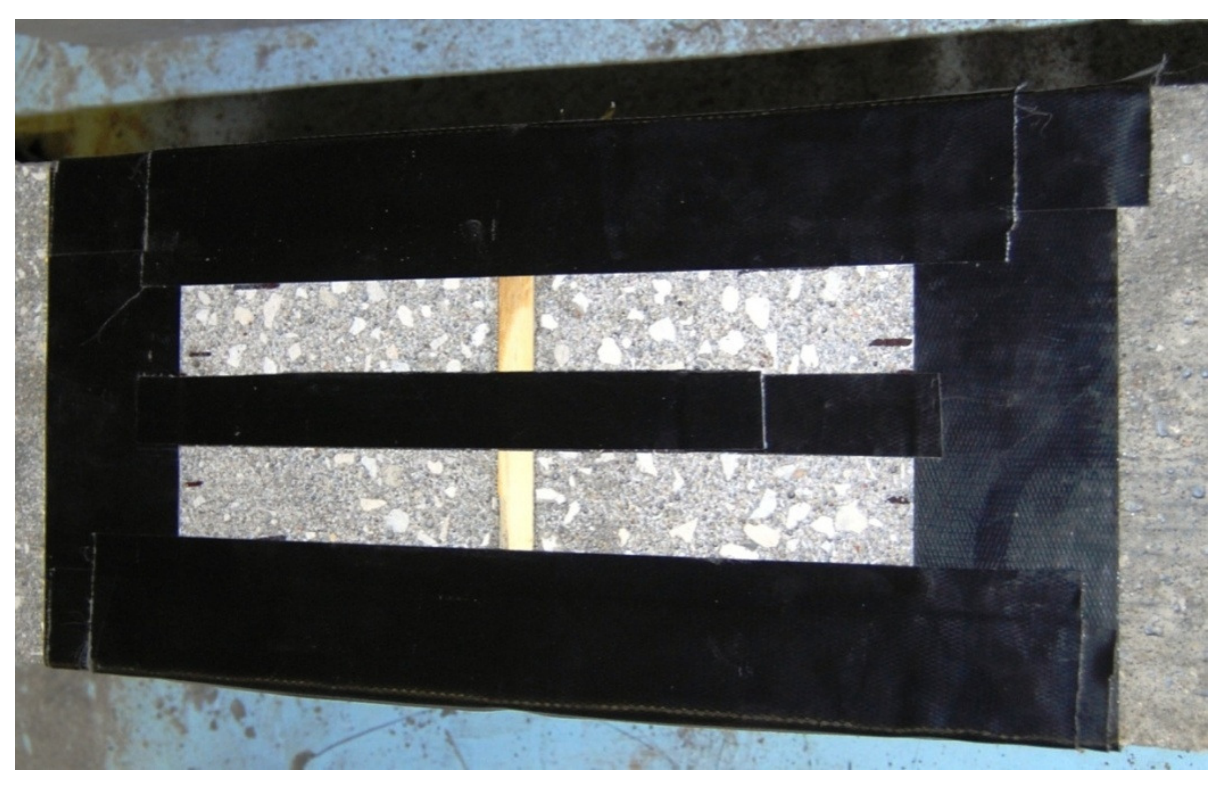

FIGURE 3B. Photo of ASTM-C78 Concrete Beam with 75\% (Medium) Bond Area. 


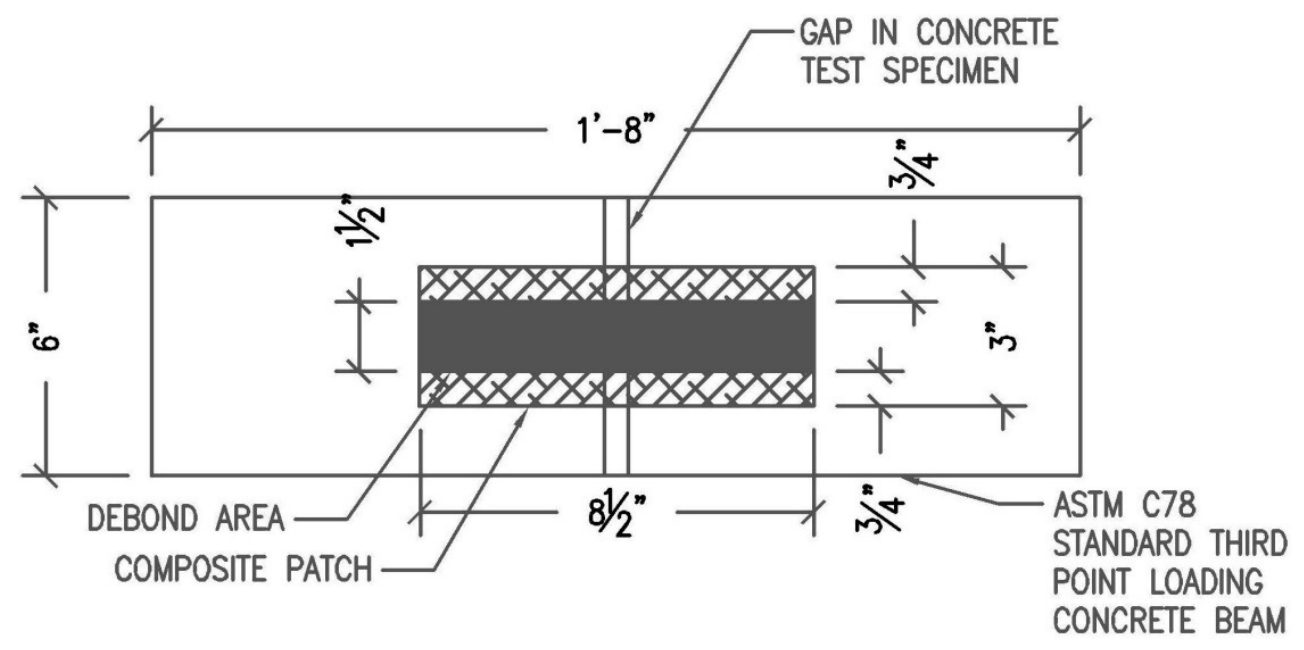

FIGURE 4A. Schematic Illustration of the Tensile Face of the ASTM-C78 Concrete Beam with 50\% (Poor) Bond Area.

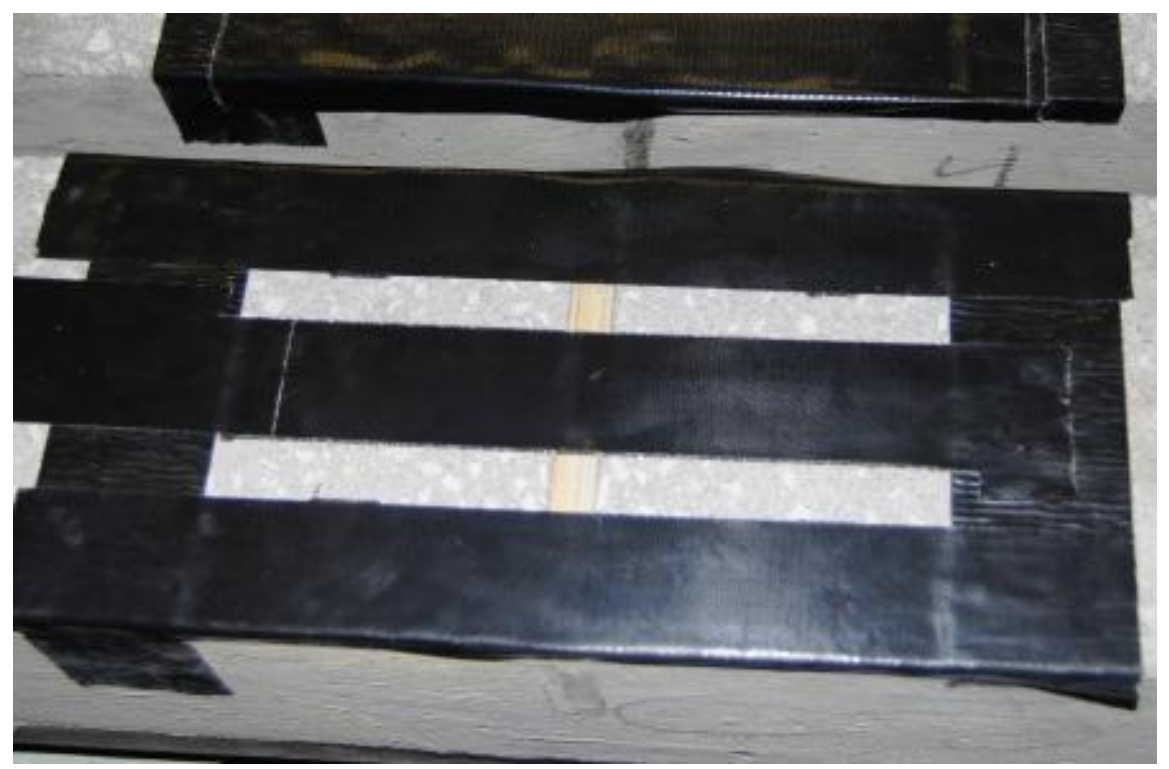

FIGURE 4B. Photo of ASTM-C78 Concrete Beam with 50\% (Poor) Bond Area. 
TABLE I

TEST SPECIMEN BOND DIMENSIONS AND FRP TYPE

\begin{tabular}{|c|c|c|c|c|}
\hline Specimen & $\begin{array}{c}\text { Width } \\
\text { in }\end{array}$ & $\begin{array}{c}\text { Length } \\
\text { in }\end{array}$ & $\begin{array}{c}\text { Area } \\
\text { in }^{2}\end{array}$ & Carbon/Glass \\
\hline A-1 & 3.00 & 4.00 & 12.00 & Carbon \\
\hline$A-2$ & 2.88 & 4.00 & 11.50 & Glass \\
\hline A-3 & 1.50 & 4.00 & 6.00 & Glass \\
\hline$A-4$ & 2.13 & 4.00 & 8.50 & Glass \\
\hline$A-5$ & 2.13 & 4.00 & 8.50 & Carbon \\
\hline$A-6$ & 1.25 & 4.00 & 5.00 & Carbon \\
\hline B-1 & 3.00 & 4.00 & 12.00 & Carbon \\
\hline B-2 & 2.88 & 4.00 & 11.50 & Glass \\
\hline B-3 & 2.13 & 4.00 & 8.50 & Carbon \\
\hline B-4 & 2.13 & 4.00 & 8.50 & Glass \\
\hline B-5 & 1.25 & 4.00 & 5.00 & Carbon \\
\hline B-6 & 1.38 & 4.00 & 5.50 & Glass \\
\hline $\mathrm{C}-1$ & 3.00 & 4.00 & 12.00 & Carbon \\
\hline $\mathrm{C}-2$ & 2.88 & 4.00 & 11.50 & Glass \\
\hline $\mathrm{C}-3$ & 2.13 & 4.00 & 8.50 & Carbon \\
\hline C-4 & 2.13 & 4.00 & 8.50 & Glass \\
\hline C-5 & 1.25 & 4.00 & 5.00 & Carbon \\
\hline C-6 & 1.25 & 4.00 & 5.00 & Glass \\
\hline
\end{tabular}


Three replicates of each specimen configuration were fabricated to evaluate typical test variability. Table II summarizes the configurations for each specimen set.

TABLE II

SPECIMEN CONFIGURATION

\begin{tabular}{lccccc}
\hline $\begin{array}{l}\text { Number } \\
\text { of Tests }\end{array}$ & Specimen No. & $\begin{array}{c}\text { Specified f' } \\
(\mathrm{psi})\end{array}$ & $\begin{array}{c}\text { Fiber } \\
\text { Type }\end{array}$ & Bond & $\begin{array}{c}\text { Unbonded } \\
\text { Area }\end{array}$ \\
\hline 3 & A-1, B-1, C-1 & 5000 & Carbon & Good & $0 \%$ \\
3 & A-5, B-3, C-3 & 5000 & Carbon & Medium & $25 \%$ \\
3 & A-6, B-5, C-5 & 5000 & Carbon & Poor & $50 \%$ \\
3 & A-2, B-2, C-2 & 5000 & Glass & Good & $0 \%$ \\
3 & A-4, B-4, C-4 & 5000 & Glass & Medium & $25 \%$ \\
\hline
\end{tabular}

The epoxy matrix used for all of the FRP overlays was Sikadur ${ }^{\circledR} 300$. This twocomponent epoxy was used to saturate the FRP fibers and to prime and seal the surface of the concrete beam specimens. Pre-cut carbon and glass fabric strips were applied in accordance with the manufacturer's specifications and air pockets and voids were tapped out using a paint brush while the epoxy matrix was wet. The specimens were cured for a minimum of 72 hours prior to testing. During the FRP overlaying preparation, Specimen A-3 cracked through the compression face. This specimen was repaired using a repair epoxy and tested alongside the other test specimens. Even though it was repaired, it appeared to give results consistent with comparable test specimens. 


\section{Acousto-Ultrasonic Evaluations}

After the specimens were cured sufficiently to achieve full bond strength, each was evaluated using theAUP NDT methodology. Two variations of the AUP evaluation methodology were performed. The first variation involved using a longitudinal transducer to both inject and receive propagating stress waves from the test specimens. The second variation involved using a longitudinal transducer to inject the stress waves and a shear wave transducer to receive them. The longitudinal transducer used in all the evaluations was an Olympus Panametric V1011 Videoscan unit with a $100 \mathrm{kHz}$ central frequency. The shear wave receiving transducer used was an Olympus Panametric V1548 Videoscan unit with a $100 \mathrm{kHz}$ central frequency.

The type of piezoelectric transducer was chosen based on the methods presented by Tanary et al. (1992) and Vary (1982). Vary reported that optimum acousto-ultrasonic evaluations are achieved at frequencies near resonance, thus the wavelength of the signals should be related to the specimen thickness, and the speed of the wave in the material as defined by Equations 3 and 4. For this investigation, the integer (n) was taken as 4 and a wave length 1.50 was calculated using Equation 1 where $\lambda_{D}$ is the wavelength and $\mathrm{D}$ is the specimen thickness. With a wave length of 1.5 and a typical concrete wave velocity $(v)$ of 4000 meters per second (Malhotra and Carino 2004), the frequency $(f)$ was calculated using Equation 4. The calculated frequency was $104 \mathrm{kHz}$, thus $100 \mathrm{kHz}$ central frequency transducers with a wide band width were chosen for this investigation.

$$
D=n \lambda_{D}
$$




$$
f=\frac{v}{\lambda_{D}}
$$

Destructive testing of the beam specimens was expected to debond the FRP overlay from the weaker side of the wood spacer; thus, it was necessary to perform the NDT evaluations on both sides of the beam specimens. For organizational and reference purposes, the side of the test specimen which had the longitudinal transmitting transducer applied to it was identified as side A or side B.

For each test specimen, the transmitting transducer was placed at two separate locations. These two locations were referred to as the near transmitting location and the far transmitting location. In the near transmitting location, the transducer was placed on the concrete surface at center width of the specimen, 1.25 inches from the end of the FRP overlay. In the far transmitting location, the transducer was placed on the concrete surface at center width of the specimen, 4.25 inches from the edge of the FRP overlay. Figures 5 and 6 show the near and far transmitting transducer locations.

Two receiving transducer locations were used in this research. The receiving transducer locations were also referred to as near and far positions. The near receiving transducer location was on the same side of the beam as the transmitting transducer, on top of the FRP, two inches from the formed gap. The far receiving transducer location was at the same location as the near receiving transducer, except it was on the opposite side of the formed gap from the transmitting transducer. In both configurations, the transducer was centered over the width of the FRP overlay. Figures 5 and 6 show the locations of the near and far transducer locations. Figure 7 shows a photo of the near to 
near testing configurations. The far to near and near to far transducer locations were similar to that shown in Figure 7.

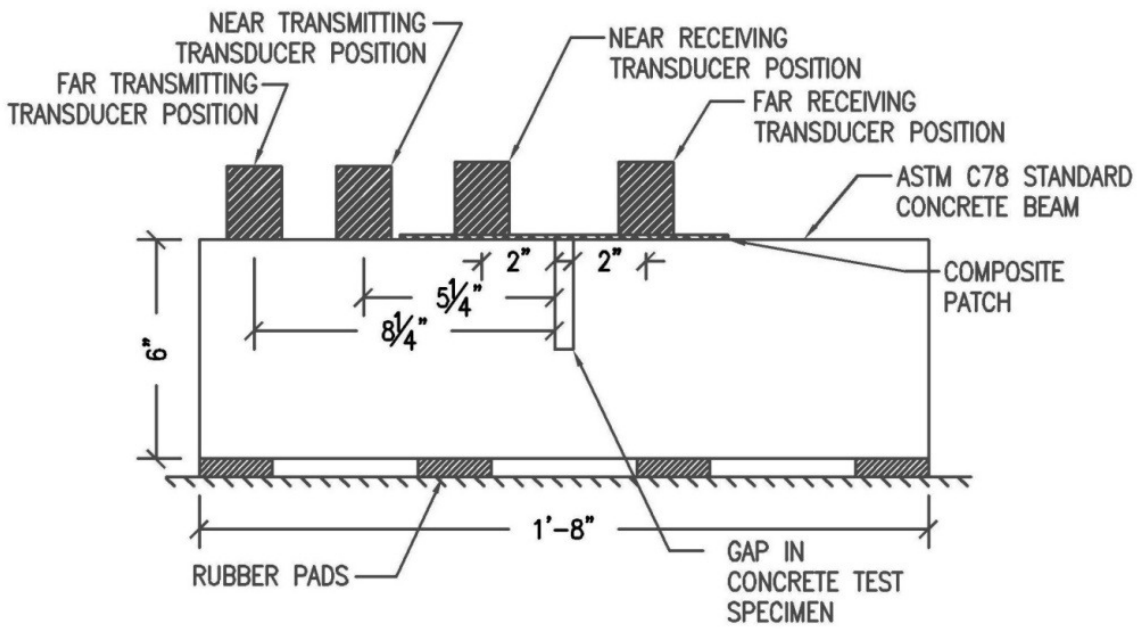

FIGURE 5. Schematic Side Elevation of AUP NDT Set-up and Dimensions.

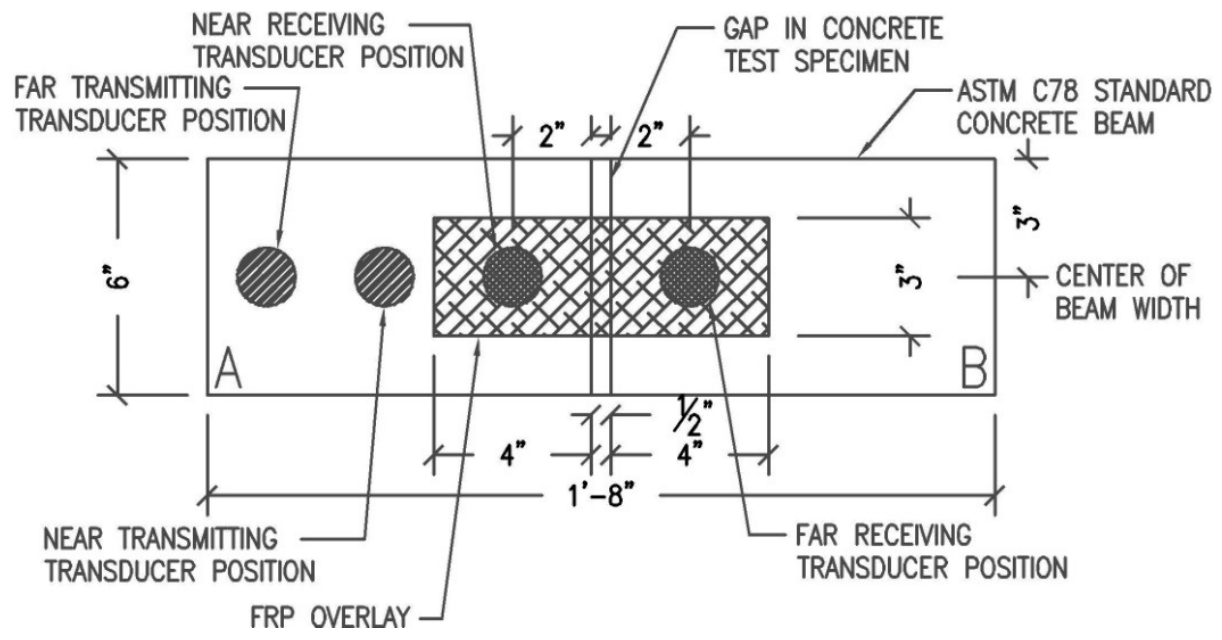

FIGURE 6. Schematic Top Elevation of AUP NDT Set-up and Dimensions. 


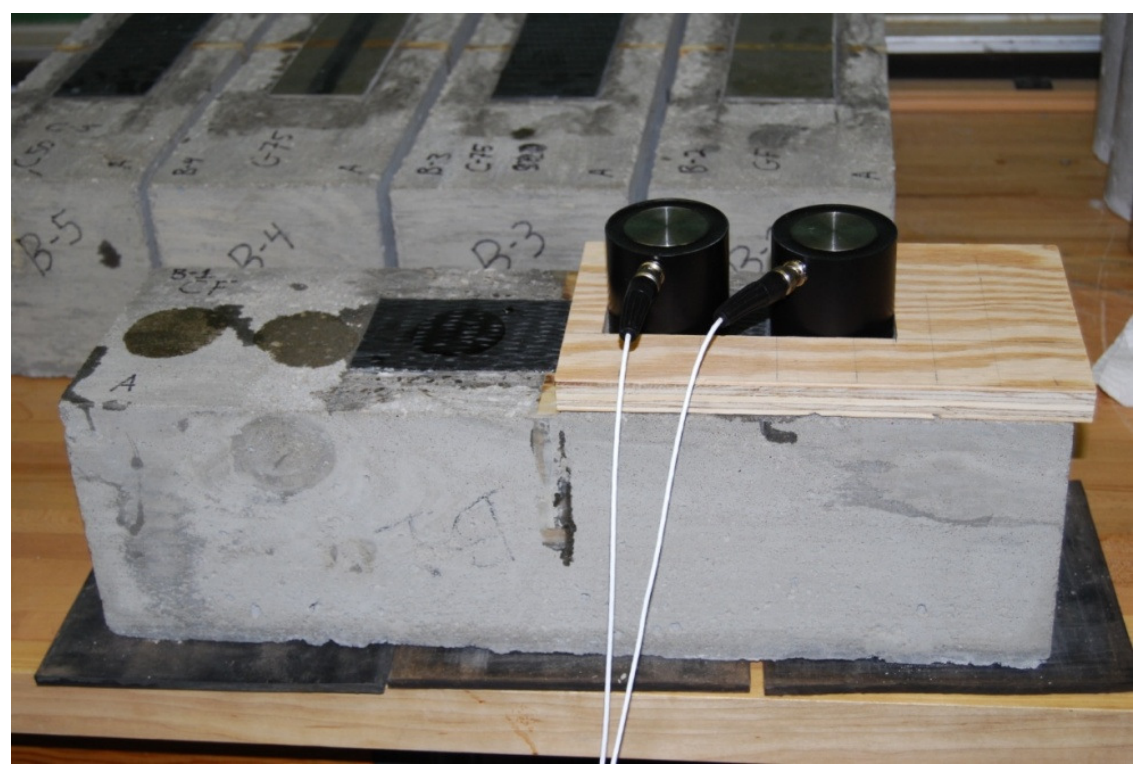

FIGURE 7. Typical Near to Near Transducer Set-up.

Each beam specimen was placed on rubber isolation pads (Figure 5), the transducer was placed and a variety of wave pulses were applied to the specimens. A range of pulse frequencies, wave amplitudes, gains, transducer couplant pressure, and locations were evaluated to investigate how these variables affect the AUP NDT results for a given FRP configuration.

An Olympus Panametrics-NDT pulser/receiver was used to excite the transmitting longitudinal transducer and amplify the received stress waves from both the longitudinal and shear wave transducers. The received signal was captured using a recording oscilloscope. Five signals were generated and recorded for each of the transmitting and receiving locations to assess the variability of the test methodology. Based on preliminary wave form results, the received stress waves were amplified by $20 \mathrm{~dB}$ and $40 \mathrm{~dB}$ for both the longitudinal and shear transducers, respectively, and then stored for 
further analysis. The longitudinal transmitting and receiving transducers were both coupled to the surface using a glycerin couplant gel and the receiving shear transducers were coupled using a manufacturer supplied shear gel. A schematic diagram of the AUP NDT system used can be seen in Figure 8.

Each received signal was analyzed to determine AUP values and total signal energy. Both the AUP and energy calculation procedures are described in Chapter IV.

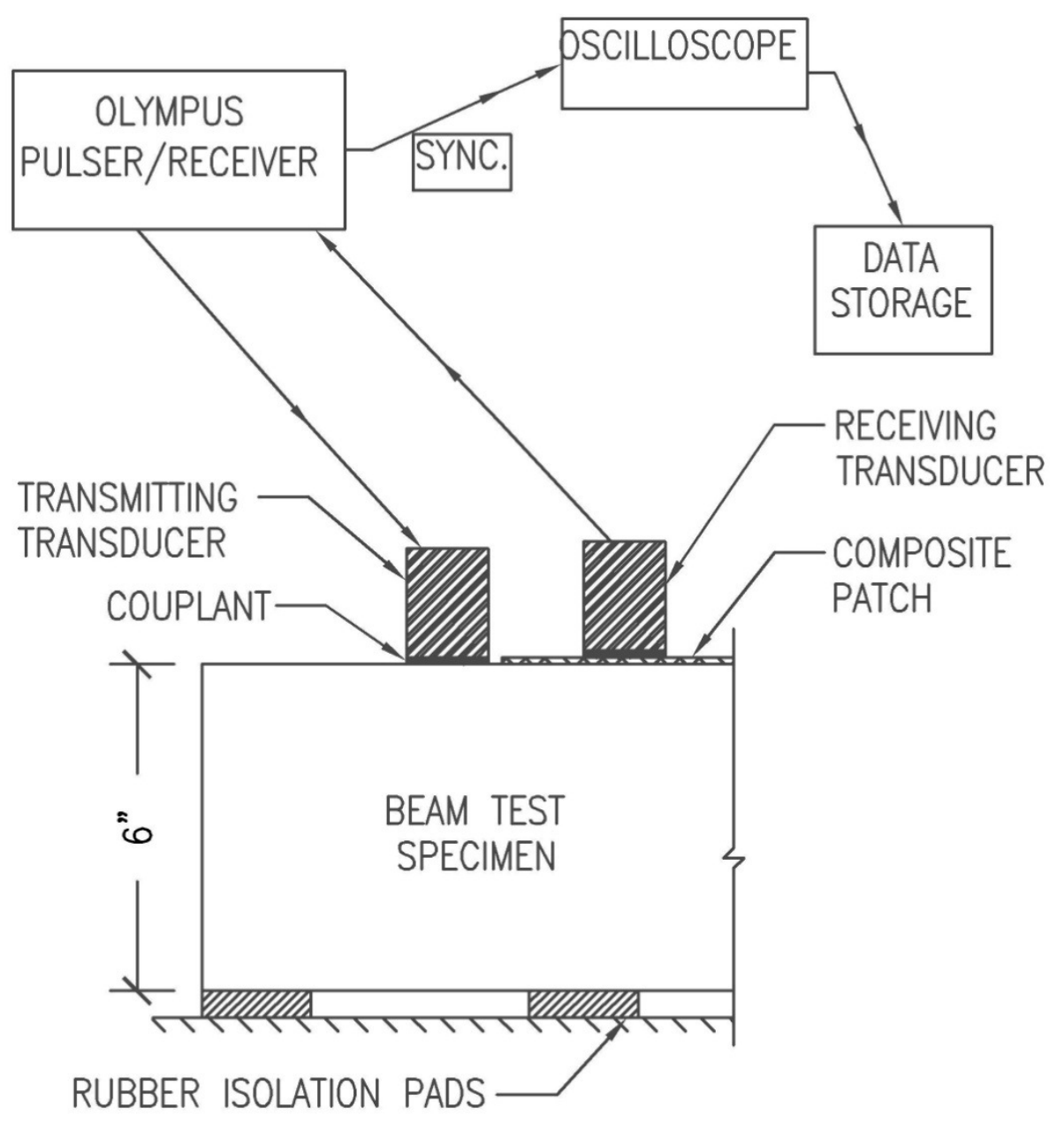

FIGURE 8. Schematic of AUP NDT System. 


\section{Testing Procedure Evaluation and Optimization}

During the initial stages of testing, the NDT procedures were varied to evaluate the effect of these procedures and maximize the stress wave energy transferred through the concrete/FRP interface. In these initial tests, the injected stress wave energy was found to be greatly affected by the smoothness of the concrete surface. Based on these results and to maximize the energy input to the specimen, the concrete beams were ground smooth using a handheld grinder.

Another parameter found to affect the stress wave energy was the type and amount of couplant used. A variety of couplants such as petroleum jelly, water, and glycerin were used initially to maximize the longitudinal transducer energy transfer. Glycerin gel was found to produce the best results when used as the couplant between both the sending and receiving longitudinal transducers. However, the time the couplant was left on the test specimen surface was found to affect the reproducibility of the test results. Vibration caused by the longitudinal transducers forced the couplant to penetrate deeper into the porous concrete. The longer the transducers were left on the test specimen surface, the more likely the transducer/concrete interface would be partially dry. To reduce variation in test results due to the depth of couplant penetration, all testing was performed in a similar time frame. It is worth noting that couplant penetration was not an issue between the transducers and the FRP, since the FRP has a relatively impermeable surface.

For the shear transducers, the manufacturer's recommended shear gel was used as the couplant. The shear gel was very viscous in comparison to the glycerin and required 
a relatively high contact pressure to maintain a constant couplant thickness and decrease variation of test results.

Contact pressure for both the longitudinal and shear wave transducers was achieved by applying weight to the tops of the transducers. Initial variation of the pressure showed the results differed little with increased pressure, provided the couplant thickness remained the same. Two 11-pound weights provided sufficient pressure to maintain a uniform couplant thickness.

\section{$\underline{\text { E. Destructive Beam Tests }}$}

Once the NDT evaluations were completed, each test beam specimen was placed on simple rocker supports (Figures 9 through 12) and loaded monotonically to failure using either a third point or a single point loading configuration. The beam test specimen FRP calculations are described later in this chapter. During the first few beam tests, it was clear that the GFRP's fiber rupture strength was much lower than expected and lower than the shear bond strength of the system. The first few tests suggested that the actual interfacial shear bond strength of the CFRP significantly exceeded the values predicted by Lorenzis et al (2001), resulting in moment failures in the beam outside of the reinforced area. The CFRP system had been designed based on both Lorenzis et al.'s. (2001) test results of developmental shear force capacity as well as shear values recommended by ACI Committee 440 (2002) and the manufacturer's literature. The measured shear capacity appeared to be significantly higher than suggested by these documents. Since nothing could be done to address the low GFRP tensile strength or 
high shear bond strength, the beam destructive testing procedures were changed from third point loading to single point loading. The simple support span was also increased by one inch (Figures 9 and 10). More discussion as to why the unexpected failures occurred and description of the failure modes is presented in Chapter V and Chapter IV, respectively.

Immediately after the destructive beam tests were completed, the companion concrete cylinders were tested for compressions strength using the procedures outlined in ASTM C39 (2005).

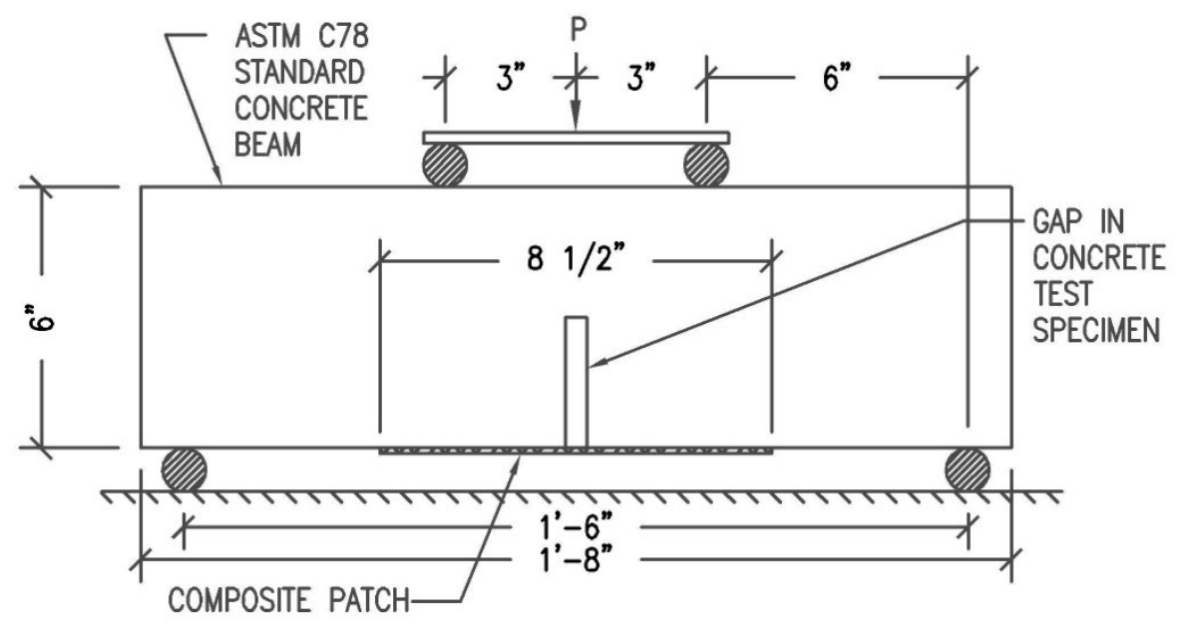

FIGURE 9. Schematic Side Elevation of Third Point Load Test Set-up. 


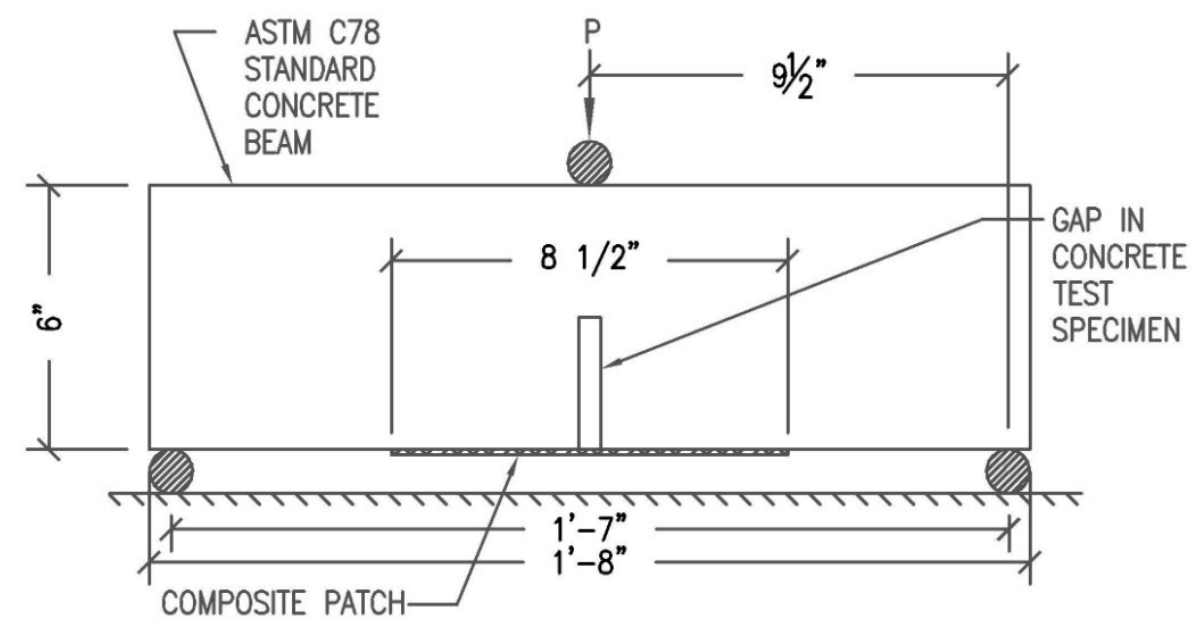

FIGURE 10. Schematic Side Elevation of Single Point Load Test Set-up.

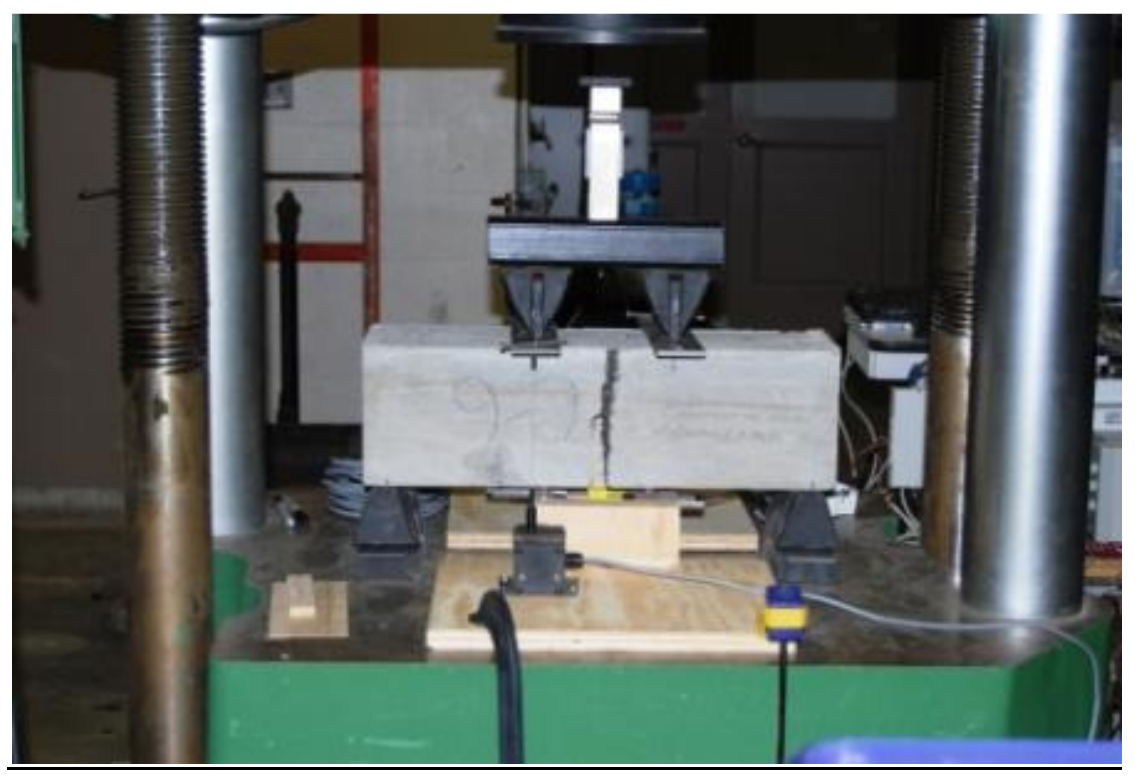

FIGURE 11. Side Elevation of Third Point Load Test Set-up. 


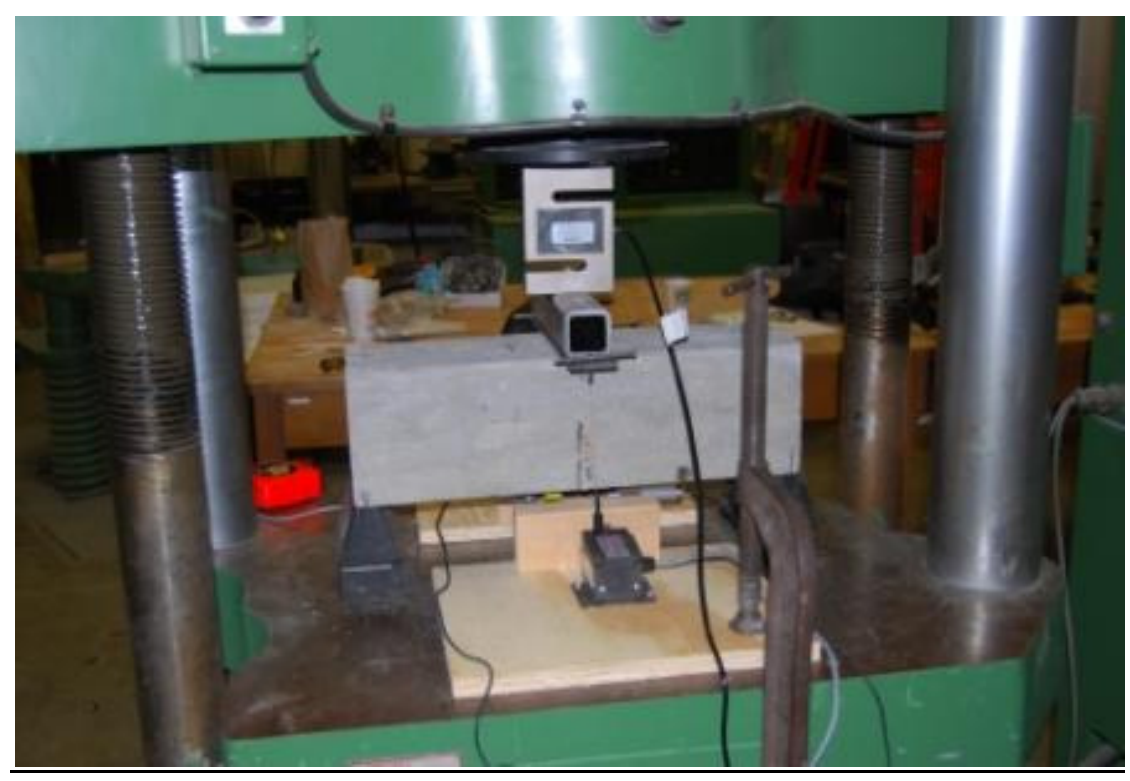

FIGURE 12. Side Elevation of Single Point Load Test Set-up.

During destructive testing, two LVDTs were attached to the FRP system and used to measure the strain in the FRP and confirm strain transfer across the concrete/FRP interface (see Figure 13).

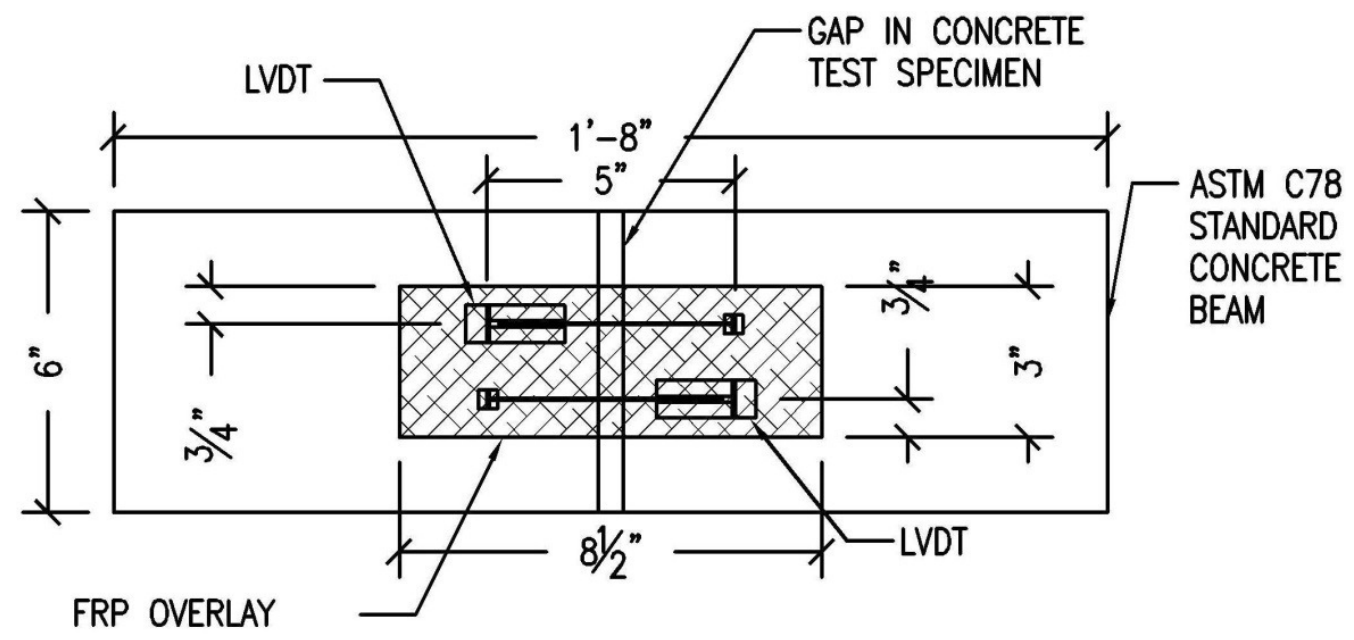

FIGURE 13. Strain Gage Configuration. 


\section{$\underline{\text { F. FRP Design Calculations }}$}

\section{General Design Calculations}

Design calculations were performed by using a conventional elastic cracked transformed section analysis procedure. Figure 14 and Equations 5 through 11 show the beam cross section and equations used to calculate the section stresses.
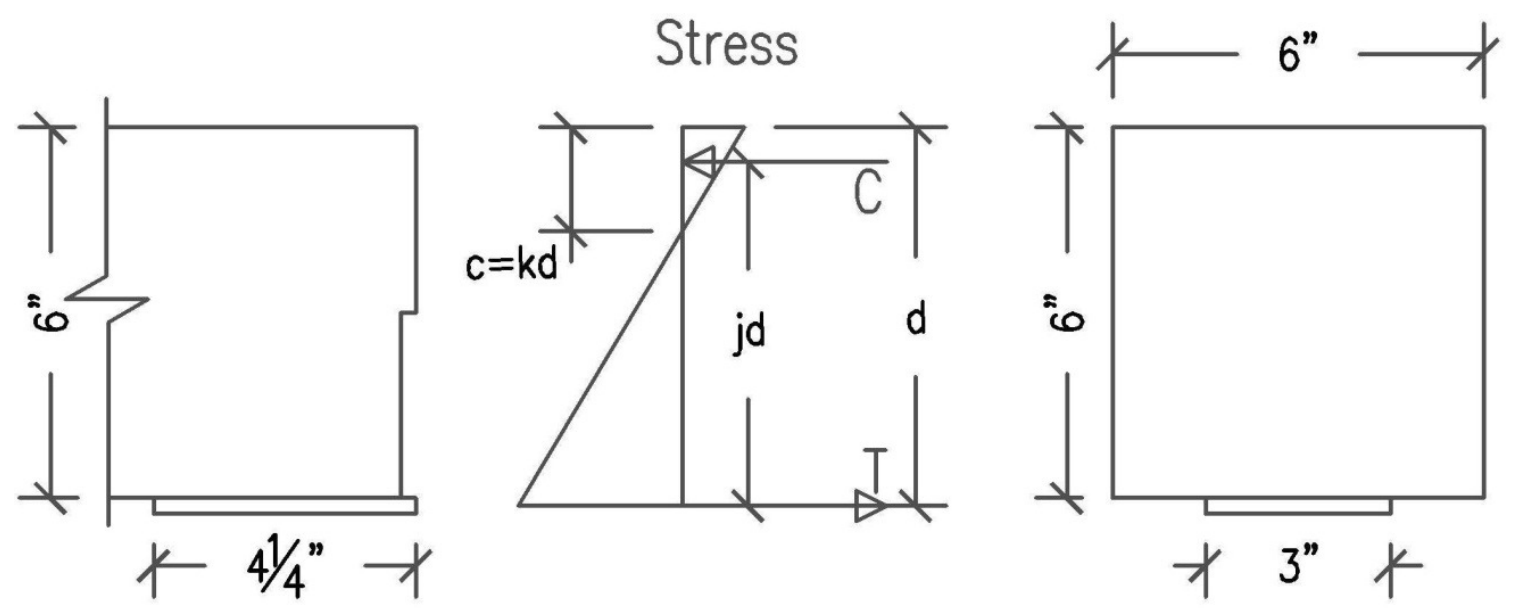

FIGURE 14. Beam Specimen Cross Section \& Stress Diagram

$$
\begin{gathered}
E_{c}=57000 \cdot \sqrt{f^{\prime}}(\text { ACI 318-08) } \\
n=\frac{E_{f}}{E_{c}} \\
A_{f}=n \cdot A_{\text {fiber }} \\
\rho=\frac{A_{f}}{b d} \\
k=\sqrt{(\rho n)^{2}+2 \rho n}-\rho n
\end{gathered}
$$




$$
\begin{aligned}
& j=1-\frac{k}{3} \\
& M=j d T
\end{aligned}
$$

The FRP reinforcing system designs were intended to ensure an interfacial shear failure occurred during destructive testing. First, an estimated interfacial shear force was determined. Lorenzis et al.'s (2001) research reported an equation for adjusting the ultimate strain in the FRP system to account for shear bond failures. This method suggests that after a certain fiber strain, shear bond failure will occur.

This method proposes that an adjusted ultimate fiber strain can be determined from the ultimate FRP strain as shown in Equation 12 where $\varepsilon_{b u}$ is the adjusted strain in the FRP and $\varepsilon_{u}$ is the maximum strain in the FRP. $k_{r}$ is a factor that accounts for bond/shear failure/slip at the concrete/FRP interface.

$$
\varepsilon_{b u}=k_{r} \cdot \varepsilon_{u}
$$

\section{Carbon Specimen Reinforcement Calculations}

For the carbon overlays, the design value for $\varepsilon_{u}$ from the manufacturer's literature is $0.011 \mathrm{in} / \mathrm{in}$. Using the chart published by Lorenzis et al. (2001) and a $E_{f} \cdot t$ value of $380 \mathrm{ksi}-\mathrm{in}, \mathrm{a} k_{r}$ was estimated to be about 0.35 . This suggests that the maximum stress in the fibers would be limited by bond failures at a fiber force, $\mathrm{T}_{\mathrm{s}}$, for a 3 -inch fiber width as shown in Equation 13. 


$$
T_{s}=104 k s i \cdot 0.35 \cdot 0.04 i n \cdot 3 i n \text { width }=4,368 \mathrm{lbs}
$$

With the interfacial shear limiting the force in the fiber, assumed to be at the upper bound of 4,368 lbs, the CFRP was designed to ensure a fiber rupture would not occur, forcing the beam test specimens to fail by interfacial fiber shearing. The fiber length of four inches was chosen based on the previous research (Lorenzis et al. 2001) since they showed that longer lengths had little effect on capacity. A width of three inches was selected to provide enough contact surface for the ultrasonic transducers during non-destructive testing. The ultimate fiber force limited by rupture of the fibers, $T_{f}$, can be calculated as shown in Equation 14 based on the design tensile strength of the CFRP with Sikadur® 300 epoxy matrix $\left(f_{f u}\right)$, as published by the manufacturer, of 104,000 psi, and a cured FRP laminate thickness of 0.04 inch. This fiber configuration results in a fiber capacity of $12,480 \mathrm{lbs}$ as shown in Equation 14 . This capacity can be compared to the fiber force based on shear of $4,368 \mathrm{lbs}$. It is clear that $\left(T_{f}>T_{s}\right)$, ensuring an interfacial shearing of the beam test specimens should occur prior to a fiber rupture.

$$
T_{f}=f_{f u} x t \times w=104000 \text { psi } x \text { 0.04in. } x \text { 3in. }=12,480 \mathrm{lbs}
$$

Using the transformed cracked section analysis procedure, jd (test specimen moment arm) was calculated to determine the expected specimen moment capacity, $\mathrm{M}$, based on the governing fiber force value, T. These calculations are shown in Equations 6 
through 11 [these equations were introduced in Chapter III and have been used here with the CFRP material and section properties].

$$
\begin{gathered}
n=\frac{9,446,600 \mathrm{psi}}{57,000 \cdot \sqrt{5000 \mathrm{psi}}}=2.34 \\
A_{f}=2.34 \cdot 3 \mathrm{in} \cdot 0.04 \mathrm{in}=0.281 \mathrm{in}^{2} \\
\rho=\frac{0.281 \mathrm{in}^{2}}{6 \mathrm{in} \cdot 6 \mathrm{in}}=0.0078 \\
k=\sqrt{(0.0078 \cdot 2.34)^{2}+2 \cdot 0.0078 \cdot 2.34}-0.0078 \cdot 2.34=0.17 \\
j=1-\frac{0.17}{3}=0.94 \\
M=j d T=0.94 \cdot 6 \mathrm{in} \cdot 4,368 \mathrm{lbs}=24,636 \mathrm{lb}-\mathrm{in}
\end{gathered}
$$

\section{Glass Specimen Reinforcement Calculations}

For the Sika Hex 100G glass overlays, the design value for $\varepsilon_{u}$ from the manufacturer's literature is 0.0212 in/in. Assuming a single layer of the Glass FRP system, using the relationship established by Lorenzis et al. (2001) and a $E_{f} \cdot t$ value of $137 \mathrm{ksi}-\mathrm{in}, k_{r}$ is 0.577 . This suggests that the maximum stress in the fibers would be limited by the bond failures at a fiber force, $\mathrm{T}_{\mathrm{s}}$, for a three-inch fiber width as shown in Equation 15.

$$
T_{s}=77.1 \mathrm{ksi} \cdot 0.577 \cdot 0.04 \mathrm{in} \cdot 3 \mathrm{in} \mathrm{width} \cdot 1 \text { layer }=5,338 \mathrm{lbs}
$$


With the interfacial shear limiting the force in the fiber, assumed to be at the upper bound of 5,338 lbs, the GFRP was designed to ensure a fiber rupture would not occur, forcing the beam test specimens to fail by interfacial fiber shearing. As with the CFRP specimens, a fiber length of four inches and a fiber width of three inches were selected. The ultimate fiber force for rupture of the fibers, $T_{f}$, can be calculated as shown in Equation 16 based on the design tensile strength of the GFRP with Sikadur@ 300 epoxy matrix $\left(f_{f u}\right)$, as published by the manufacturer, of 77,100 psi, and a cured FRP laminate thickness of 0.04 inch. This fiber configuration results in a fiber capacity of 9,252 lbs. This capacity can be compared to the fiber force based on shear of 5,338 lbs. It is clear that $\left(T_{f}>T_{s}\right)$, ensuring that an interfacial shearing of the beam test specimens should occur prior to a fiber rupture.

$$
T_{f}=f_{f u} \cdot t \cdot w=77,100 p s i \cdot 0.04 \mathrm{in} \cdot 3 \mathrm{in} \cdot 1 \text { layers }=9,252 \mathrm{lbs}
$$

As with the carbon specimens, jd (test specimen moment arm) was calculated to determine specimen moment capacity, $\mathrm{M}$, based on the governing fiber force value, $\mathrm{T}$. These calculations are shown in Equations 6 through 11 [these equations were introduced in Chapter III and have been used here with the GFRP material and section properties].

$$
\begin{gathered}
n=\frac{3,426,300 p s i}{57,000 \cdot \sqrt{5000 p s i}}=0.85 \\
A_{f}=0.85 \cdot 3 \mathrm{in} \cdot 0.04 \mathrm{in} \mathrm{thk}=0.102 \mathrm{in}^{2} \\
\rho=\frac{0.102 \mathrm{in}^{2}}{6 \mathrm{in} \cdot 6 \mathrm{in}}=0.00283
\end{gathered}
$$




$$
\begin{gathered}
k=\sqrt{(0.00283 \cdot 0.85)^{2}+2 \cdot 0.00283 \cdot 0.85}-0.00283 \cdot 0.85=0.0670 \\
j=1-\frac{0.0670}{3}=0.977 \\
M=j d T=0.977 \cdot 6 \mathrm{in} \cdot 5,926 \mathrm{lbs}=34,489 \mathrm{lb}-\mathrm{in}
\end{gathered}
$$

It should be noted that these calculations are not valid for the actual construction but were intended in the specimen design. This is discussed further in Chapter V. 


\title{
IV. TEST RESULTS
}

\author{
A. Introduction
}

Eighteen FRP reinforced concrete beam specimens were tested using ultrasonic transducers to evaluate the strength of the FRP concrete interface, as previously described in Chapter III. For each testing configuration, a longitudinal transducer was used to inject stress waves into the concrete specimens and then either a shear or a longitudinal transducer was used to intercept the stress waves traveling through the concrete/FRP interface. This chapter presents results of the non-destructive and destructive tests.

\section{B. Acousto-Ultrasonic Parameter Calculation Procedures}

The AUP values were determined using the procedure expressed mathematically by Equation 17 and detailed by the following procedure:

1) A signal/noise level was determined and a threshold level was set just above noise levels $\left(V_{0}\right) . V_{0}$ for our research was set to 0.1 . This voltage level was deemed sufficient to exclude the signal noise from our calculations.

2) The total number of signal counts above $V_{0}$ was determined.

3) The threshold was increased subsequently by a small interval $\Delta \mathrm{V}$ and the number of counts above the new threshold was determined. 
4) The difference between the two counts was obtained and multiplied by the amplitude at that threshold level.

5) The above process was repeated until the threshold was equal to or greater than the peak amplitude of the waveform and the results of these products were summed to give a total. This total was defined as the AUP value.

6) $\Delta \mathrm{V}$ was decreased incrementally and Step 3 through 5 were repeated until there was no significant change in the AUP value. Equation 19 was used to define $\Delta \mathrm{V}$ and produce maximum AUP values.

$$
A U P=\sum_{i=0}^{p} V i\left(C_{i}-C_{i+1}\right)=\int_{C 0}^{C p} V d c
$$

Where $V_{i}$ and $C_{i}$ are the thresholds and the number of counts at the $\mathrm{i}^{\text {th }}$ level, respectively, and $V_{p}$ corresponds to the peak amplitude of the waveform. This is illustrated schematically in Figure 15 and an example calculation is shown (Tanary et al. 1992) in Equation 20. 


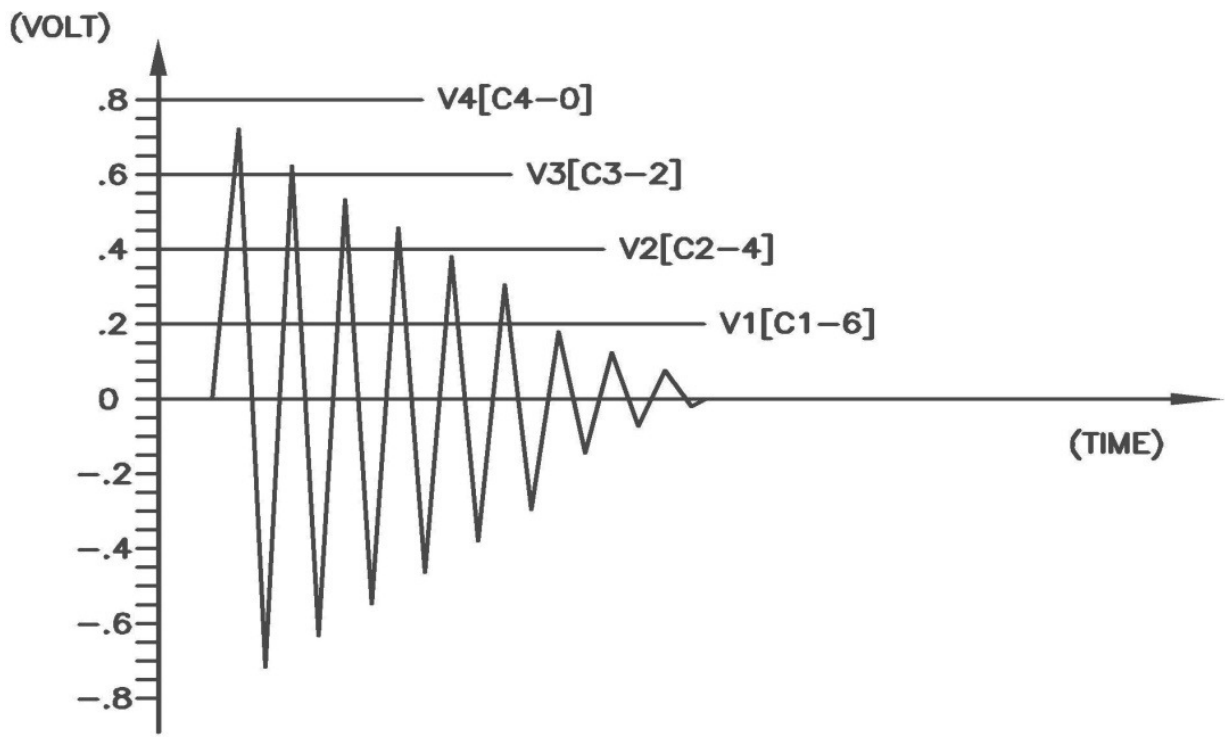

FIGURE 15. Schematic Illustration of the AUP Calculation Process [Modified from Tanary et al, (1992)].

$$
\begin{aligned}
A U P & =\sum_{i=1}^{3} V_{i}\left[C_{i}-C_{i+1}\right] \\
& =V_{1}\left(C_{1}-C_{2}\right)+\cdots+V_{3}\left(C_{3}-C_{4}\right) \\
& =0.2(6-4)+0.4(4-2)+0.6(2-0) \\
& =2.4 \text { Volts } \\
\Delta V= & \frac{(\text { Noise Threshold-Max V) }}{-2500}
\end{aligned}
$$

In addition to calculating the AUP values for each test performed, the received signals were also analyzed to determine total waveform energy as shown in Equation 20. The total wave energy was calculated as the area under the waveform using a trapezoidal 
numerical integration procedure as shown in Equation 21. The entire signal trace (2500 us) was used in the numerical integration and the absolute voltage values were used.

$$
\begin{gathered}
\int_{t=0}^{2500 \mu s}|V| d t \\
E=\sum_{i=0}^{2500 \mu s}\left[\left(t_{i}-t_{i-1}\right) \cdot \frac{\left(V_{i-1}+V_{i}\right)}{2}\right]
\end{gathered}
$$

\section{Acoustic Test Results}

Samples of the received wave signals are presented in this section for each type of non-destructive evaluation performed. Figures 16 through 18 show the differences in the waves received by the longitudinal transducer for carbon reinforced beam specimens with varying void area percentage. Figure 16 shows a wave signal collected from Specimen

C-1 (a 100\% bond area) CFRP beam specimen, using a longitudinal receiving transducer, amplified with a gain of $20 \mathrm{~dB}$, from the near to near transducer configuration. This signal frequency and amplitude was typical for $100 \%$ bond carbon fiber specimens. 


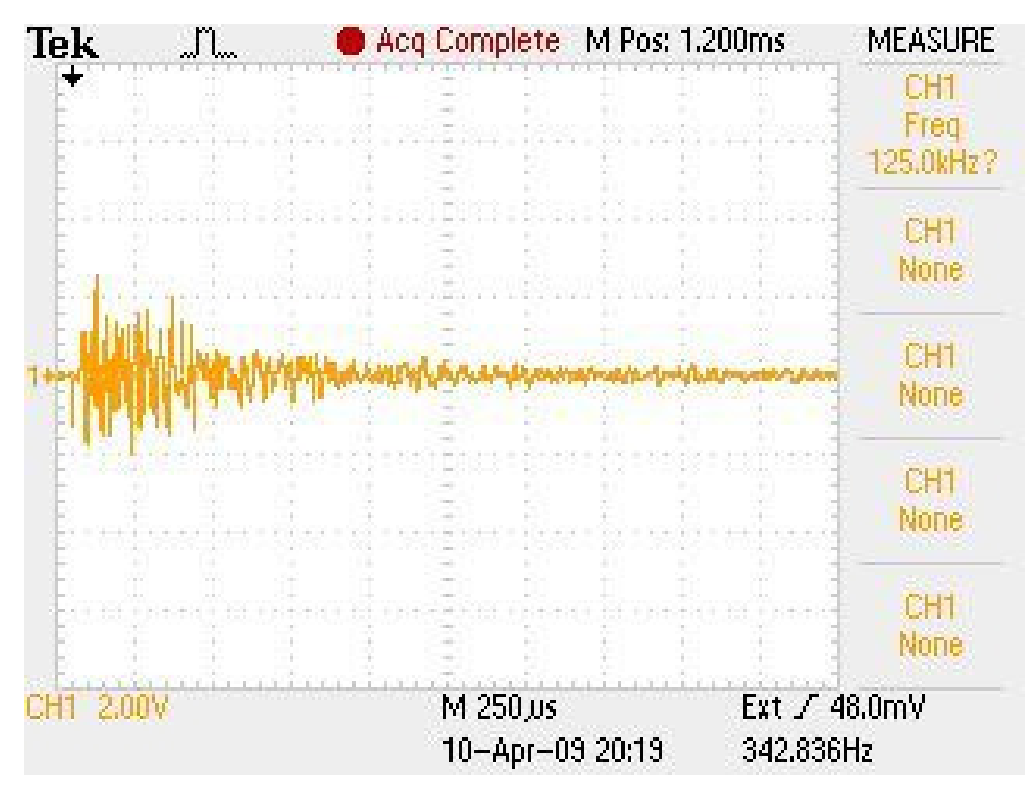

FIGURE 16. Received Wave Signal Collected from Specimen C-1 (Carbon Reinforced $100 \%$ Bond Area) using a Longitudinal Receiving Transducer With a Gain of $20 \mathrm{~dB}$ in the Near to Near Transducer Configuration.

Figure 17 shows a wave signal collected from Specimen C-3( a 75\% bond area) CFRP beam specimen, using a longitudinal receiving transducer, amplified with a gain of $20 \mathrm{~dB}$ and taken from the near to near transducer configuration. This signal frequency and amplitude was typical for $75 \%$ bond carbon fiber specimens. 


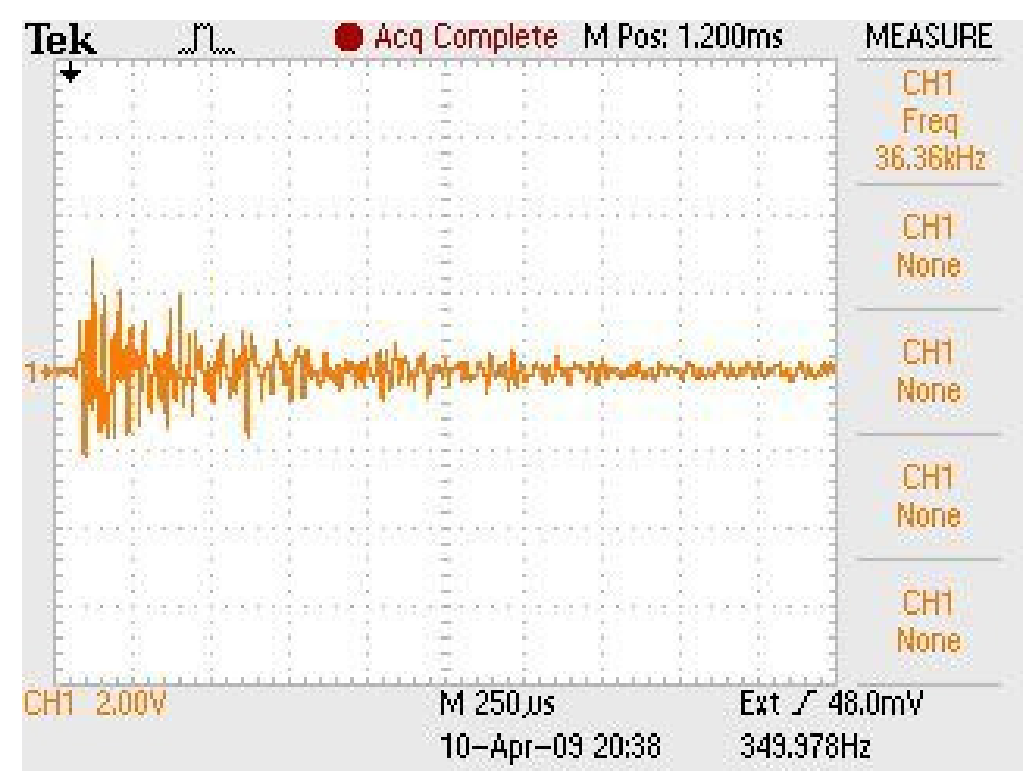

FIGURE 17. Received Wave Signal Collected from Specimen C-3 (Carbon Reinforced 75\% Bond Area) using a Longitudinal Receiving Transducer With a Gain of 20dB in the Near to Near Transducer Configuration.

Figure 18 shows a wave signal collected from Specimen C-5, a 50\% bond area, CFRP beam specimen, using a longitudinal receiving transducer, amplified with a gain of $20 \mathrm{~dB}$ and taken from the near to near transducer configuration. 


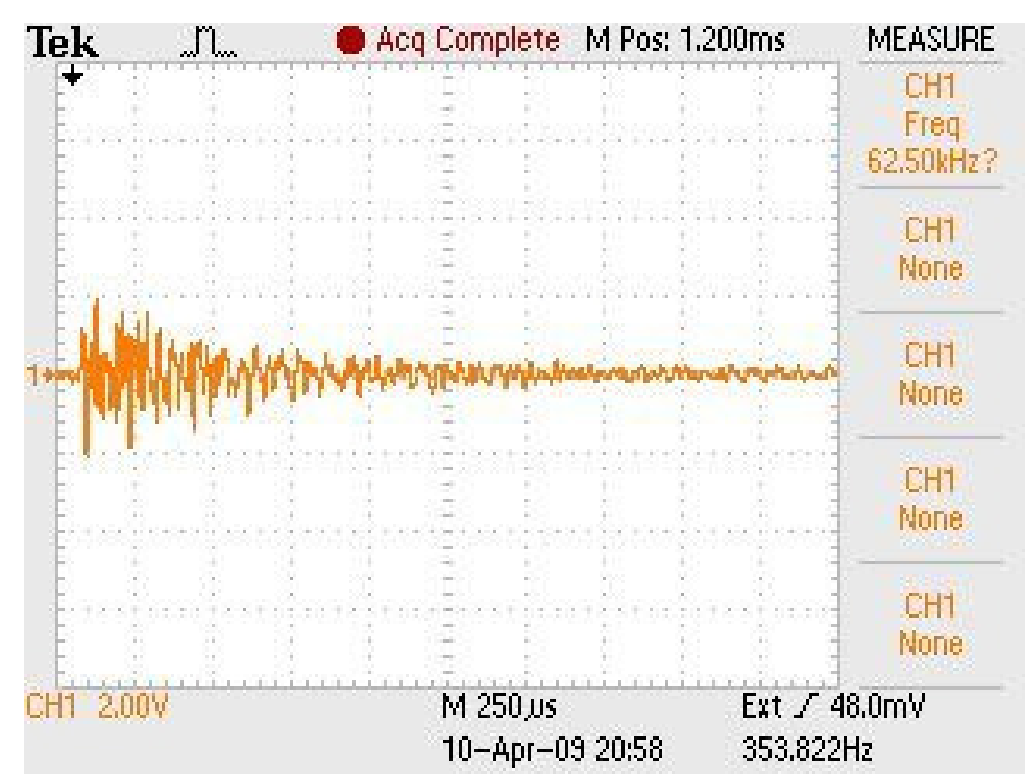

FIGURE 18. Received Wave Signal Collected from Specimen C-5 (Carbon Reinforced 50\% Bond Area) using a Longitudinal Receiving Transducer With a Gain of 20dB in the Near to Near Transducer Configuration.

The previous figures clearly show that both the amplitude and the signal decay duration decrease with increasing void ratio. A comparison of Figure 16, 19 and 20, shows the differences in longitudinal wave signals when the transducer sending and receiving locations are altered. Figure 19 shows a wave signal from Specimen C-1 (a $100 \%$ bond area) CFRP beam specimen, using a longitudinal receiving transducer, amplified with a gain of $20 \mathrm{~dB}$ with a far to near transducer configuration. This far to near signal was very similar to the near to near signal (Figure 17) with the exception of a lateral shift in signal trace This shift indicates a longer signal travel time through the concrete/FRP interface. 


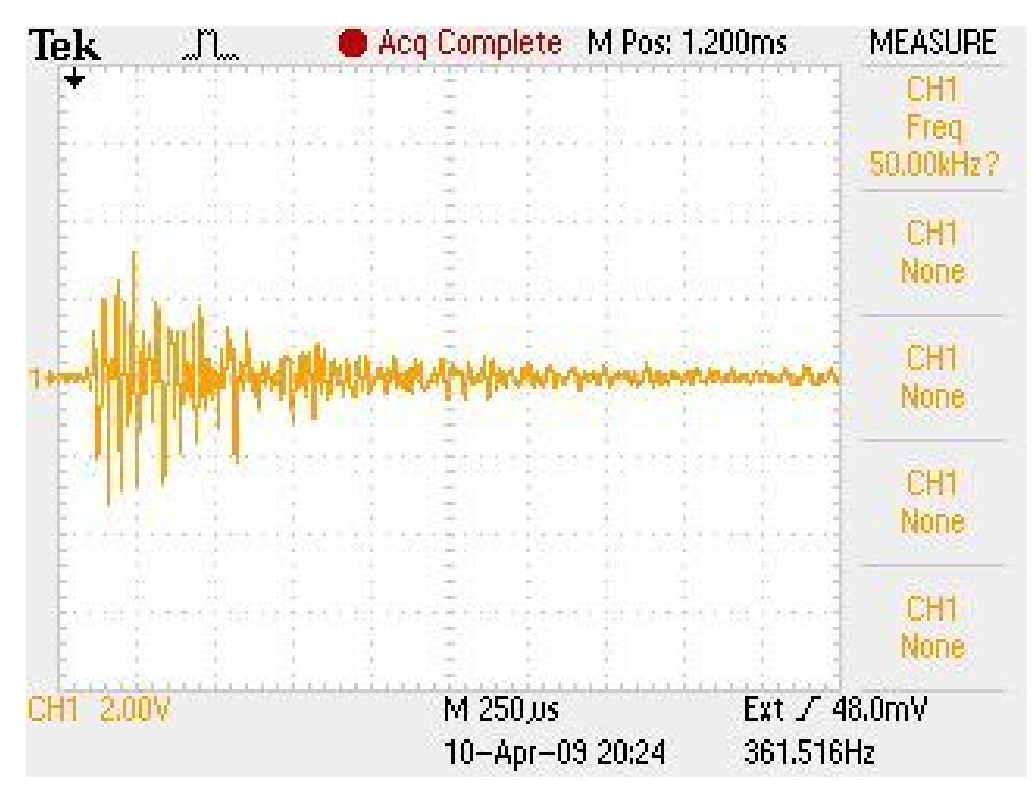

FIGURE 19. Received Wave Signal Collected from Specimen C-1 (Carbon Reinforced $100 \%$ Bond Area) using a Longitudinal Receiving Transducer With a Gain of $20 \mathrm{~dB}$ in the Far to Near Transducer Configuration.

Figure 20 shows the wave signal from Specimen C-1 (a 100\% bond area) CFRP beam specimen, using a longitudinal receiving transducer, amplified with a gain of $20 \mathrm{~dB}$ and taken from the near to far transducer configuration. This received signal shows a lateral shift to the right, which is again, produced by the longer signal travel time. The signal amplitude and decay time are also reduced. The signal energy was likely reduced since the gap forced almost all the energy signal to be transferred through the FRP material. The tests using the near to far longitudinal transducer configuration provided limited information due to signal alteration; thus, only the test specimens reinforced with $100 \%$ and 50\% CFRP were evaluated using this transducer location. 


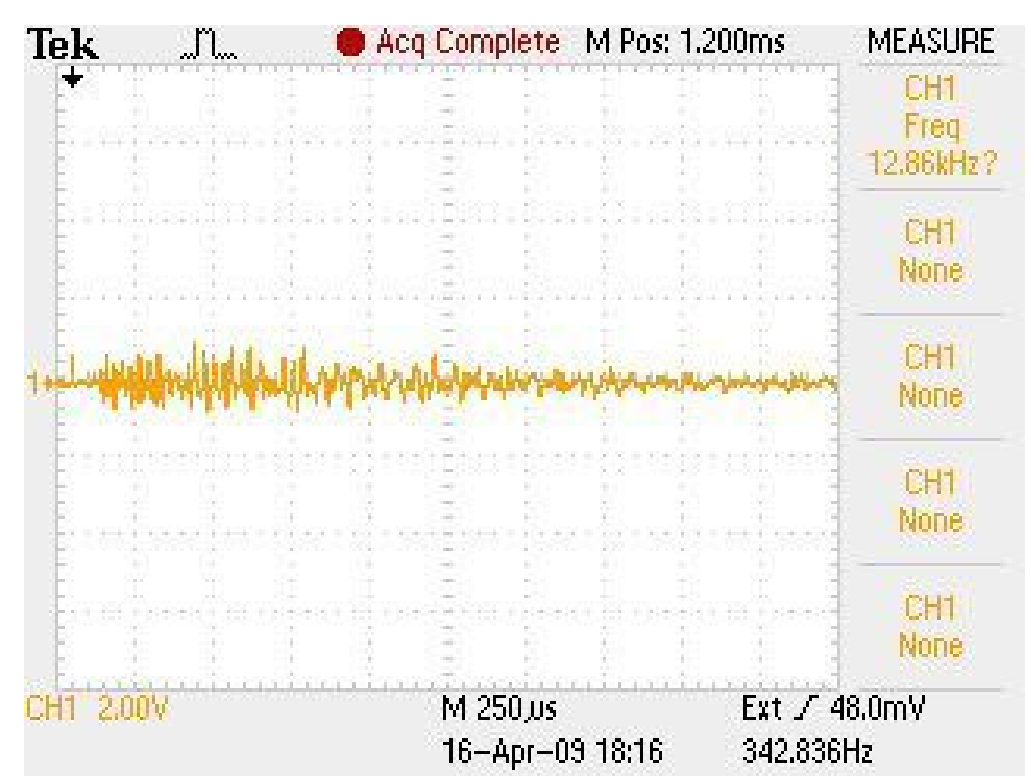

FIGURE 20. Received Wave Signal Collected from Specimen C-1 (Carbon Reinforced $100 \%$ Bond Area) using a Longitudinal Receiving Transducer With a Gain of $20 \mathrm{~dB}$ in the Near to Far Transducer Configuration.

Figures 21 through 22 show the longitudinal waves received for glass reinforced test specimens with varying sending transducer locations. Figure 21 shows a wave received from Specimen C-2 (a 100\% bond area) GFRP beam specimen, using a longitudinal receiving transducer, amplified with a gain of $20 \mathrm{~dB}$ and taken from the near to near transducer configuration. The signal energy and amplitude tended to be higher for the glass reinforced beam specimens when compared to carbon reinforced test specimens. This may be due to the fact that the surface of the glass specimens was smoother than the carbon fiber specimens, allowing better coupling of the receiving transducers. 


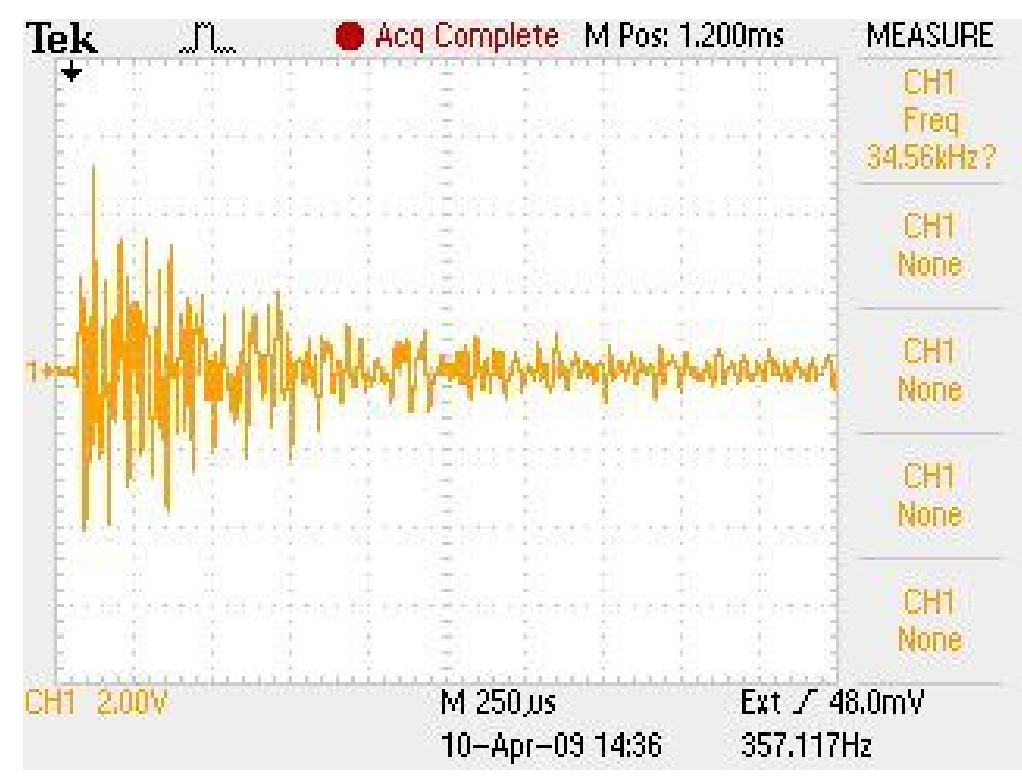

FIGURE 21. Received Wave Signal Collected from Specimen C-2 (Glass Reinforced $100 \%$ Bond Area) using a Longitudinal Receiving Transducer With a Gain of 20dB in the Near to Near Transducer Configuration.

Figure 22 shows the wave signal received from Specimen C-2 (a 100\% bond area) GFRP beam specimen, using a longitudinal receiving transducer, amplified with a gain of $20 \mathrm{~dB}$ and taken from the far to near transducer configuration. As was found with the carbon reinforced specimens, the glass specimens tested using the far to near transducer locations showed a signal shift to the right. This is again, representative of the longer signal travel time. 


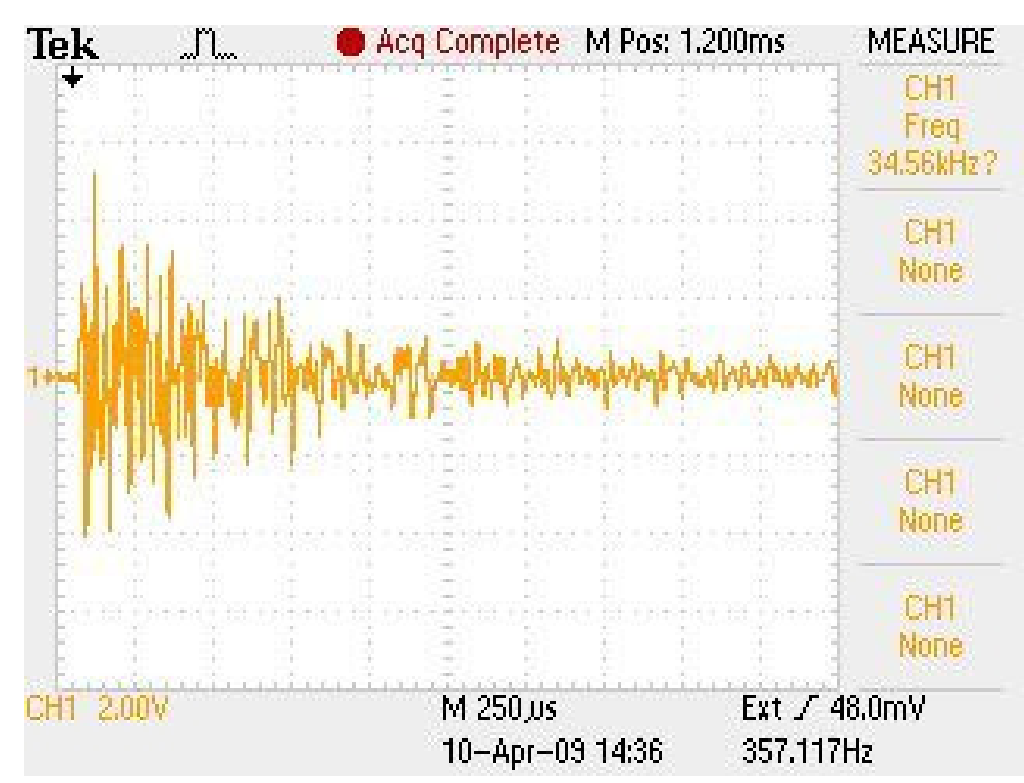

FIGURE 22. Received Wave Signal Collected from Specimen C-2 (Glass Reinforced $100 \%$ Bond Area) using a Longitudinal Receiving Transducer With a Gain of $20 \mathrm{~dB}$ in the Far to Near Transducer Configuration.

Figures 23 through 25 show the shear waves received for carbon reinforced test specimens at various sending and receiving transducer locations. Figure 23 shows a wave signal received from Specimen B-1 (a 100\% bond area) CFRP beam specimen, using a shear receiving transducer, amplified with a gain of $40 \mathrm{~dB}$ and near to near transducer locations. This signal amplitude and ring-down were typical for all 100\% bond carbon fiber specimens tested using this configuration. 


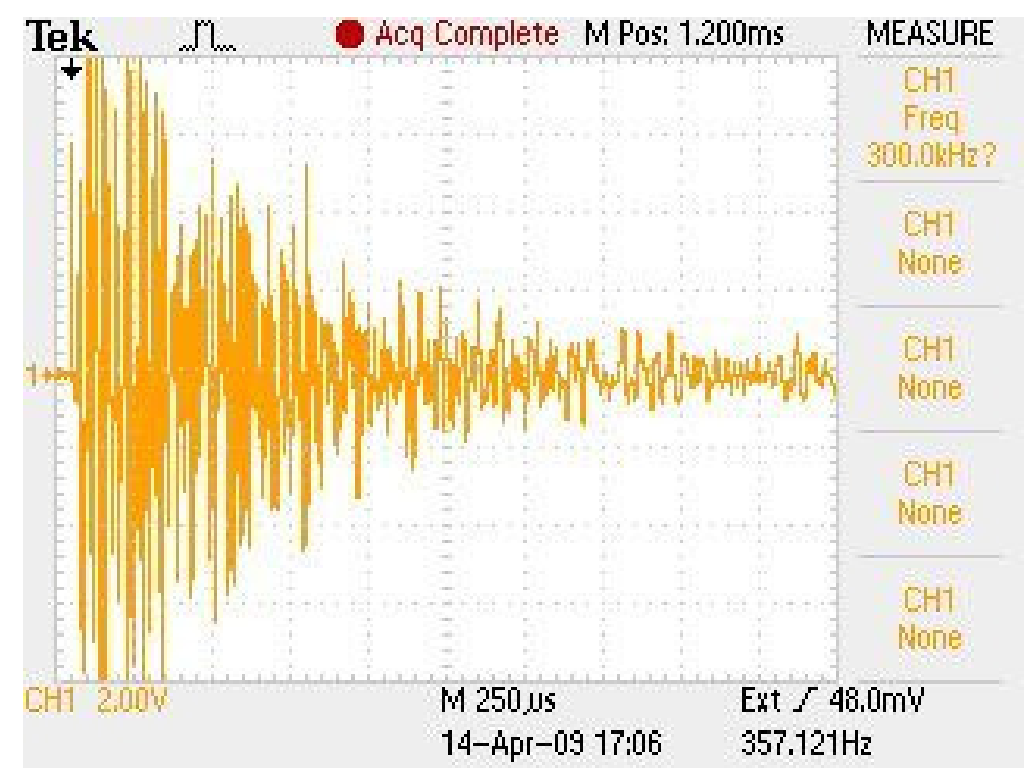

FIGURE 23. Received Wave Signal Collected from Specimen B-1 (Carbon Reinforced $100 \%$ Bond Area) using a Shear Receiving Transducer With a Gain of 40dB in the Near to Near Transducer Configuration.

Figure 24 shows the wave signal received from Specimen B-1 (a 100\% bond area) CFRP beam specimen, using a shear receiving transducer, amplified with a gain of $40 \mathrm{~dB}$ and taken from the far to near transducer configuration. This far to near received signal was similar to the near to near signal (Figure 23) with the exception of a lateral shift to the right, due to the longer signal travel time. 


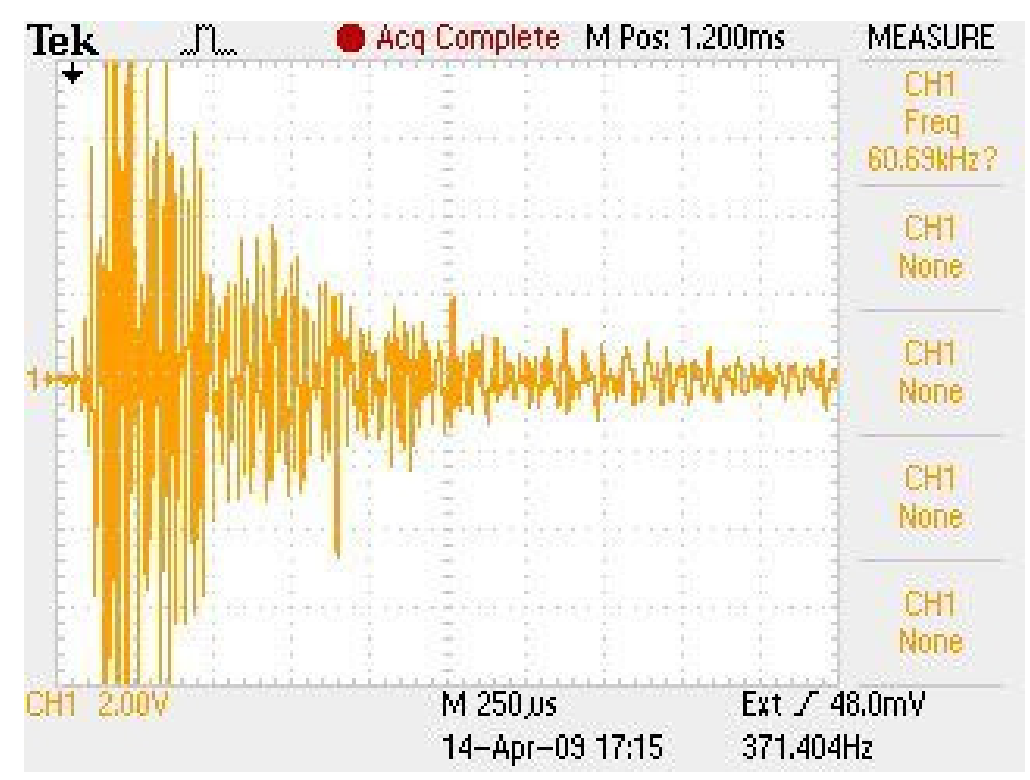

FIGURE 24. Received Wave Signal Collected from Specimen B-1 (Carbon Reinforced $100 \%$ Bond Area) using a Shear Receiving Transducer With a Gain of 40dB in the Far to Near Transducer Configuration.

Figure 25 shows the wave signal received from Specimen C-1 (a 100\% bond area) CFRP beam specimen, using a shear receiving transducers, amplified with a gain of $40 \mathrm{~dB}$ and taken from the near to far transducer configuration. This received signal shows a lateral shift to the right, resulting from the longer signal travel time. Like the longitudinal signals, the shear wave amplitude was reduced with higher void area. The tests using the near to far shear transducer configuration provided limited information due to signal attenuation; thus, only the carbon reinforced $100 \%$ and $50 \%$ specimens were tested using this configuration. Similar results were expected to be obtained from glass fiber beams tested with the same transducer locations so these tests were not performed. 


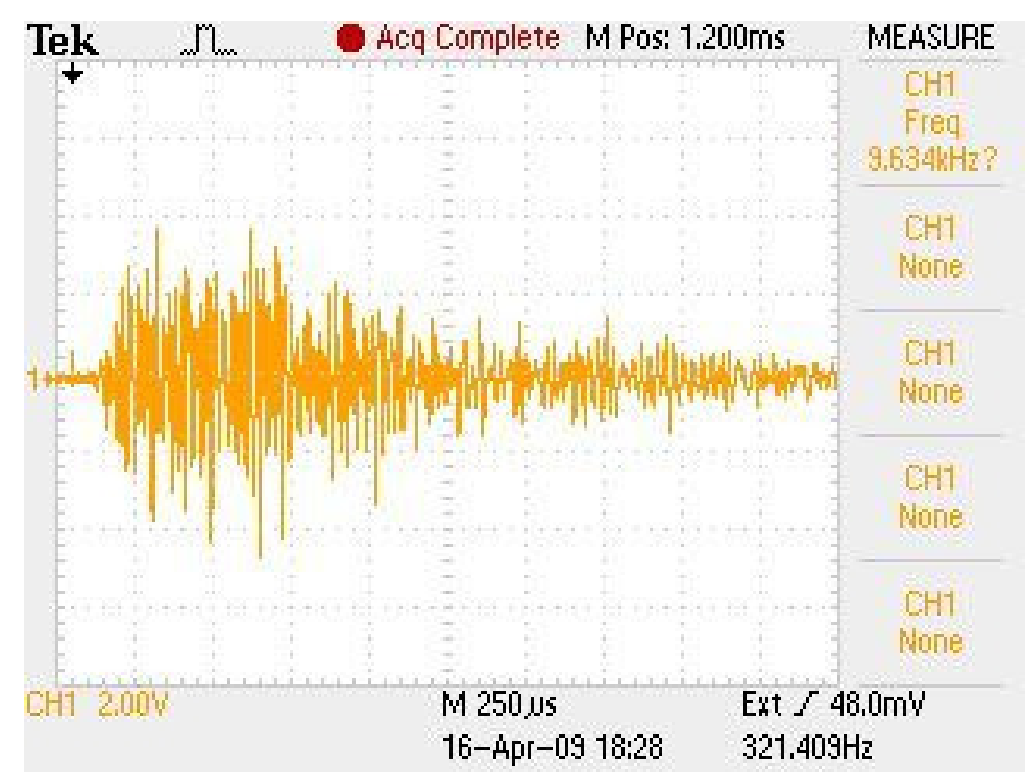

FIGURE 25. Received Wave Signal Collected from Specimen C-1 (Carbon Reinforced $100 \%$ Bond Area) using a Shear Receiving Transducer With a Gain of 40dB in the Near to Far Transducer Configuration.

\section{AUP and Energy Test Results}

The AUP and total signal energy results were calculated using previously described methodologies for each of the eighteen specimens. Table III shows the AUP and energy results of Specimens A-1 and A-5, for the near to near configuration with a longitudinal receiving transducer. The variation in individual tests is quite low for both the AUP and energy results and was typical for all the NDE tests. The results of all five tests on both sides of the eighteen beam specimens are summarized in tables in the Appendix.

The following figures summarize the results for both longitudinal and shear wave receiving transducers sorted according to the various transducer locations used during the 
non-destructive evaluations. Only the average values for AUP and signal energy for ech side of the beam specimens are shown.

TABLE III

CARBON SPECIMENS TESTED IN THE NEAR TO NEAR CONFIGURATION WITH LONGITUDINAL RECEIVING TRANSDUCER

\begin{tabular}{|c|c|c|c|c|c|c|c|}
\hline Beam & $\begin{array}{c}\text { Void } \\
\text { Area } \\
(\%)\end{array}$ & $\begin{array}{c}\text { Sending } \\
\text { Transducer } \\
\text { Location } \\
\text { (side of } \\
\text { beam) }\end{array}$ & $\begin{array}{c}\text { AUP } \\
\text { Results } \\
\text { (V) }\end{array}$ & $\begin{array}{c}\text { Average } \\
\text { Test } \\
\text { AUP } \\
\text { Results } \\
\text { (V) }\end{array}$ & $\begin{array}{c}\text { Total } \\
\text { Energy } \\
\left(\mathbf{V}^{*} \mathbf{s}\right)\end{array}$ & $\begin{array}{c}\text { Average } \\
\text { Test } \\
\text { Energy } \\
\text { Results } \\
(\mathbf{V} * \mathbf{s})\end{array}$ & $\begin{array}{c}\text { Max } \\
\text { Received } \\
\text { Amplitude } \\
\text { (V) }\end{array}$ \\
\hline A-1 & 0 & $\mathrm{~A}$ & 54.33 & 55.82 & 140.53 & 143.47 & 3.52 \\
\hline A-1 & 0 & A & 55.45 & & 142.45 & & 3.6 \\
\hline A-1 & 0 & A & 56.57 & & 143.89 & & 3.68 \\
\hline A-1 & 0 & A & 56.18 & & 145.38 & & 3.68 \\
\hline A-1 & 0 & A & 56.58 & & 145.11 & & 3.76 \\
\hline A-1 & 0 & B & 58.98 & 59.22 & 166.68 & 167.92 & 3.12 \\
\hline A-1 & 0 & B & 59.06 & & 167.74 & & 3.2 \\
\hline A-1 & 0 & B & 59.45 & & 168.66 & & 3.2 \\
\hline A-1 & 0 & B & 60.49 & & 168.13 & & 3.28 \\
\hline A-1 & 0 & B & 58.10 & & 168.38 & & 3.28 \\
\hline A-5 & 25 & A & 39.96 & 40.79 & 102.14 & 104.54 & 2.24 \\
\hline A-5 & 25 & A & 41.32 & & 104.36 & & 2.24 \\
\hline A-5 & 25 & A & 40.76 & & 105.23 & & 2.24 \\
\hline A-5 & 25 & A & 41.08 & & 105.60 & & 2.24 \\
\hline A-5 & 25 & A & 40.84 & & 105.36 & & 2.24 \\
\hline A-5 & 25 & B & 42.92 & 43.14 & 120.32 & 121.01 & 2.40 \\
\hline A-5 & 25 & B & 42.68 & & 121.12 & & 2.40 \\
\hline A-5 & 25 & B & 43.16 & & 121.23 & & 2.40 \\
\hline A-5 & 25 & B & 43.72 & & 121.06 & & 2.40 \\
\hline A-5 & 25 & B & 43.24 & & 121.32 & & 2.40 \\
\hline
\end{tabular}

Figures 26 and 27 summarize the averaged AUP and signal energy results, respectively, for tests performed on carbon reinforced beam specimens using a longitudinal receiving transducer in the near to near configuration. 


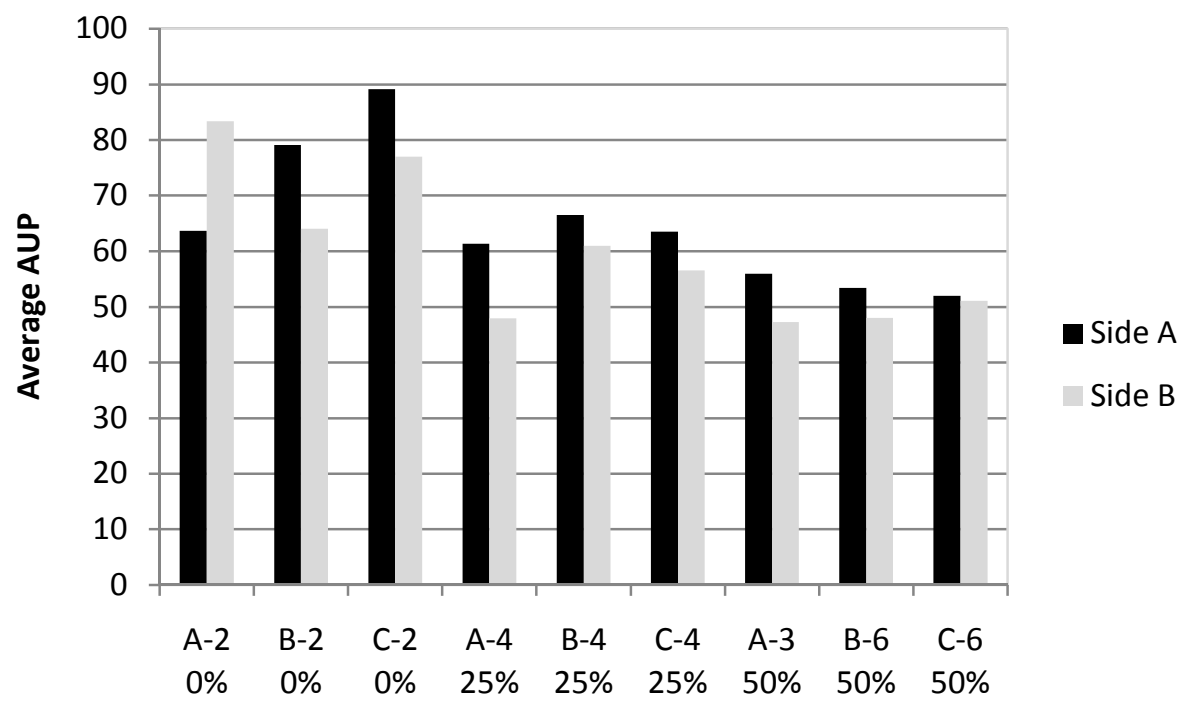

FIGURE 26. Average AUP Test Results for Carbon Specimens Tested in the Near to Near Configuration with Longitudinal Receiving Transducer

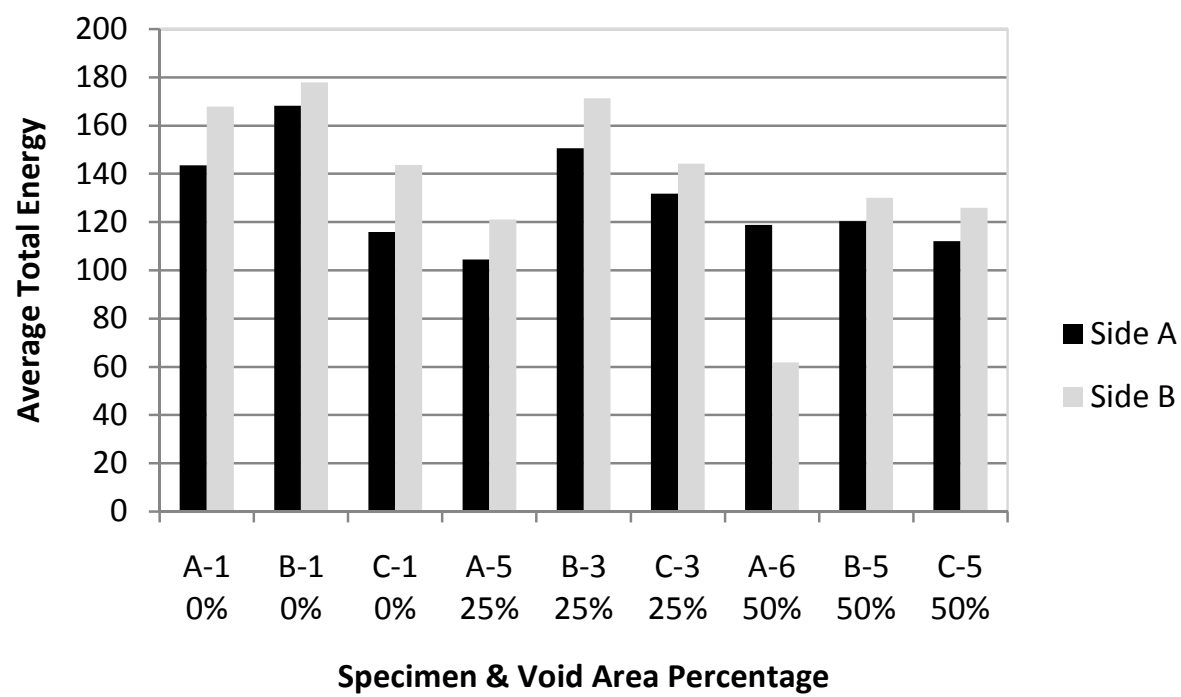

FIGURE 27. Average Total Energy Test Results for Carbon Specimens Tested in the Near to Near Configuration with Longitudinal Receiving Transducer 
Figures 28 and 29 summarize the averaged AUP and signal energy results, respectively, for tests performed on glass reinforced beam specimens using a longitudinal receiving transducer in the near to near configuration.

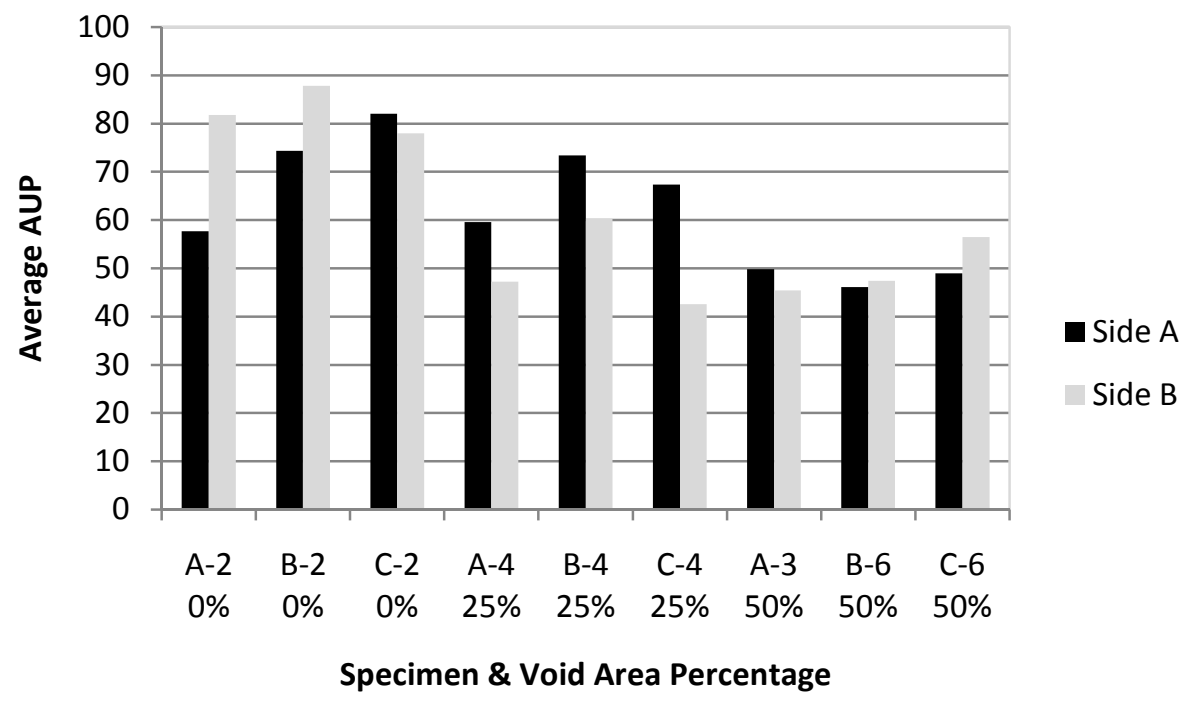

FIGURE 28. Average AUP Test Results for Glass Specimens Tested in the Near to Near Configuration with Longitudinal Receiving Transducer 


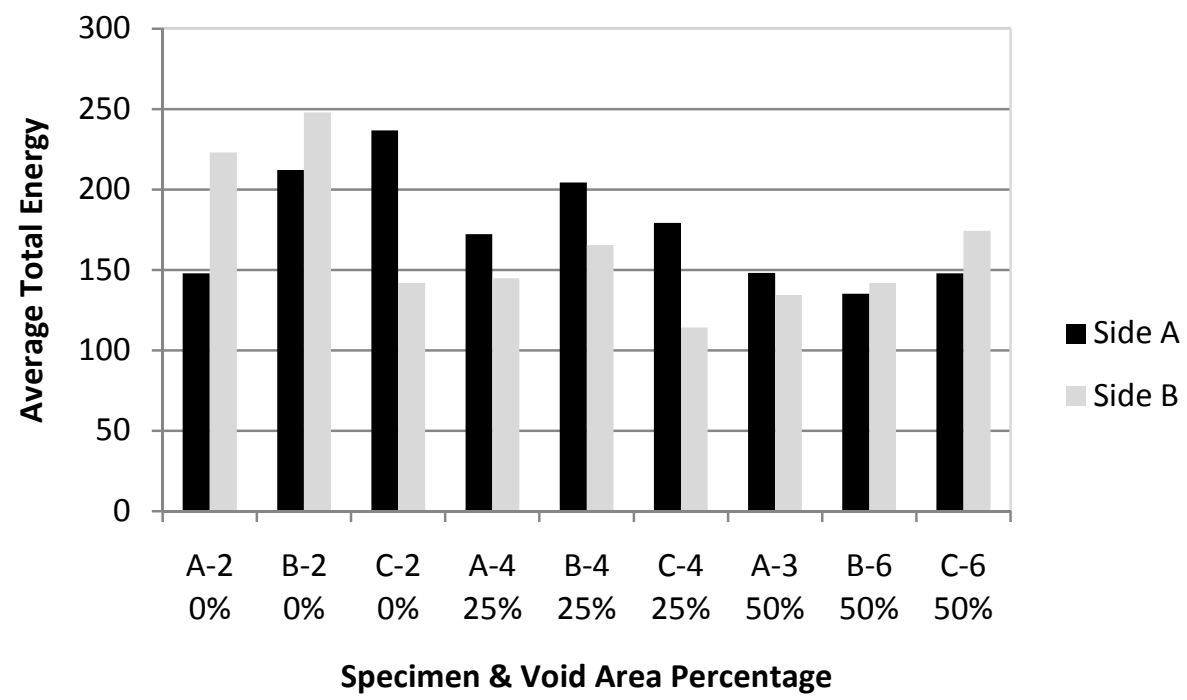

FIGURE 29. Average Total Energy Test Results for Glass Specimens Tested in the Near to Near Configuration with Longitudinal Receiving Transducer

Figures 30 and 31 summarize the AUP and energy results for tests performed on carbon reinforced beam specimens using a longitudinal receiving transducer in the far to near configuration.

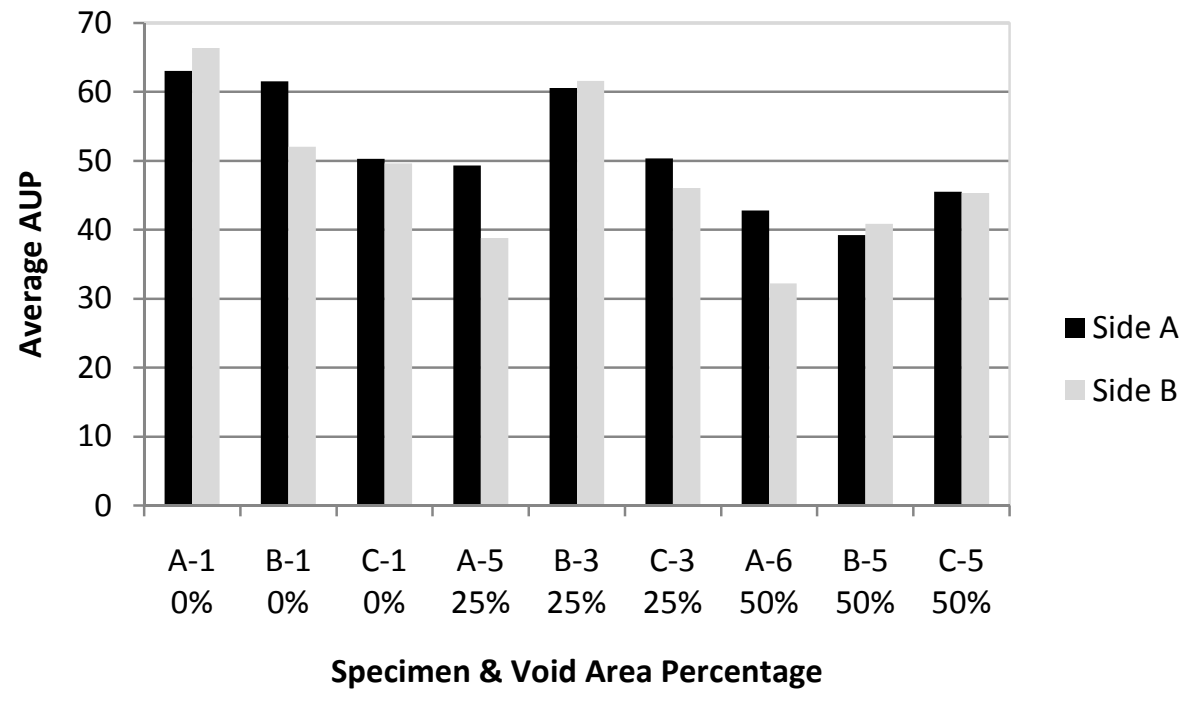

FIGURE 30. Average AUP Test Results for Carbon Specimens Tested in the Far to Near Configuration with Longitudinal Receiving Transducer 


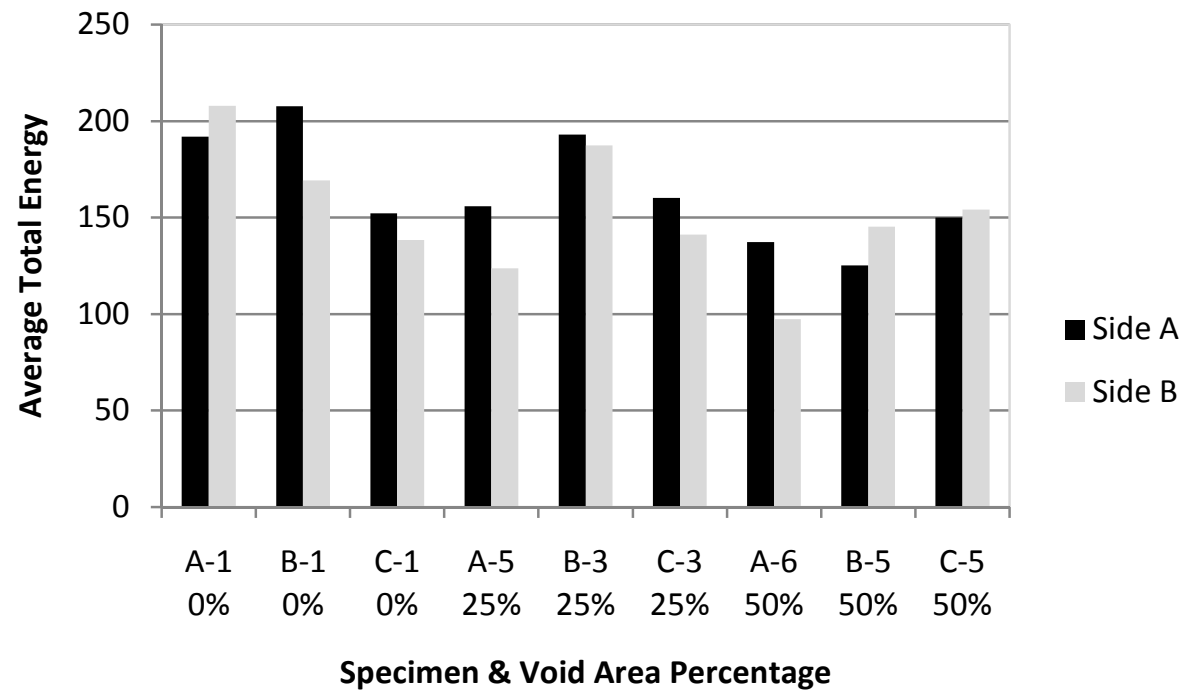

FIGURE 31. Average Total Energy Test Results for Carbon Specimens Tested in the Far to Near Configuration with Longitudinal Receiving Transducer

Figures 32 and 33 summarize the results for tests performed on glass reinforced beam specimens using a longitudinal receiving transducer in the far to near configuration. 


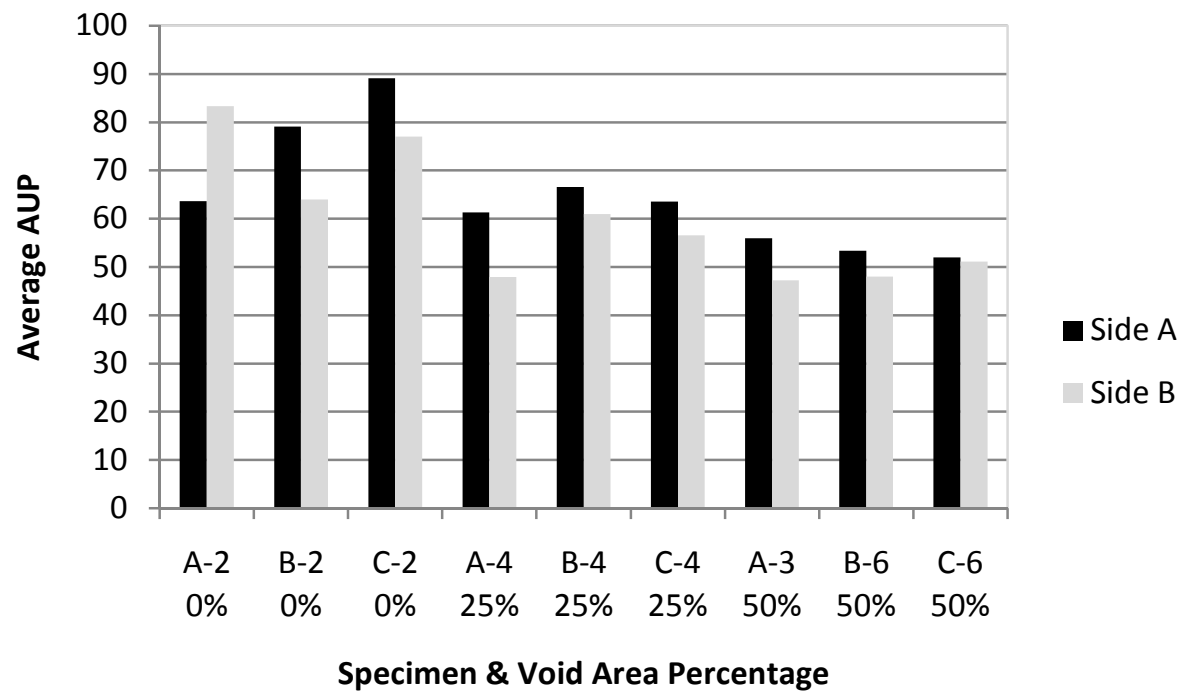

FIGURE 32. Average AUP Test Results for Glass Specimens Tested in the Far to Near Configuration with Longitudinal Receiving Transducer

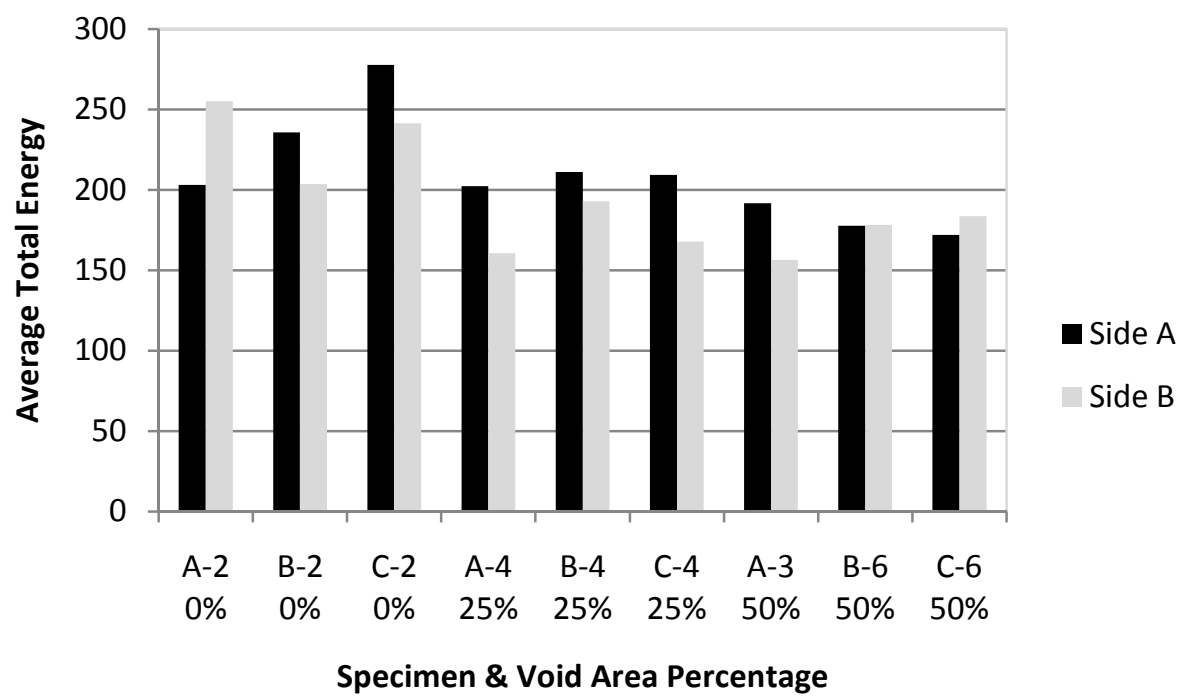

FIGURE 33. Average Total Energy Test Results for Glass Specimens Tested in the Far to Near Configuration with Longitudinal Receiving Transducer

Only test specimens A-1, A-6, C-1 and C-5 were tested in the near to far transducer configuration. These tests were performed twice, at two different gains (20dB 
and $40 \mathrm{~dB}$ ) to determine if more information could be obtained from this transducer configuration. Figures 34 and 35 summarize the AUP and signal energy results for tests performed on carbon reinforced beam specimens using a longitudinal receiving transducer in the near to far configuration.

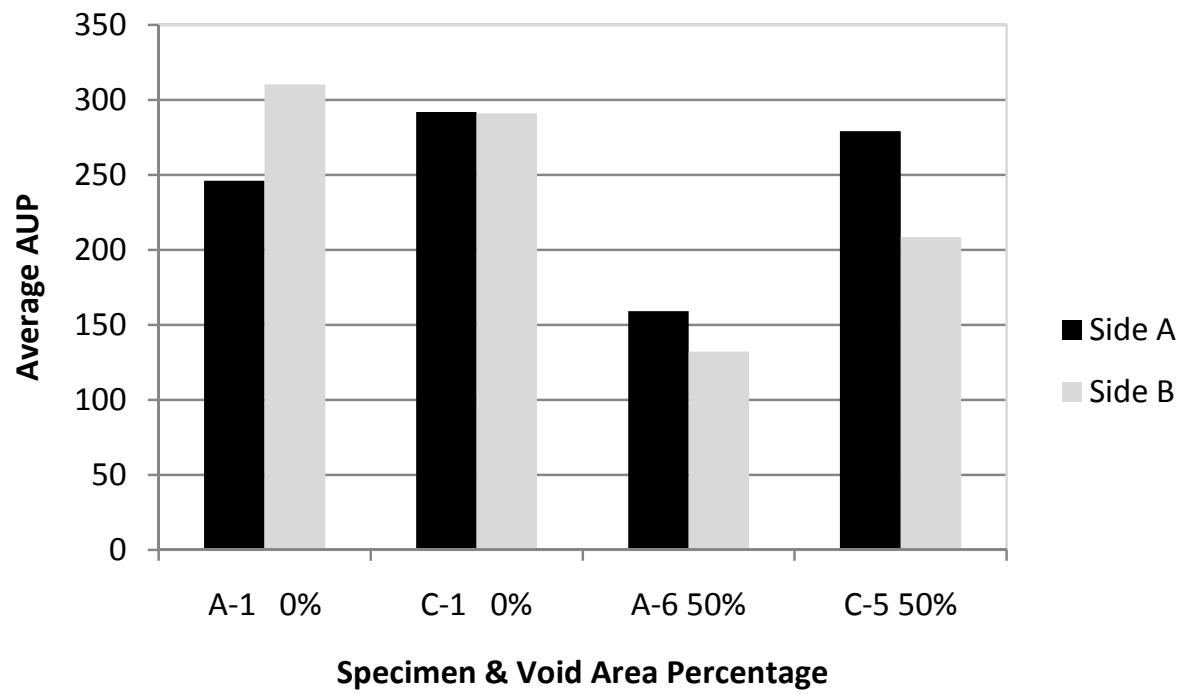

FIGURE 34. Average AUP Test Results for Carbon Specimens Tested in the Near to Far Configuration with Longitudinal Receiving Transducer 


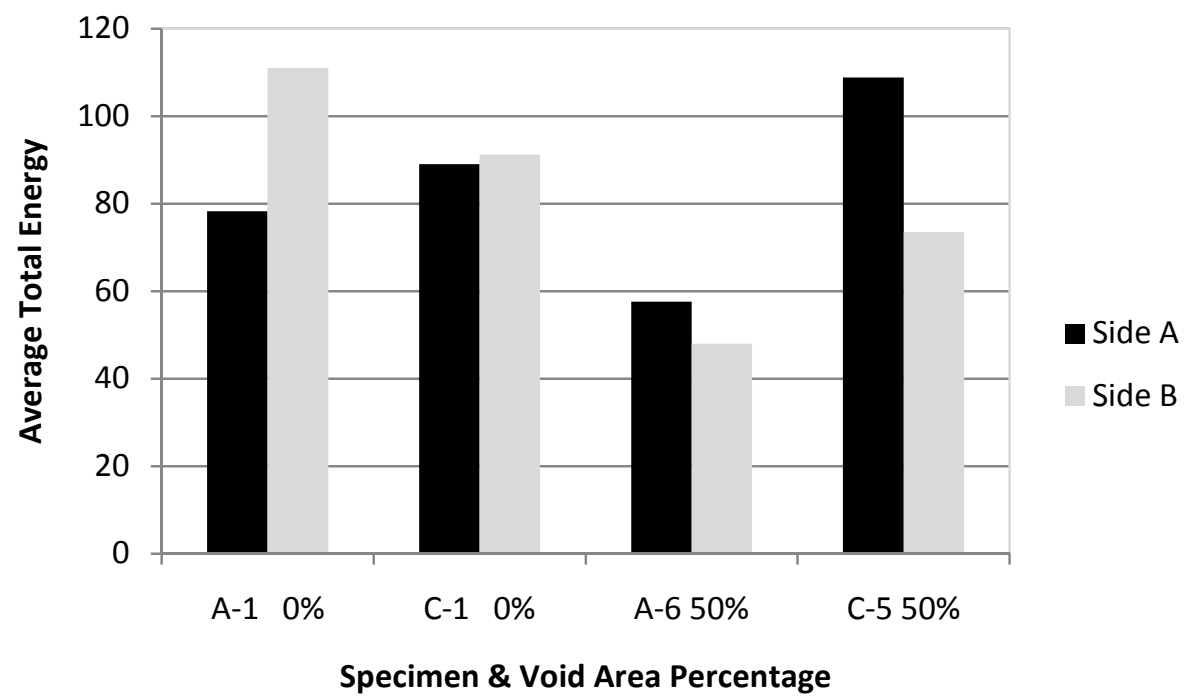

FIGURE 35. Average Total Energy Test Results for Carbon Specimens Tested in the $\underline{\text { Near to Far Configuration with Longitudinal Receiving Transducer }}$

Figures 36 and 37 summarize both the AUP and signal energy results for tests performed on carbon reinforced beam specimens using a shear receiving transducer in the near to near configuration.

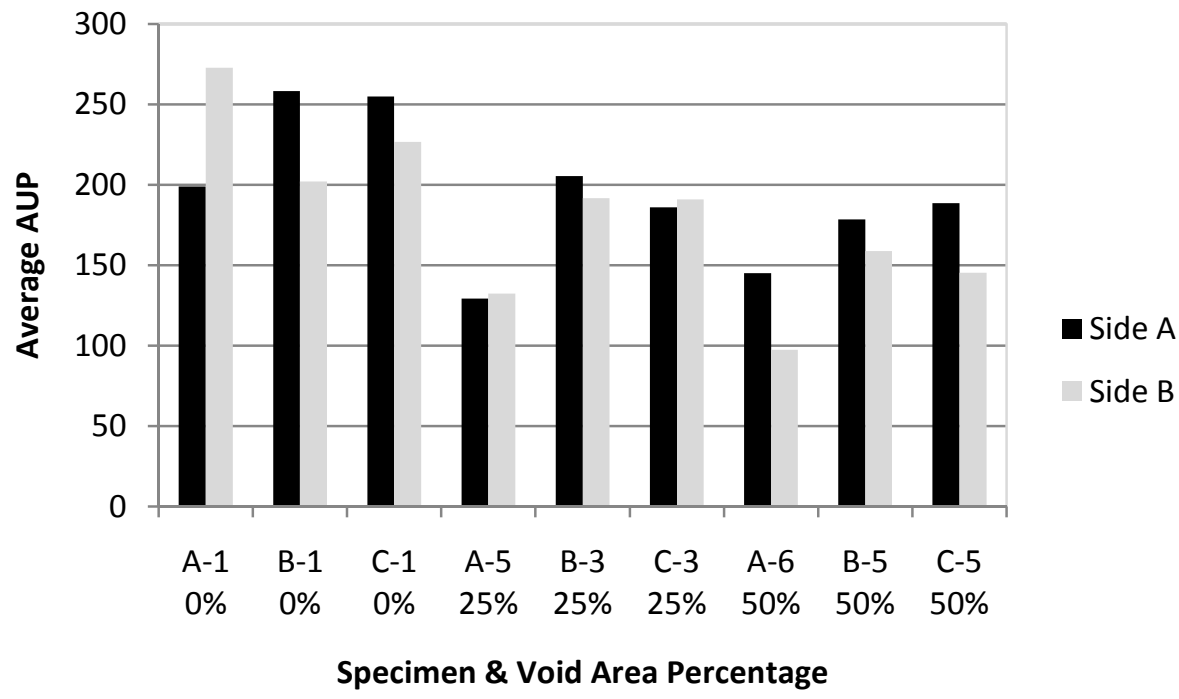

FIGURE 36. Average AUP Test Results for Carbon Specimens Tested in the Near to Near Configuration with Shear Receiving Transducer 


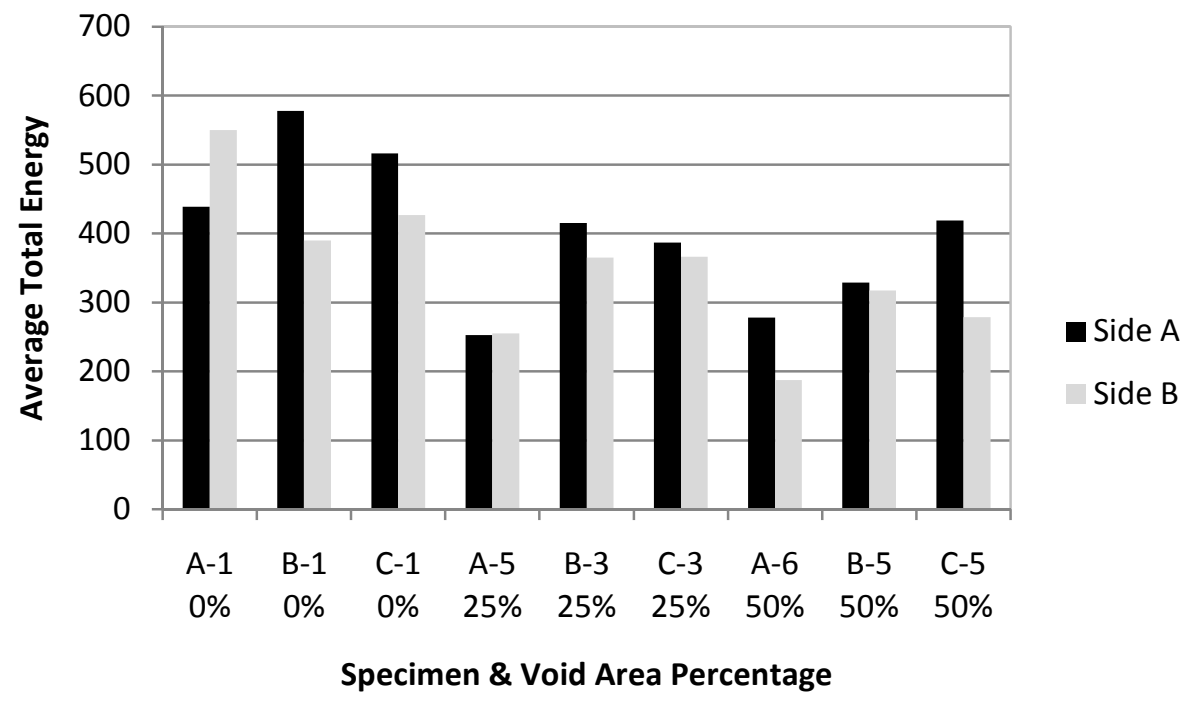

FIGURE 37. Average Total Energy Test Results for Carbon Specimens Tested in the Near to Near Configuration with Shear Receiving Transducer

Only glass reinforced test specimens, B-2, B-6, C-2 and C-6, were evaluated in the near to near transducer configuration using shear wave receiving transducers. Figures 38 and 39 summarize the AUP and signal energy test results for these tests. 


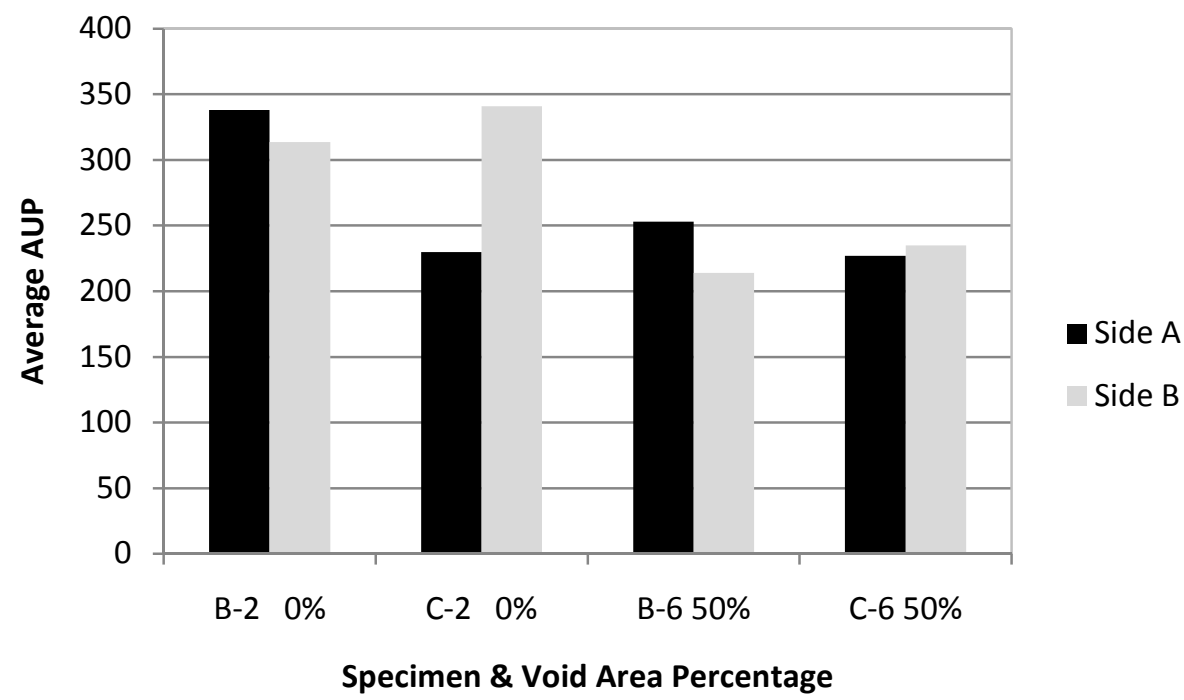

FIGURE 38. Average AUP Test Results for Glass Specimens Tested in the Near to Near Configuration with Shear Receiving Transducer

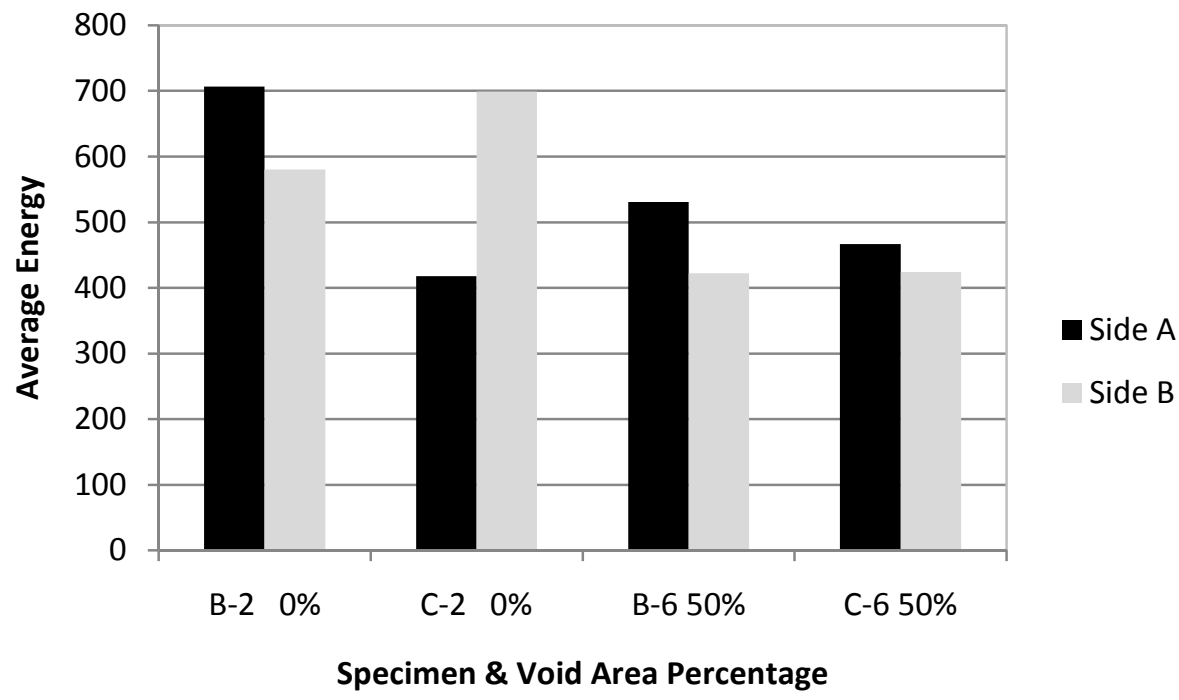

FIGURE 39. Average Total Energy Test Results for Glass Specimens Tested in the Near to Near Configuration with Shear Receiving Transducer 
Figures 40 and 41 summarize the AUP and signal energy results for tests performed on carbon reinforced beam specimens using a shear receiving transducer in the far to near configuration.

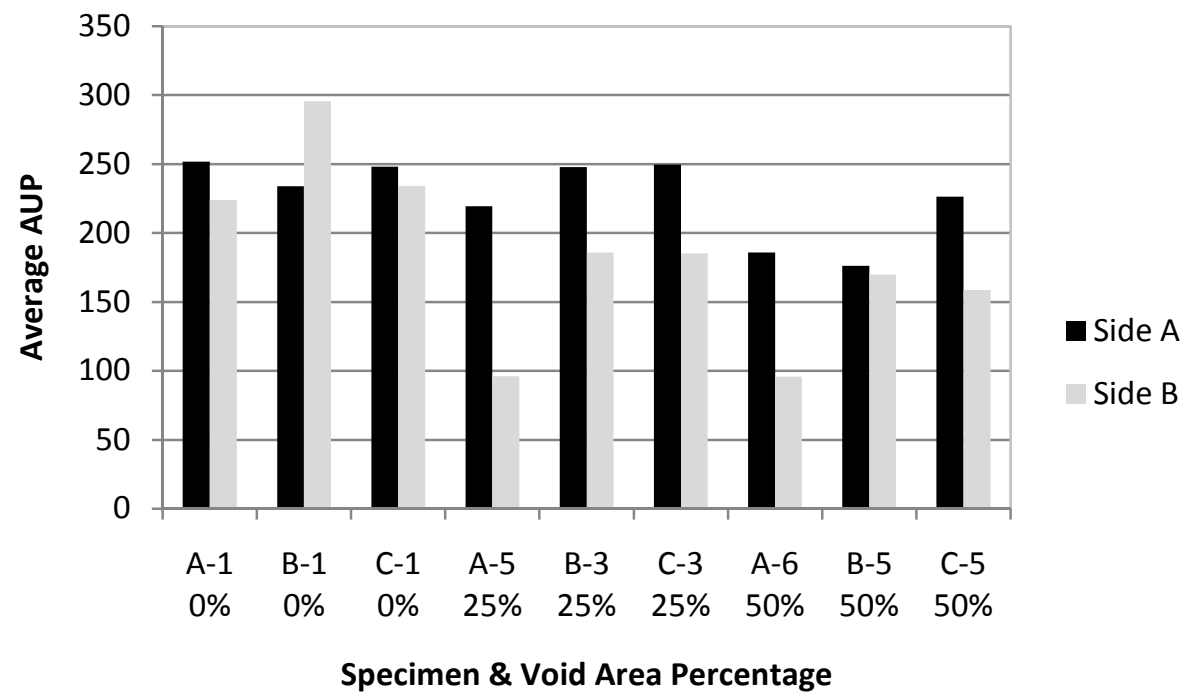

FIGURE 40. Average AUP Test Results for Carbon Specimens Tested in the Far to Near Configuration with Shear Receiving Transducer

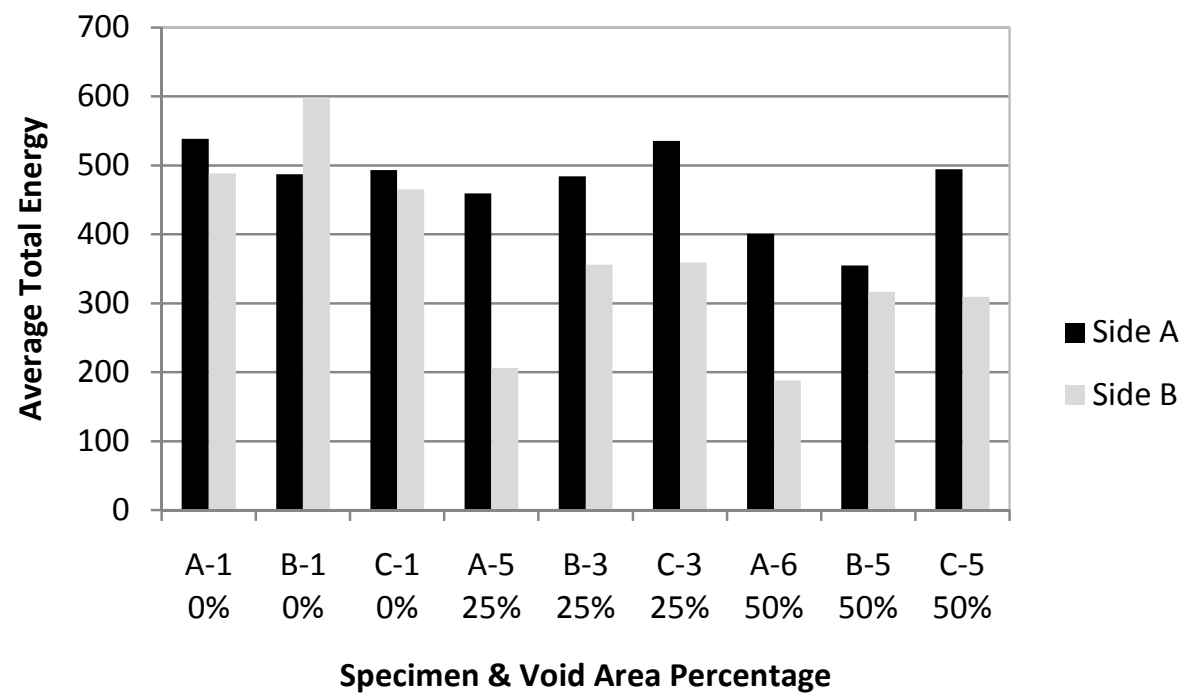

FIGURE 41. Average Total Energy Test Results for Carbon Specimens Tested in the Far to Near Configuration with Shear Receiving Transducer 
Only the $100 \%$ and $50 \%$ void areas of Specimen series B and C, Specimens, B-2, B-6, C-2 and C-6, were tested in the far to near transducer configuration using a shear wave receiving transducer. Figures 42 and 43 summarize the AUP and signal energy test results for these tests.

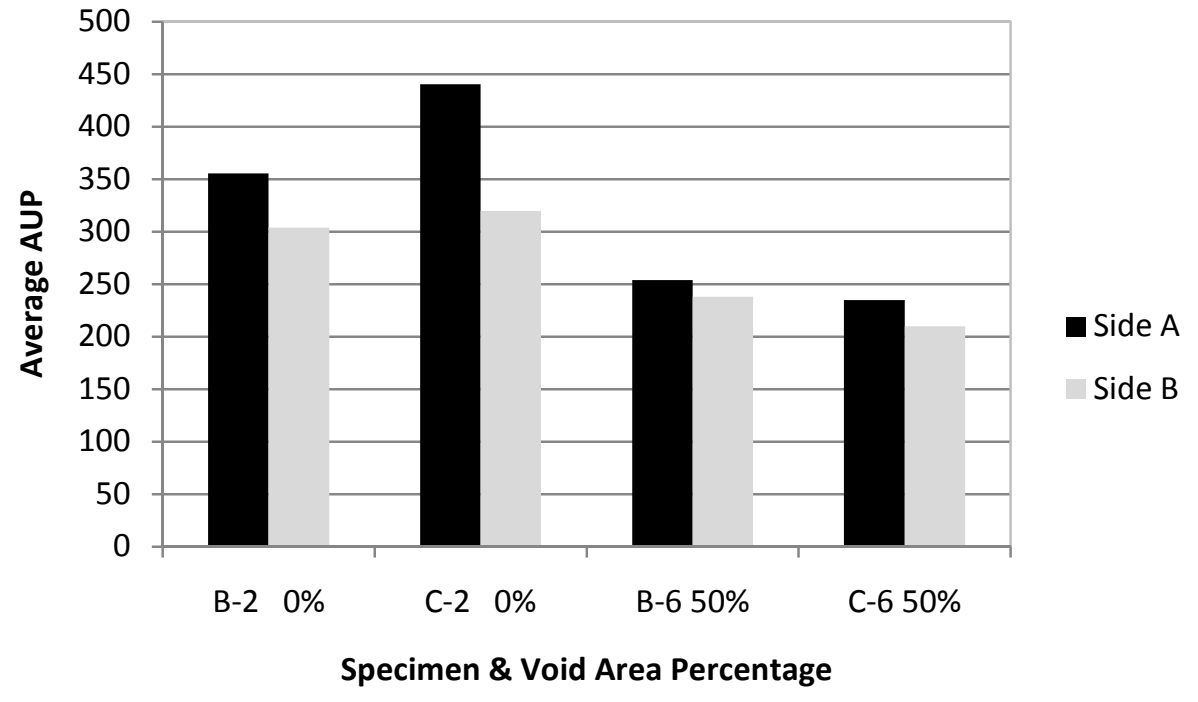

FIGURE 42. Average AUP Test Results for Glass Specimens Tested in the Far to Near Configuration with Shear Receiving Transducer 


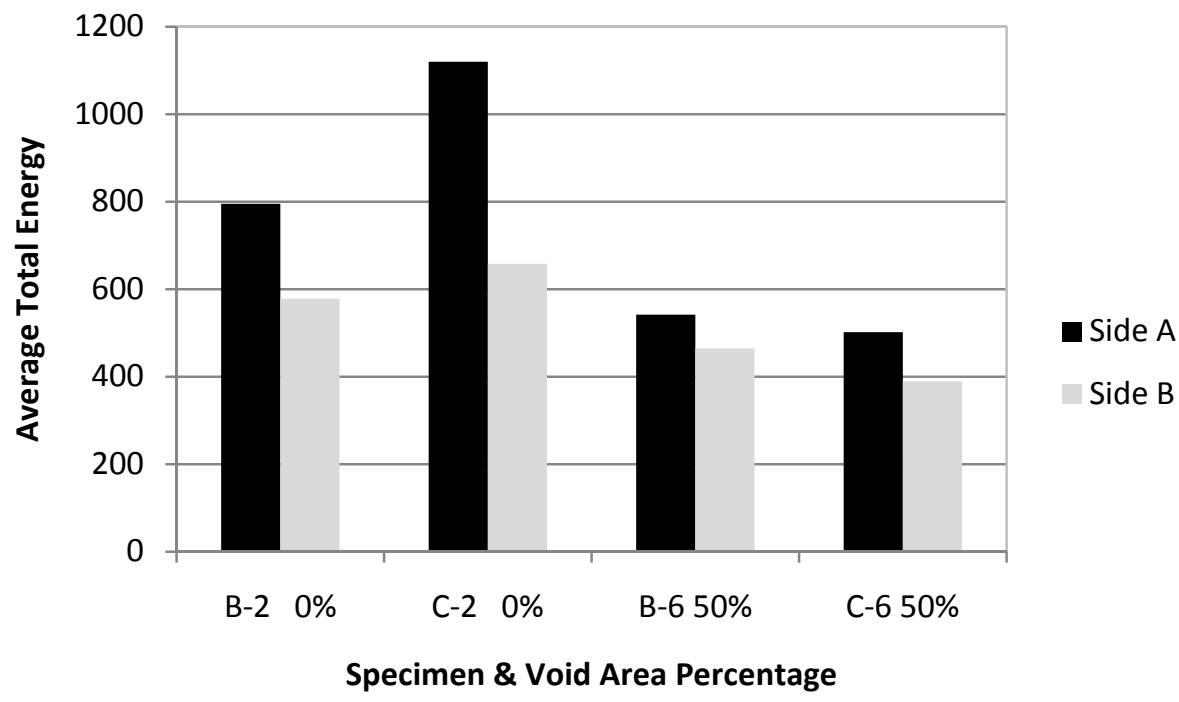

FIGURE 43. Average Total Energy Test Results for Glass Specimens Tested in the Far to Near Configuration with Shear Receiving Transducer

\section{E. Destructive Beam Test Results}

Table IV summarizes the maximum load, beam deflection and strain values measured during destructive testing of the carbon reinforced specimens. "Void Area" represents the percentage of FRP area that was not bonded to the concrete specimen during construction. The "Load Type" shows whether the beam was loaded using the third point $\left({ }^{1} / 3 \mathrm{Pt}\right)$ loading configuration or the single point load $(\mathrm{Pt} \mathrm{Ld})$ configuration. The "Side of Beam Break" represents the side of the test specimen that experienced FRP debond or moment failure. The "Maximum Load" refers to the maximum load applied at the center of the beam for single point load or, or the total load (2P), when the third point loading configuration was used. "Type of Break" is designated as either "M" for moment failure, "SB/C" for shear bond/concrete failure, "Sh" for shear of concrete or "F" for a fiber rupture. 
TABLE IV

CFRP BEAM DESTRUCTIVE LOAD TEST RESULTS

\begin{tabular}{cccccccccc}
\hline & $\begin{array}{c}\text { Void } \\
\text { Area } \\
(\%)\end{array}$ & $\begin{array}{c}\text { Load } \\
\text { Type }\end{array}$ & $\begin{array}{c}\text { Side of } \\
\text { Beam } \\
\text { Break }\end{array}$ & $\begin{array}{c}\text { Max } \\
\text { Load } \\
(\mathrm{lbs})\end{array}$ & $\begin{array}{c}\text { Max } \\
\text { Strain } \\
(\mu \varepsilon)\end{array}$ & $\begin{array}{c}\text { Max } \\
\text { Strain } \\
\text { Beam }\end{array}$ & $\begin{array}{c}\text { Max } \\
\text { Deflection } \\
(\text { in })\end{array}$ & $\begin{array}{c}\text { Max } \\
\text { Deflection } \\
(\text { in })\end{array}$ & $\begin{array}{c}\text { Type of } \\
\text { Break }\end{array}$ \\
\hline A-1 & 0 & Pt Ld & B & 6041 & 3639 & 3300 & -0.03984 & -0.01937 & M \\
A-5 & 25 & Pt Ld & A & 4688 & 2733 & 2606 & 0.00472 & -0.06335 & SB/C \\
A-6 & 50 & Pt Ld & A & 5168 & 3555 & 3980 & -0.03407 & -0.02722 & SB/C \\
B-1 & 0 & Pt Ld & A & 6151 & 4469 & 5542 & -0.02883 & -0.03246 & M \\
B-3 & 25 & Pt Ld & B & 5904 & 5489 & 3888 & -0.03617 & -0.03560 & SB/C \\
B-5 & 50 & Pt Ld & B & 4405 & 2706 & 3567 & -0.04927 & -0.03455 & Sh \\
C-1 & 0 & Pt Ld & B & 5995 & 4459 & 5812 & -0.03145 & -0.04607 & SB/C \\
C-3 & 25 & $1 / 3$ Pt & B & 9912 & 3354 & 7087 & -0.06447 & -0.05078 & M \\
C-5 & 50 & $1 / 3$ Pt & A & 7276 & 4474 & 4448 & -0.04822 & -0.04241 & SB/C \\
\hline
\end{tabular}

Table V summarizes the maximum load, beam deflection and strain values measured during simple support loading of glass reinforced test specimens. Values represented in Table $\mathrm{V}$ are similar to those previously discussed in Table IV. When "N/A" is denoted in the "Side of Beam Break Column," a glass fiber rupture occurred during destructive testing. 
TABLE V

GFRP BEAM DESTRUCTIVE LOAD TEST RESULTS

\begin{tabular}{lccccccccc}
\hline & $\begin{array}{c}\text { Void } \\
\text { Area } \\
(\%)\end{array}$ & $\begin{array}{c}\text { Load } \\
\text { type }\end{array}$ & $\begin{array}{c}\text { Side of } \\
\text { Beam }\end{array}$ & $\begin{array}{c}\text { Max } \\
\text { Break } \\
(\mathrm{lbs})\end{array}$ & $\begin{array}{c}\text { Max } \\
\text { Strain }\end{array}$ & $\begin{array}{c}\text { Max } \\
\text { Strain } \\
(\mu \varepsilon)\end{array}$ & $\begin{array}{c}\text { Max } \\
\text { Deflection }\end{array}$ & $\begin{array}{c}\text { Max } \\
\text { Deflection } \\
\text { (in) }\end{array}$ & $\begin{array}{c}\text { Type of } \\
\text { Failure }\end{array}$ \\
\hline A-2 & 0 & Pt Ld & N/A & 3604 & 7307 & 8051 & -0.04508 & -0.03455 & F \\
A-3 & 50 & Pt Ld & A & 3331 & 4501 & 4710 & -0.03198 & -0.02199 & SB/C \\
A-4 & 25 & Pt Ld & N/A & 3331 & 4501 & 4710 & -0.03198 & -0.02199 & F \\
B-2 & 0 & Pt Ld & N/A & 3897 & 11861 & 11792 & -0.05871 & -0.04712 & F \\
B-4 & 25 & Pt Ld & N/A & 3432 & 6207 & 6580 & -0.04298 & -0.03665 & F \\
B-6 & 50 & Pt Ld & N/A & 2896 & 6503 & 7351 & -0.02883 & -0.05131 & F \\
C-2 & 0 & Pt Ld & N/A & 3851 & 10717 & 10766 & -0.06972 & -0.01518 & F \\
C-4 & 25 & Pt Ld & B & 3811 & 13147 & 10589 & -0.06028 & -0.06178 & SB/C \\
C-6 & 50 & $1 / 3$ Pt & N/A & 4799 & 6159 & 6324 & -0.05714 & -0.03927 & F \\
\hline
\end{tabular}

Figures 44 and 45 show typical cracking moment failures of the CFRP concrete test specimens. These occurred at the ends of the FRP reinforcement. Moment failures occurred in Specimens A-1, B-1, and C-3 and appeared to be a result of the bond strength of the CFRP being much higher than anticipated. For these specimens, the capacity of the fiber bond, and thus the capacities of the test specimens, was significantly larger in the reinforced area of the beam causing moment failure outside the reinforced region prior to interfacial shear failure (see further discussion of this in Chapter III). Specimen C-1 was the only $100 \%$ bond area test specimen to fail in somewhat of an interfacial shear fashion (see Figure 46). The concrete appeared to shear near the interface of the FRP and the concrete surface over most of the FRP area. Specimens A-5 and B-3, 75\% 
bond area specimens, failed by concrete interfacial shearing as shown in Figure 47. The last carbon reinforced test specimens, A-6, B-5 and C-5, with 50\% bond area, all failed through concrete interfacial shearing as shown in the typical Figure 48. Specimens with $75 \%$ bond and $50 \%$ bond area also exhibited this interfacial concrete shear failure, although the $75 \%$ and $50 \%$ bond specimens affected less concrete area.

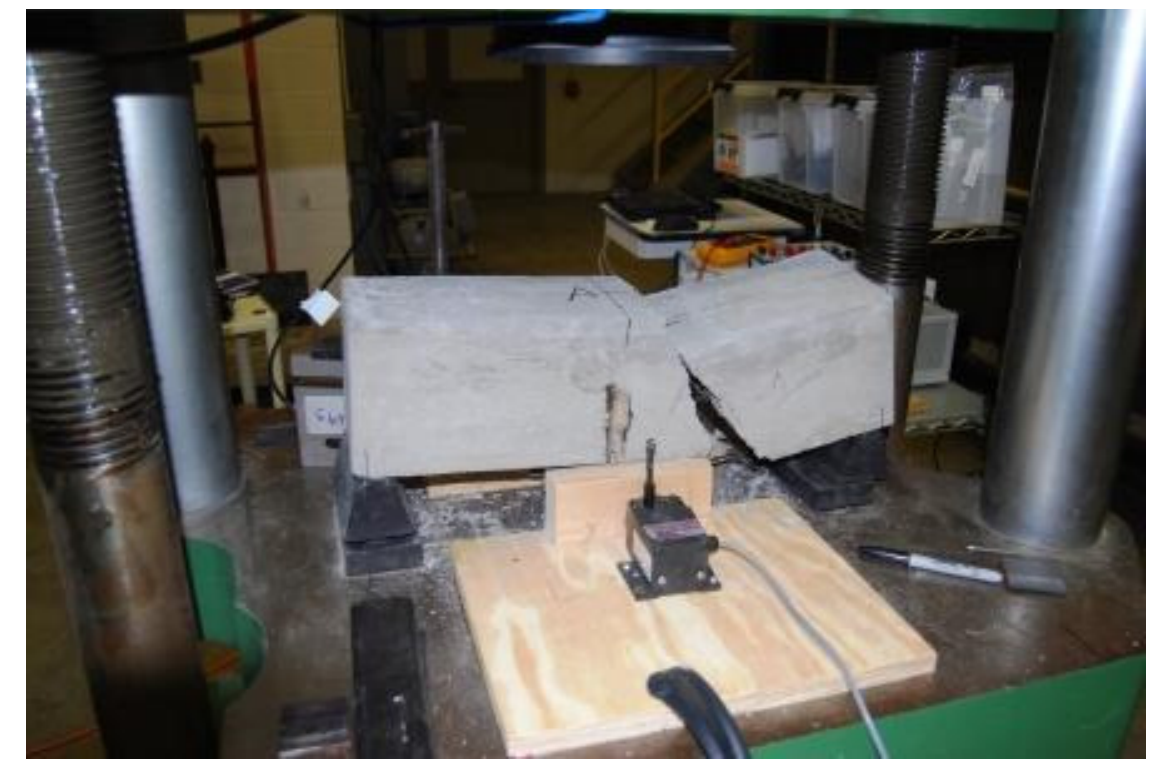

FIGURE 44. Typical Cracking Moment Type Failure at the End of FRP Reinforcement. 


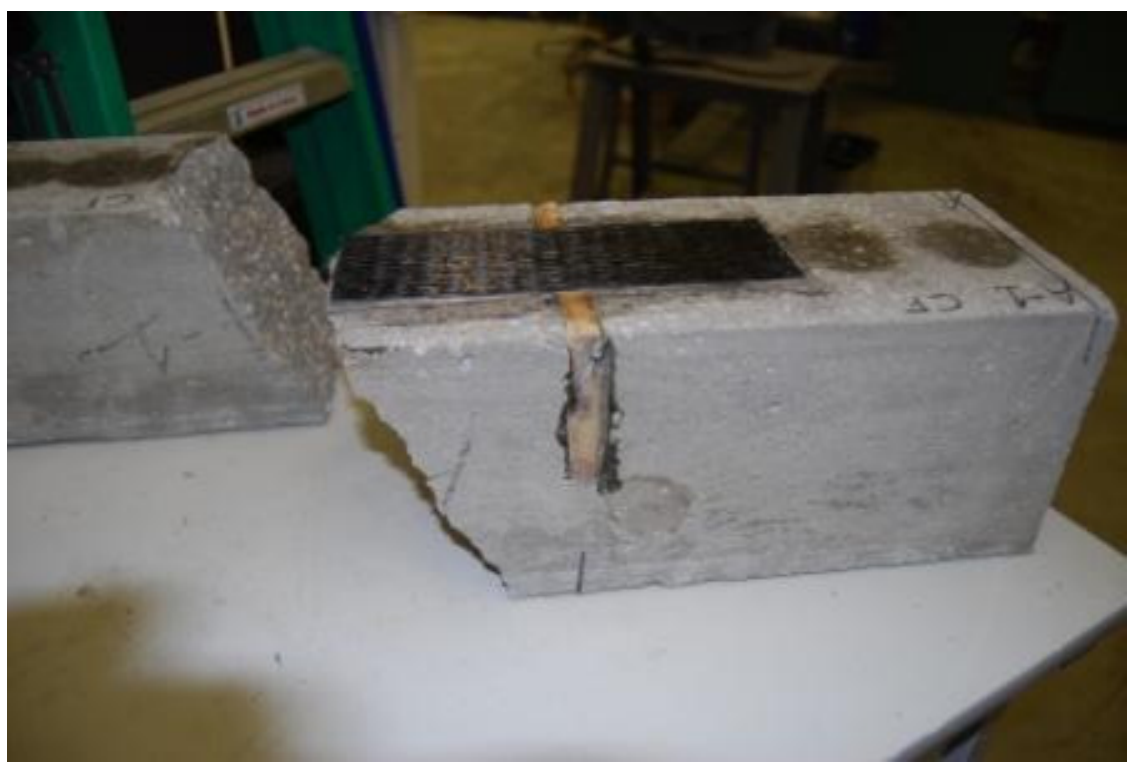

FIGURE 45. Typical Cracking Moment Type Failure at the end of the CFRP Reinforcement (Bottom Side).

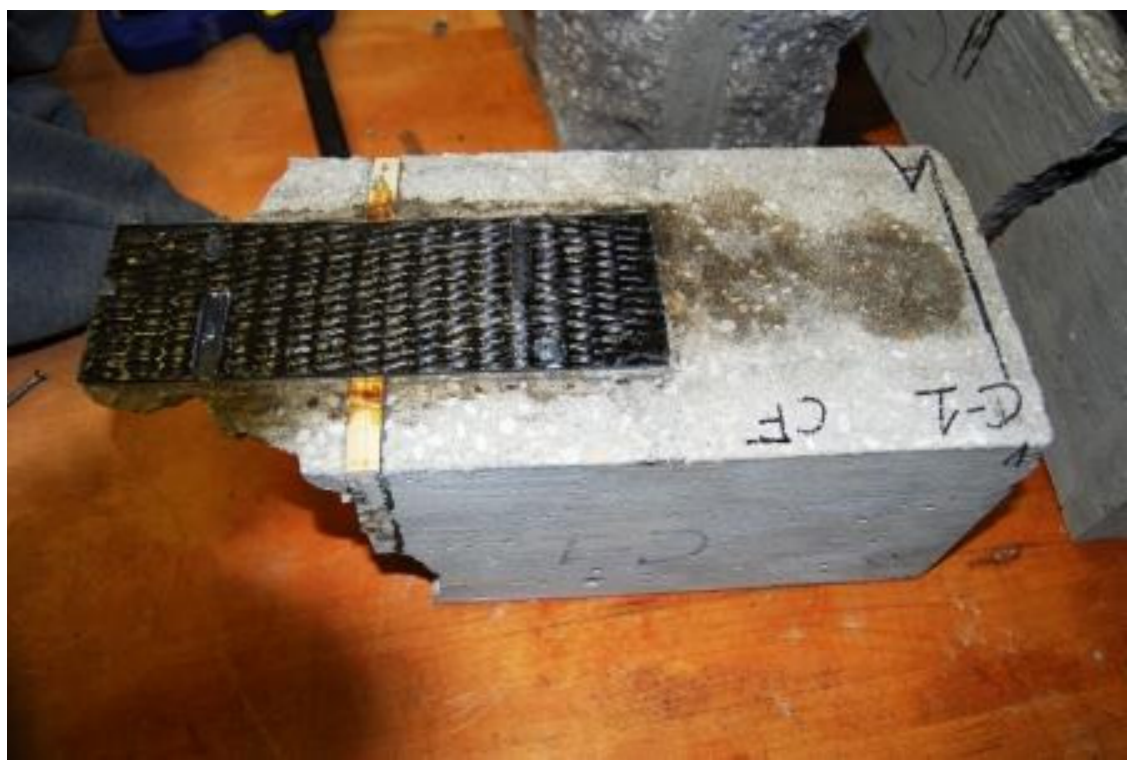

FIGURE 46. Carbon Interfacial Shear Debond (Specimen C-1, a 100\% Bond Area Specimen) with the Largest Amount of Fractured Concrete Material 


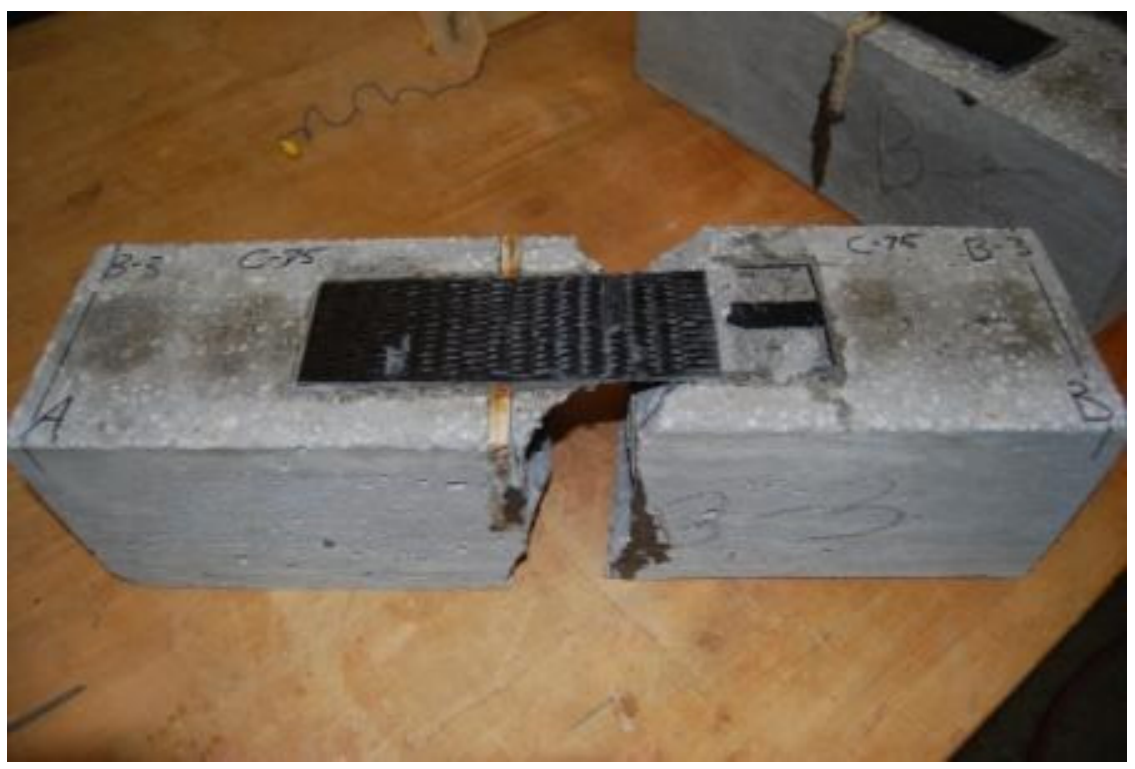

FIGURE 47. Typical Carbon Interfacial Shear Debond (Specimen B-3 a 75\% Bond Area Specimen) with Same Fractured Concrete Material

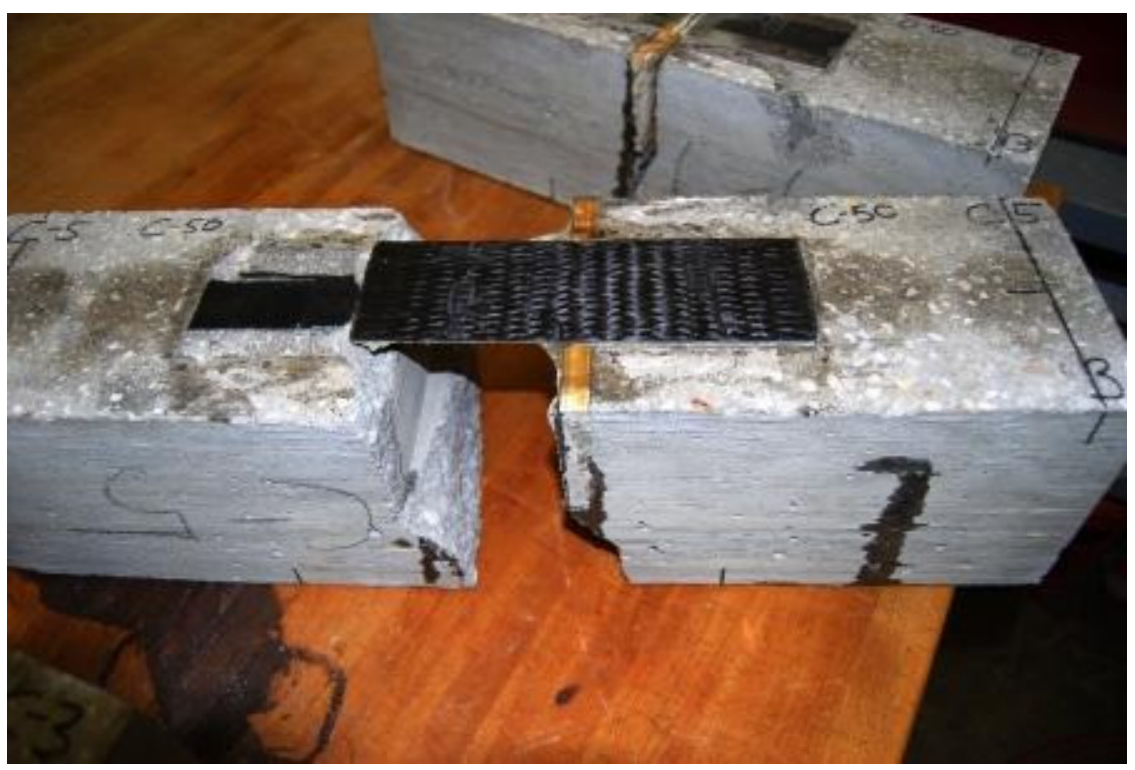

FIGURE 48. Typical Carbon Interfacial Shear Debond (Specimen C-5, a 50\% Bond Area Specimen) with a Small Amount of Fractured Concrete Material

Since most of the glass reinforced specimens failed in fiber rupture, an effort was made to quantify the portion of the FRP patch that appeared to have interfacial shear bond failure. The contrast in color between the bonded and debonded glass fibers, as 
shown in Figure 49, was used to estimate the percent of debonded area. Light colored areas were assumed to be completely debonded. When calculating the debonded area, the observed debonded glass fiber area and any fiber area that was attached to the fractured concrete were summed. Table VI shows the estimated percentage of bond area beneath the patches for each side of the ruptured GFRP specimens. 
TABLE VI

ESTIMATION OF GLASS TEST SPECIMEN DEBONDED AREA

\begin{tabular}{|c|c|c|c|c|}
\hline Beam & Side & $\begin{array}{c}\text { Original Bond } \\
\text { Area } \\
\left(\mathrm{in}^{2}\right)\end{array}$ & $\begin{array}{c}\text { Debonded Area } \\
\left(\text { in }^{2}\right)\end{array}$ & $\begin{array}{l}\text { Percent } \\
\text { Debond }\end{array}$ \\
\hline A-2 & $\mathrm{A}$ & 11.5 & 5.86 & 51.0 \\
\hline A-2 & B & 11.5 & 7.86 & 68.3 \\
\hline A-3 & A & 6.00 & 6.00 & 100 \\
\hline A-3 & B & 6.00 & 2.57 & 42.9 \\
\hline A-4 & A & 8.50 & 3.23 & 38.0 \\
\hline A-4 & B & 8.50 & 3.06 & 36.0 \\
\hline B-2 & A & 11.5 & 6.51 & 56.6 \\
\hline B-2 & B & 11.5 & 8.90 & 77.4 \\
\hline B-4 & A & 8.50 & 3.90 & 45.9 \\
\hline B-4 & B & 8.50 & 3.93 & 46.2 \\
\hline B-6 & A & 5.50 & 3.58 & 65.1 \\
\hline B-6 & B & 5.50 & 1.51 & 27.4 \\
\hline C-2 & A & 11.5 & 8.15 & 70.9 \\
\hline $\mathrm{C}-2$ & B & 11.5 & 6.41 & 55.7 \\
\hline $\mathrm{C}-4$ & A & 8.50 & 5.90 & 69.4 \\
\hline $\mathrm{C}-4$ & B & 8.50 & 8.50 & 100 \\
\hline C-6 & A & 5.00 & 2.170 & 43.4 \\
\hline C-6 & B & 5.00 & 2.100 & 42.0 \\
\hline
\end{tabular}




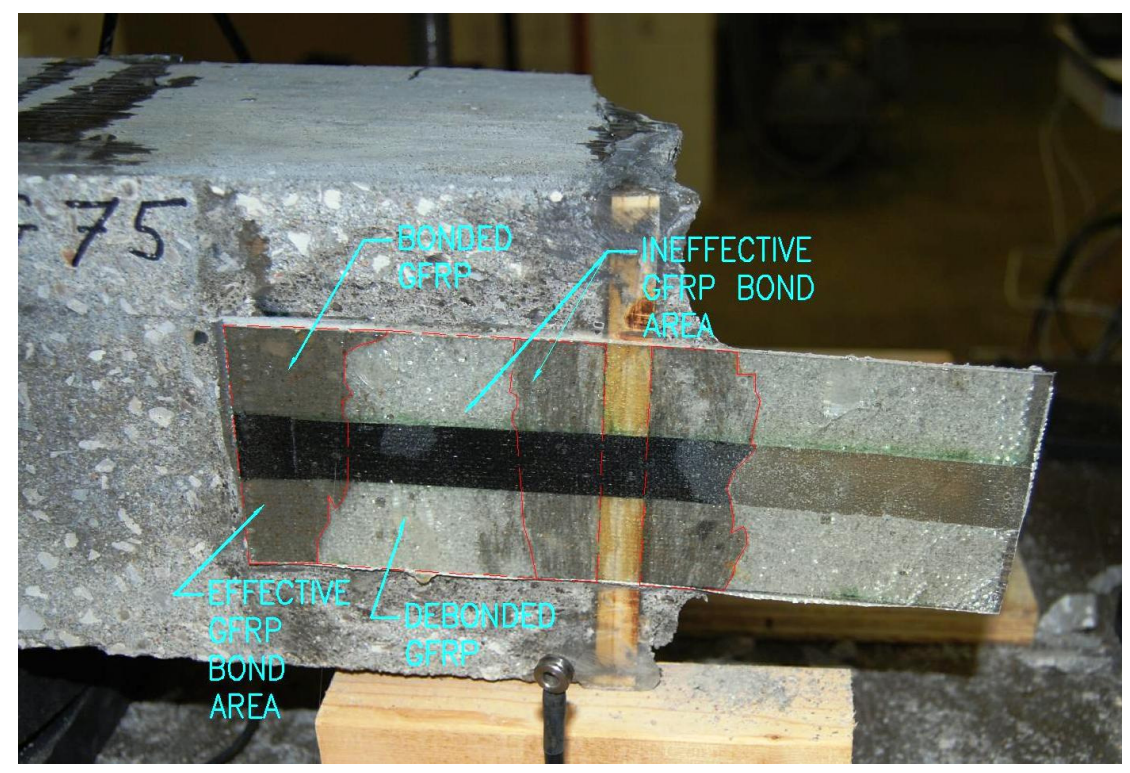

FIGURE 49. Test Specimen C-4 Shows the Contrast in Color of the Bonded and Debonded FRP.

Figure 50 shows a typical GFRP rupture. This failure type occurred in all of the glass reinforced beams except A-3 and C-4. Figure 51 shows a typical concrete/GFRP interfacial shear debond failure (Specimens A-3 and C-4).

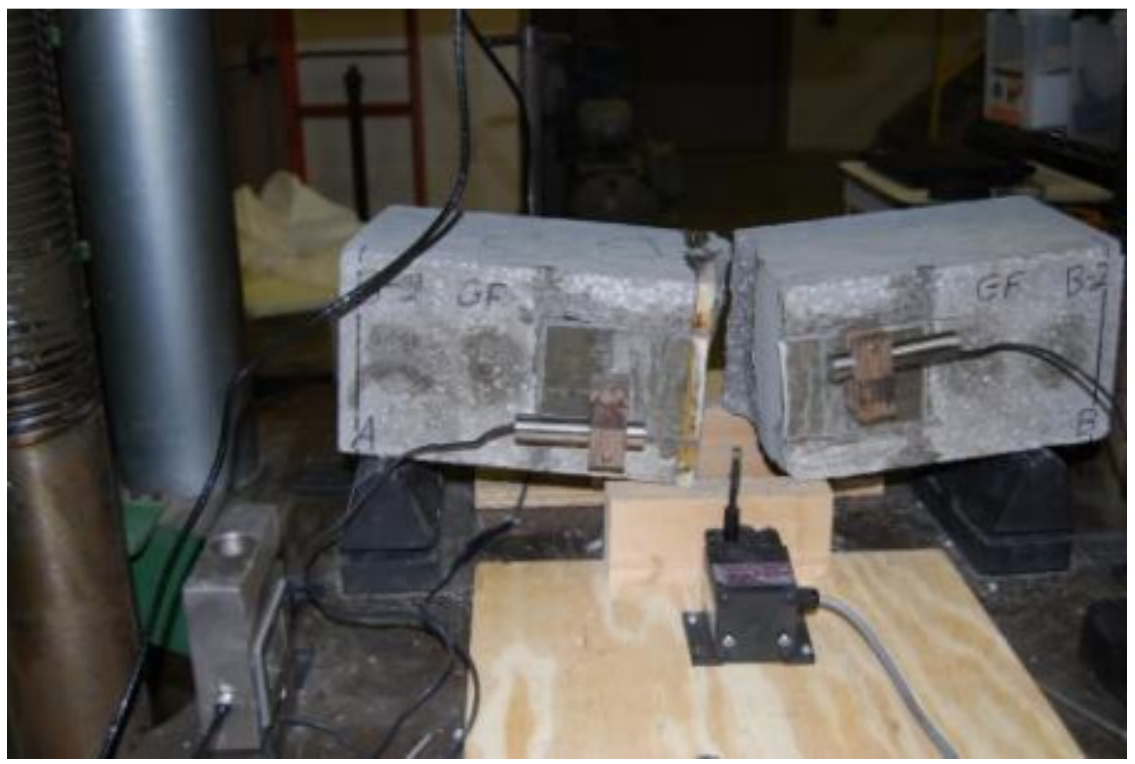

FIGURE 50. Typical Glass Fiber Rupture Failure 


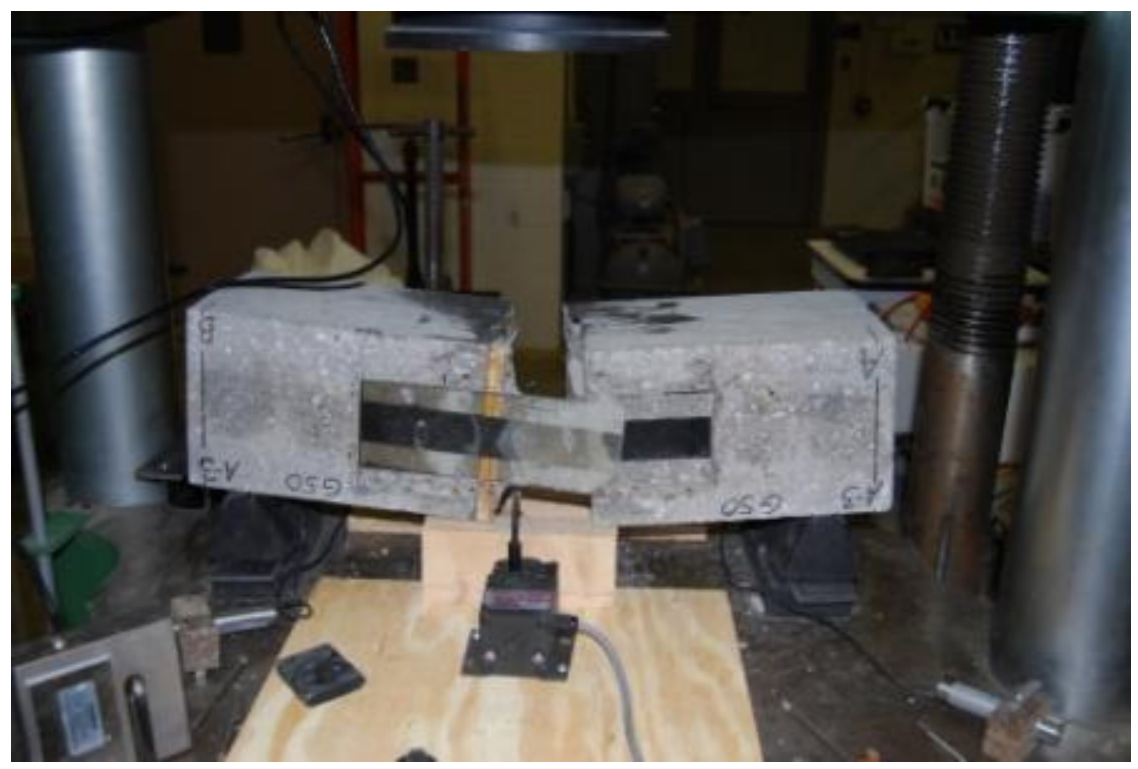

FIGURE 51. Typical Glass Interfacial Shear Debond Failure

Companion concrete cylinders were tested simultaneously with the destructive testing, in accordance with ASTM C39/C39M-05e2 Standard Test Method for Compressive Strength of Cylindrical Concrete Specimens, to establish an average concrete compression strength $\left(\mathrm{f}_{\mathrm{c}}{ }_{\mathrm{c}}\right)$. Concrete cylinder samples $\mathrm{A} 1$ and $\mathrm{A} 2$ were constructed from the same batch of concrete used to construct the A series test specimens. Samples B1, B2, C1 and C2 were constructed correspondingly to Series B and $\mathrm{C}$, respectively. The average diameter was calculated from three measurement locations on each test cylinder using the top, bottom and middle heights. The average area for each sample was then calculated from the average diameter. The compression strength, $\mathrm{f}_{c}$, was determined from maximum load and average area. The overall average of the concrete cylinder tests, $\mathrm{f}_{\mathrm{c}}{ }_{\mathrm{c}}$ was $5829 \mathrm{psi}$. Tabulated values for these tests are shown in Table VII. 
TABLE VII

COMPANION CONCRETE CYLINDER COMPRESSION TEST RESULTS

\begin{tabular}{lcccc}
\hline Sample & $\begin{array}{c}\text { Average } \\
\text { diameter } \\
\text { (in) }\end{array}$ & $\begin{array}{c}\text { Area } \\
\text { (based on average } \\
\text { diameter) } \\
\left(\mathrm{in}^{2}\right)\end{array}$ & $\begin{array}{c}\text { Maximum } \\
\text { Load } \\
(\mathrm{lbs})\end{array}$ & $\begin{array}{c}\text { Concrete } \\
\text { Compressive } \\
\text { Strength } \\
\text { (psi) }\end{array}$ \\
\hline A1 & 4.023 & 12.713 & 74000 & 5821 \\
B1 & 4.023 & 12.713 & 74300 & 5844 \\
B2 & 4.017 & 12.671 & 77100 & 6085 \\
C1 & 4.013 & 12.650 & 73500 & 5810 \\
C2 & 4.030 & 12.756 & 71500 & 5605 \\
& 4.013 & 12.650 & 73500 & 5810 \\
\hline
\end{tabular}




\title{
V. DISCUSSION
}

\author{
$\underline{\text { A. Introduction }}$
}

The goal of this investigation was to evaluate whether an NDT procedure could be used to predict the strength of the bond developed between the composite FRP and concrete systems. Specifically, the effectiveness of the AUP methodology as a means of evaluating the strength of the bond between CFRP or GFRP and concrete substrates was addressed. A discussion of the non-destructive AUP and signal energy methodologies are presented in the following sections.

\section{B. Received Signals}

Several differences in the received wave signals were observed during the testing. Surface roughness at the transducer contact had a large effect. When tests were performed on glass reinforced test specimens, the receiving transducer coupled very well to the smooth surface of GFRP in comparison to the rougher surface of the CFRP test specimens. Thus, for GFRP tests, more signal energy was transferred during both the shear and longitudinal transducer tests. Additionally, initial testing performed on the concrete test specimens placed the transmitting longitudinal transducer on un-ground rough concrete surface. This rough surface significantly reduced the amount of stress 
wave energy injected into the test specimens. By grinding the concrete test specimens smooth at the transducer application points, NDT variation was greatly reduced and signal energy transfer was maximized.

\section{Destructive Beam Tests}

The FRP reinforced beam test specimens did not behave as expected. They were designed so that an interfacial shear failure should have occurred during destructive testing; however, a moment type failure occurred in carbon reinforced test Specimens A1, B-1, and C-3 and fiber rupture failures occurred in all glass reinforced Specimens except A-3 and C-4. Clearly these results differed from what was expected in a number of cases.

Examination of the CFRP specimens suggests that the applied loads produced moments that exceeded the cracking moment capacity $\left(\mathrm{M}_{\mathrm{cr}}\right)$ of the concrete beam in the unreinforced sections of the specimens. To examine this more closely, $\mathbf{M}_{\mathrm{cr}}$ of the sixinch by six-inch concrete beam was calculated using the procedures described in ACI 318-08 (ACI, 2008), where the modulus of rupture $\left(f_{r}\right)$ of the concrete was calculated from the average measured concrete compressive strength, $f_{c}{ }_{c}$. This moment capacity of 20,628 lb-in, calculated as shown in Equations 22 and 23, can be compared to the applied moment at the end of the fiber reinforced region in each test beam at the failure load and these are summarized in Table VIII. The test specimens exhibiting moment type failures either had developed moments in excess or close to the $\mathrm{M}_{\mathrm{cr}}$ capacity. Note that 
"Moment" designates a cracking moment failure at the end of the FRP reinforced sections and "Fiber Shear" is a shear failure in the concrete or FRP at the interface.

$$
\begin{gathered}
f_{r}=7.5 \cdot \lambda \cdot \sqrt{f^{\prime}}=7.5 \cdot 1 \cdot \sqrt{5829 p s i}=573 p s i \\
M_{c r}=\frac{f_{r} I_{g}}{y}=\frac{573 p s i x \frac{6 \text { in } x(6 \mathrm{in})^{3}}{12}}{3 i n}=20,628 \mathrm{lb}-\mathrm{in} .
\end{gathered}
$$

As previously discussed in Chapter III, after the first three tests were performed, the test configuration was modified to increase the fiber force and maximize the moment in the reinforced section of the test specimen by changing the loading configuration from $1 / 3$ point loading to single point loading and increasing the simple support span from 18 inches to 19 inches. As can be seen in Table VIII, this reduced the moment produced at the fiber edge for equivalent applied loads.

It is also clear that the shear bond strength at the FRP/concrete interface was stronger than the anticipated 4,368 lbs shear capacity which was predicted in Chapter III for the 3-inch wide, zero-percent void configuration. This predicted capacity implies a bond strength of 1,456 lbs per inch width of FRP. This value can be compared to the average shear stress at the fiber from the applied loads at failure by assuming the tension in the fiber is equal to the shear at the interface. The total fiber tension force (T) was calculated based on the applied maximum moment $(\mathrm{M})$ using a transformed section analysis as previously discussed in Chapter III and assuming the fiber centroid was at the middle of the fiber overlay. Equations 24 and 25 show how the fiber force for Specimen A-1 was determined using the maximum single point load of 6,041 lbs and a simple 
support span of 19 inches. The Moment was calculated using principles of basic mechanics.

$$
\begin{gathered}
M=4.75 \cdot P_{\text {Max }}=4.75 \cdot 6,041 \mathrm{lbs}=28,695 \mathrm{lb}-\mathrm{in} \\
T=\frac{M}{j d}=\frac{28,695 \mathrm{lb}-\mathrm{in}}{0.94 \cdot 6 \mathrm{in}}=5088 \mathrm{lbs}
\end{gathered}
$$

T was considered to be equivalent to the "Interfacial Shear Load" and values for each beam are shown in Table VIII. The "Interfacial Shear Force" was calculated by dividing the interfacial shear load by the fiber bond width. Table VIII clearly shows tested fiber interfacial shear forces were greatly in excess of the predicted capacity, 1,456 lbs per inch width. 


\section{TABLE VIII}

CFRP REINFORCED TEST SPECIMEN LOADING VALUES AND FAILURE TYPE

Moment

\begin{tabular}{|c|c|c|c|c|c|c|c|c|}
\hline Beam & $\begin{array}{c}\text { Percent } \\
\text { Void } \\
\text { Area }\end{array}$ & $\begin{array}{l}\text { Load } \\
\text { Type }\end{array}$ & $\begin{array}{c}\text { Span } \\
\text { (in) }\end{array}$ & Failure Type & $\begin{array}{l}\text { Max } \\
\text { Load } \\
\text { (lbs) }\end{array}$ & $\begin{array}{c}\text { Interfacial } \\
\text { Shear Load } \\
\text { (kips) }\end{array}$ & $\begin{array}{l}\text { Interfacial } \\
\text { Shear Force } \\
\text { (lb/in-width) }\end{array}$ & $\begin{array}{c}\text { @ end of } \\
\text { Fiber } \\
\text { (lb-in) }\end{array}$ \\
\hline A-1 & 0 & $\mathrm{pt}$ & 19.00 & Moment & 6041 & 5.09 & 1690 & 17400 \\
\hline A-5 & 25 & $\mathrm{pt}$ & 19.00 & Fiber Shear & 4688 & 3.95 & 1850 & 13500 \\
\hline A-6 & 50 & $\mathrm{pt}$ & 19.00 & Fiber Shear & 5168 & 4.35 & 3480 & 14900 \\
\hline B-1 & 0 & $\mathrm{pt}$ & 19.00 & Moment & 6151 & 5.18 & 1730 & 17700 \\
\hline B-3 & 25 & $\mathrm{pt}$ & 19.00 & Fiber Shear & 5904 & 4.97 & 2340 & 17000 \\
\hline B-5 & 50 & $\mathrm{pt}$ & 19.00 & Fiber Shear & 4405 & 3.71 & 2970 & 12700 \\
\hline C-1 & 0 & $\mathrm{pt}$ & 19.00 & Fiber Shear & 5995 & 5.05 & 1680 & 17200 \\
\hline C-3 & 25 & $1 / 3 \mathrm{pt}$ & 18.00 & Moment & 9912 & 5.27 & 2480 & 23500 \\
\hline C-5 & 50 & $1 / 3 \mathrm{pt}$ & 18.00 & Fiber Shear & 7276 & 3.87 & 3100 & 17300 \\
\hline
\end{tabular}

The shear strength of the bond between the FRP and the concrete was higher than expected. The bond appeared to be sufficiently high to force the failure into the concrete substrate. Examination of tests reported by Lorenzis et al. (2002) suggests that when higher strength concretes are used, and the failure is forced in to the concrete, then the interfacial shear strengths can approach 2,965 lbs per inch width.

Examination of the GFRP specimens suggests that the applied load produced tension forces in the fiber that exceeded the rupture strength of the glass fibers. The GFRP test specimens were designed using Sika Hex 100G, a unidirectional glass fiber; however, it was later determined that Sika Hex 106G, a bidirectional fiber with 
significantly lower strength values, was used to reinforce the glass test specimens.

Examining this more closely, the tensile capacity of the three layers bidirectional fiber used was calculated as shown to be $4,130 \mathrm{lbs}$, which is less than both the anticipated shear bond calculated in Chapter III of 5,366 lbs (Sika Hex 100G) and the measured fiber forces. The calculations assumed three layers of Sika Hex 106G, a $f_{f u}$ is 35,300 psi, and a cured laminate thickness of 0.013 inches per layer.

$$
T_{f}=35.3 \mathrm{ksi} \cdot 0.013 \mathrm{in} \cdot 3 \mathrm{in} \text { width } \cdot 3 \text { layers }=4,130 \mathrm{lbs}
$$

It is also clear that the shear bond strength at the FRP/concrete interface was not the as-designed 5,366 lb shear capacity predicted in Chapter III for the 3-inch wide layer of Sika Hex 100G, zero percent void configuration. This predicted capacity implies a bond strength of 1,788 lbs per inch width of FRP. As shown in the calculations above, when the properties of the three layers of Sika Hex 106G are used in the calculations, a predicted fiber shear capacity of 2,910 lbs with a bond shear strength of $970 \mathrm{lbs}$ per inch width of FRP result. These values can be compared to the average shear stress at the fiber produced by the applied loads at failure by assuming the tension in the fiber at the failure load is equal to the shear at the interface.

The measured fiber tension force $(\mathrm{T})$ was calculated using the procedures described for the CRFP specimens with the moment arm for the glass beam specimens being recalculated to account for the changes in the FRP properties. This calculation is shown. 


$$
\begin{aligned}
& n=\frac{2,350,000 p s i}{57,000 \cdot \sqrt{5829 p s i}}=0.54 \\
& A_{f}=0.54 \cdot 3 \mathrm{in} \cdot 0.013 \mathrm{in} \mathrm{thk} \cdot 3 \text { layers }=0.063 \mathrm{in}^{2} \\
& \rho=\frac{0.063 \mathrm{in}^{2}}{6 \mathrm{in} \cdot 6 \mathrm{in}}=0.00175 \\
& k=\sqrt{(0.00175 \cdot 0.54)^{2}+2 \cdot 0.00175 \cdot 0.54}-0.00175 \cdot 0.54=0.0425 \\
& j=1-\frac{0.0425}{3}=0.985
\end{aligned}
$$

Table IX summarizes the tension forces calculated for the glass reinforced test specimens. Note that in the table "Failure Type" is either denoted as "Glass Rupture," where the failure mechanism was rupture of the glass fibers, or "Fiber Shear" where the $\mathrm{FRP} /$ concrete interface failed in interfacial shear.

Examination of Table IX shows that seven of the nine GFRP test specimens failed by glass rupture rather than the designed concrete/FRP interfacial shearing. It is clear from the data, that the shear bond strength developed between the FRP and concrete is greater than expected, for the as-built GFRP configuration. Furthermore this strength was high enough to shift the mode of failure to fiber rupture even though the predicted fiber/concrete interface shear strength is smaller than the predicted fiber strength. It is conjectured that this may be occurring due to stress concentration effects in the fiber (as a result of the void configuration and the wood gap), and the much higher variation in shear bond/interface strengths relative to the variation in the fiber rupture strengths (Lorenzis et al. 2001). This supposition is further supported by the observation that the predicted fiber rupture strength (about 4 kips for a 3-inch wide strip) is much higher than any of the 
measured tensions at the maximum peak loads. This effect should be investigated further, possibly by changing the shape and distribution of the voids. The test methodology will need to be adjusted to preclude this premature failure mode.

Because a large number of the GFRP specimens failed by fiber rupture, an effort was made to salvage the data by deriving an "Estimated Interfacial Shear Load" using the following procedure. The tensile force generated during testing caused a partial interfacial shearing of the glass fibers. The percentage of interfacial shearing was measurable due to the fiber color contrast as discussed previously in Chapter IV. By estimating the amount of debonded glass fiber, linear interpolation could be used to estimate the actual force required to cause complete interfacial shearing of the glass fibers. This calculation was performed by dividing the interfacial shear load by the percentage of debonded area from the side of the test specimen which had a larger percentage of debond, assuming that this side would debond before the other side.

However, estimated interfacial shear loads above about 5.0 kips (the average tension force for the zero percent void area carbon specimens) were removed from the test data. This cap on shear strength was assumed to be appropriate because the GFRP/concrete interface shear strength should not exceed the CFRP/concrete interfacial shear strength since the same epoxy matrix was used for both types of specimens. 
TABLE IX

GFRP REINFORCED TEST SPECIMEN LOADING VALUES AND FAILURE TYPE

\begin{tabular}{|c|c|c|c|c|c|c|c|c|}
\hline \multirow[b]{2}{*}{ Beam } & \multirow[b]{2}{*}{$\begin{array}{c}\text { Percent } \\
\text { Void }\end{array}$} & \multirow[b]{2}{*}{$\begin{array}{c}\text { Load } \\
\text { type }\end{array}$} & \multirow[b]{2}{*}{$\begin{array}{c}\text { Span } \\
\text { (in) }\end{array}$} & \multirow[b]{2}{*}{ Failure Type } & \multicolumn{3}{|c|}{ Interfacial } & \multirow{2}{*}{$\begin{array}{c}\text { Estimated } \\
\text { Interfacial } \\
\text { Shear load } \\
\text { (kips) } \\
\end{array}$} \\
\hline & & & & & $\begin{array}{l}\text { Max } \\
\text { Load } \\
(\mathrm{lbs}) \\
\end{array}$ & $\begin{array}{l}\text { Shear } \\
\text { Load } \\
\text { (kips) } \\
\end{array}$ & $\begin{array}{c}\text { Interfacial } \\
\text { Shear Force } \\
\text { (lb/in-width) }\end{array}$ & \\
\hline A-2 & 0 & $\mathrm{pt}$ & 19.00 & Glass Rupture & 3604 & 2.90 & 1000 & 4.27 \\
\hline A-3 & 50 & $\mathrm{pt}$ & 19.00 & Fiber Shear & 3331 & 2.68 & 1790 & 2.68 \\
\hline A-4 & 25 & $\mathrm{pt}$ & 19.00 & Glass Rupture & 3331 & 2.68 & 1260 & 7.10 \\
\hline B-2 & 0 & $\mathrm{pt}$ & 19.00 & Glass Rupture & 3897 & 3.13 & 1090 & 4.07 \\
\hline B-4 & 25 & $\mathrm{pt}$ & 19.00 & Glass Rupture & 3432 & 2.76 & 1300 & 6.01 \\
\hline B-6 & 50 & $\mathrm{pt}$ & 19.00 & Glass Rupture & 2896 & 2.33 & 1690 & 3.60 \\
\hline $\mathrm{C}-2$ & 0 & $\mathrm{pt}$ & 19.00 & Glass Rupture & 3851 & 3.10 & 1080 & 4.40 \\
\hline C-4 & 25 & $\mathrm{pt}$ & 19.00 & Fiber Shear & 3811 & 3.06 & 1440 & 3.08 \\
\hline C-6 & 50 & $1 / 3 \mathrm{pt}$ & 18.00 & Glass Rupture & 4799 & 2.44 & 1950 & 5.65 \\
\hline
\end{tabular}

\section{AUP vs. CFRP Test Specimen Shear Bond Capacity}

\section{Longitudinal Receiving Transducer}

Figure 52 shows the correlation between the interfacial shear loads and the AUP test results using a longitudinal receiving transducer in the near to near transducer configuration. This figure includes test specimens which exhibited moment failures prior to FRP interfacial shearing. Thus, the data does not solely represent the FRP interfacial shear capacity for these test specimens. The plotted shear value was the calculated 
tension in the fiber at the time of moment failure. Also, the reported interfacial shear failure load could only be determined for the side of the test specimen which reached failure; therefore, the AUP value for that specimen side was used for comparisons. Normalization of the AUP value was derived by dividing the average of the five AUP test results by the maximum AUP value for all reinforced specimens tested under the same transducer configuration.

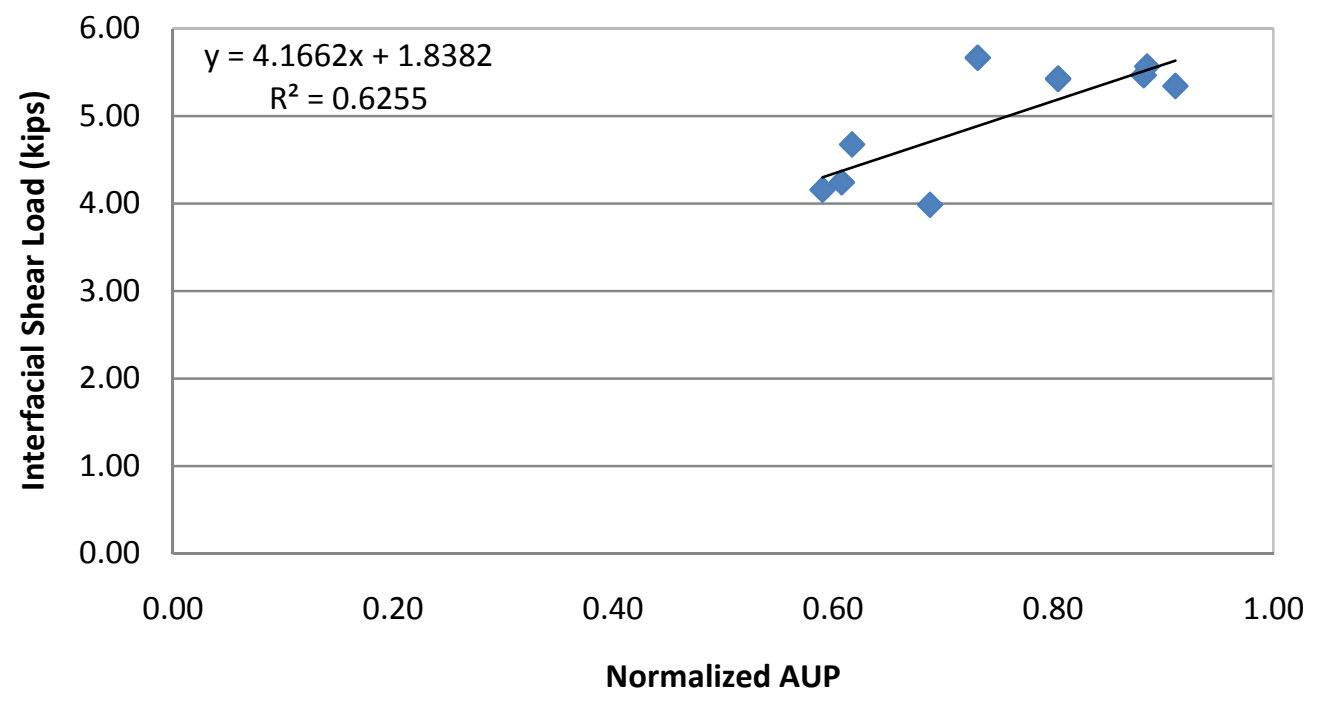

FIGURE 52 - Interfacial Shear Load of Carbon Reinforced Test Specimen (Including Moment Failures) vs. Near to Near Longitudinal Normalized AUP Evaluations

Figure 53 shows the correlation between the interfacial shear load and the AUP test results using a longitudinal receiving transducer in the near to near transducer configuration without the data from specimens which exhibited moment failure prior to concrete/FRP interfacial shearing. Removal of the test data affected by moment failures increased the correlation coefficient $\left(\mathrm{R}^{2}\right)$ by about 5 percent. 


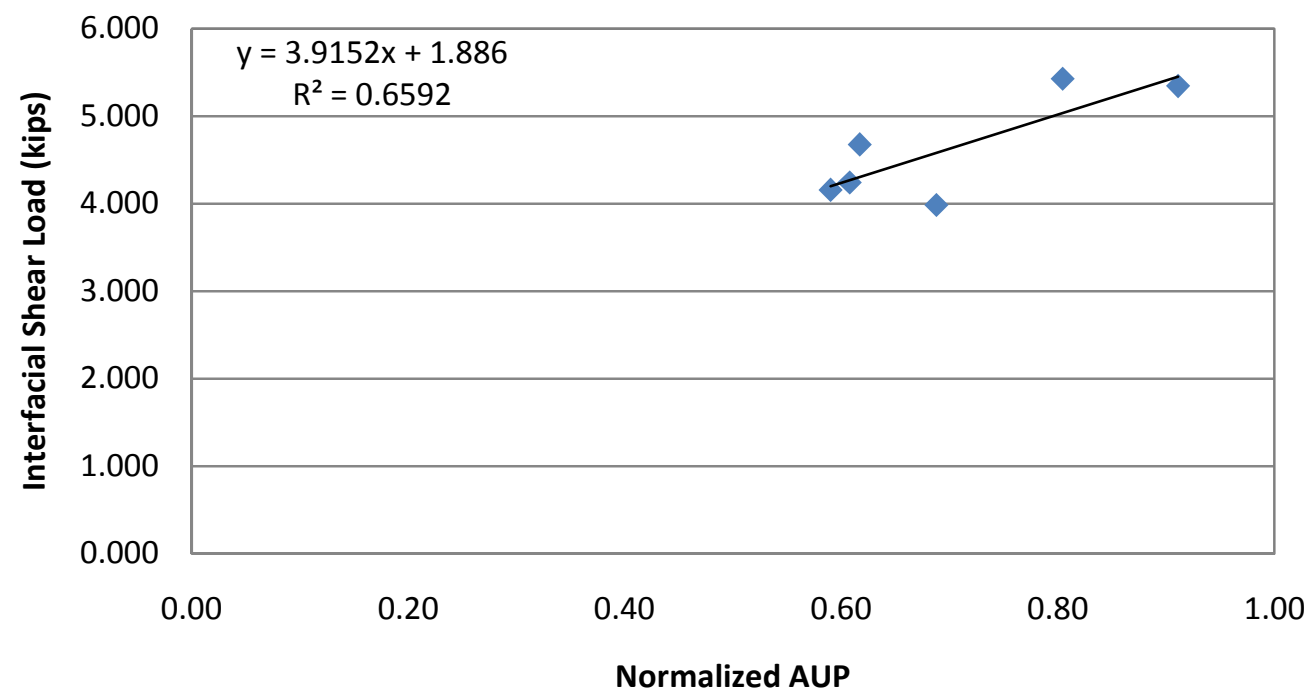

FIGURE 53 - Interfacial Shear Load of Carbon Reinforced Test Specimen (Excluding Moment Failures) vs. Near to Near Longitudinal Normalized AUP Evaluations

Figure 54 shows the correlation between the interfacial shear loads and the AUP test results using a longitudinal receiving transducer in the far to near transducer configuration. As with Figure 53, this figure does not include test specimens which exhibited a moment failure prior to concrete/FRP interfacial shearing. Removal of the moment failure data increased the correlation coefficient by about 19 percent, although the correlation of the shear strength and AUP for this transducer configuration appears to be weaker than the near to near configuration.

As was stated in Chapter IV, there was a very weak signal for the near to far transducer configuration and the correlation between shear strength and AUP was very low; thus, these plots were not shown. 


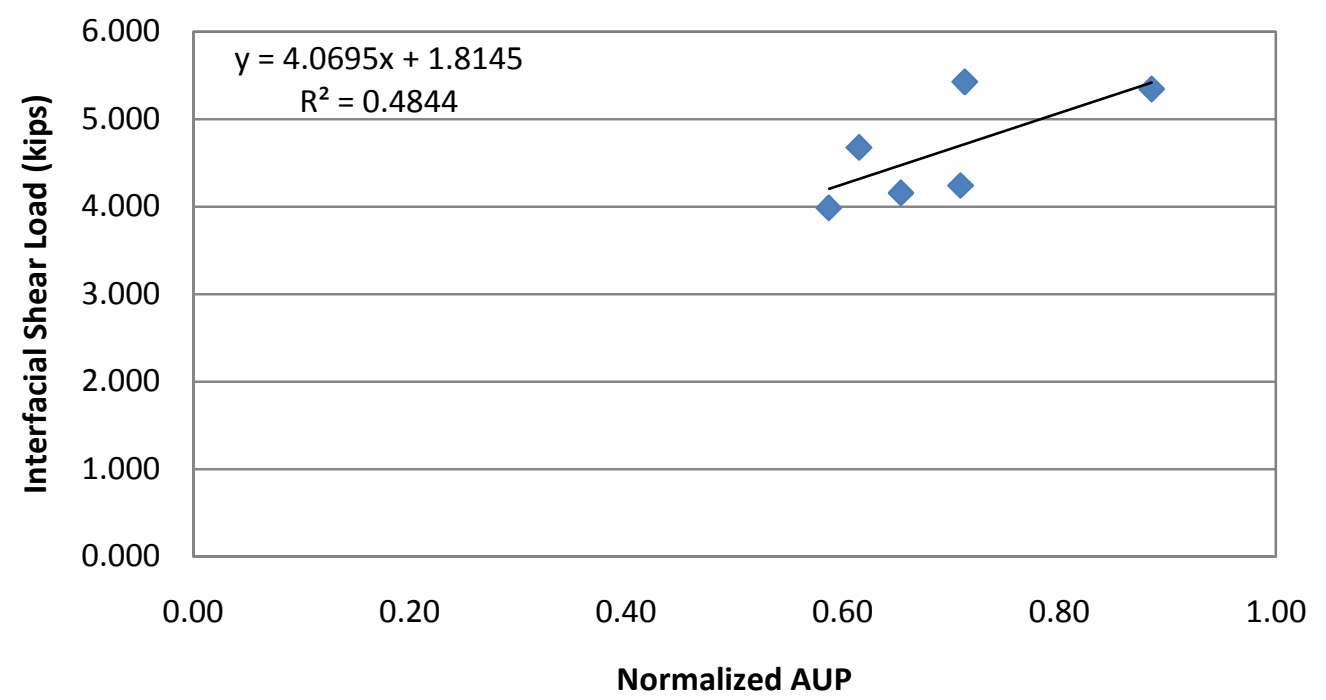

FIGURE 54 - Interfacial Shear Load of Carbon Reinforced Test Specimen (Excluding Moment Failures) vs. Far to Near Longitudinal Normalized AUP Evaluations

\section{Shear Receiving Transducers}

Figure 55 shows the relationship between the carbon interfacial shear loads and the AUP test results using a shear receiving transducer in the near to near transducer configuration. This figure includes the data from test specimens which exhibited moment failures prior to concrete/FRP interfacial shearing. 


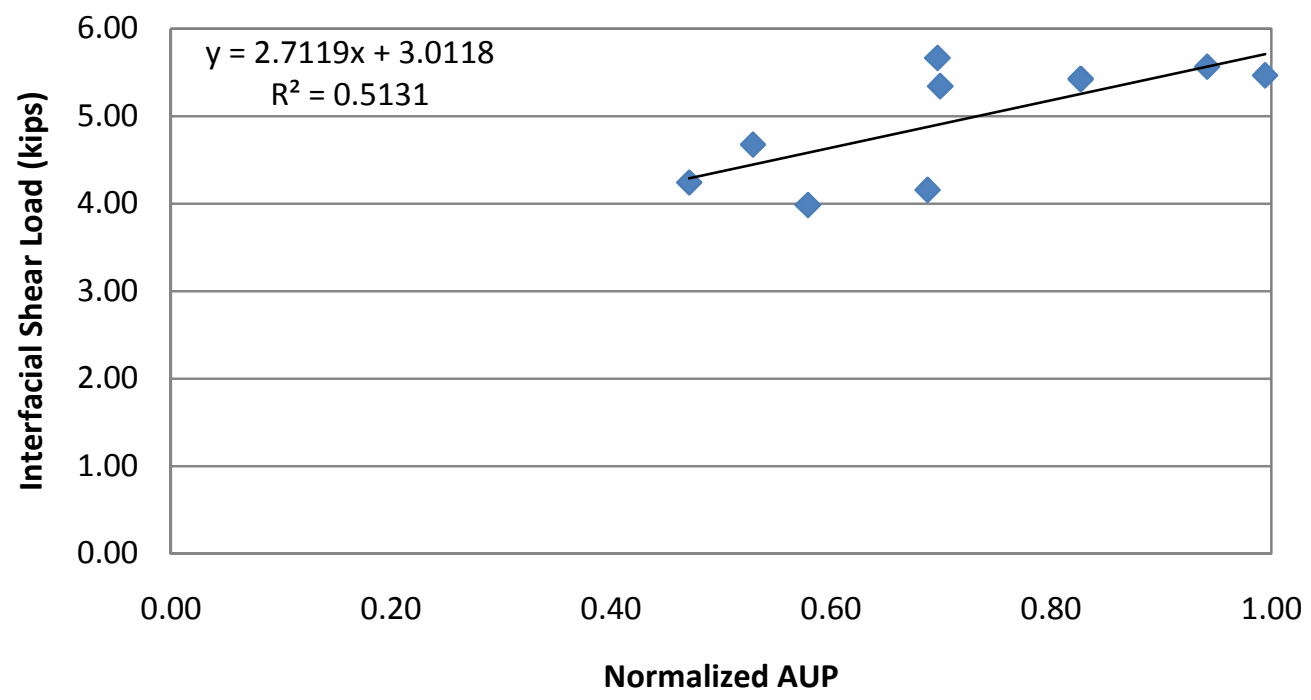

FIGURE 55 - Interfacial Shear Load of Carbon Reinforced Test Specimen (Including Moment Failures) vs. Near to Near Shear Normalized AUP Evaluations

Figure 56 shows the correlation between the interfacial shear loads and the AUP test results using a shear receiving transducer in the near to near transducer configuration with test specimens which exhibited moment failures prior to concrete/FRP interfacial shearing excluded. Removal of the test data affected by moment failures actually decreases the correlation a little. 


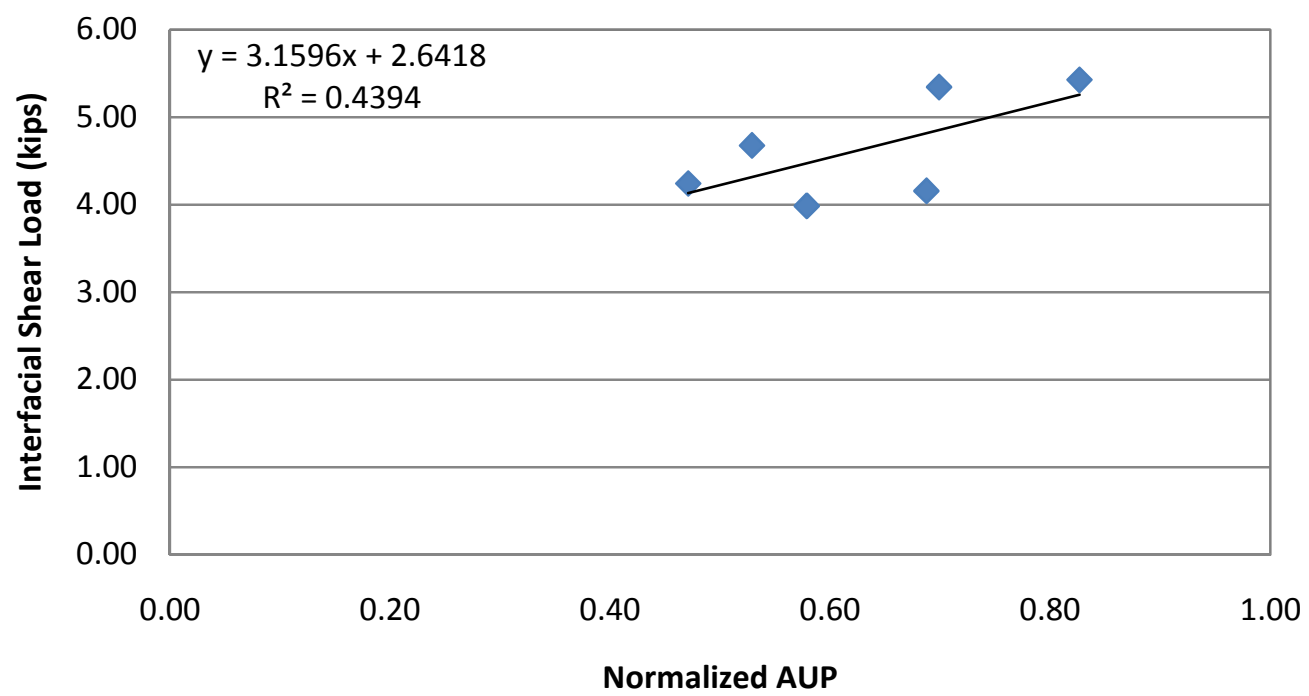

FIGURE 56 - Interfacial Shear Load of Carbon Reinforced Test Specimen (Excluding Moment Failures) vs. Near to Near Shear Normalized AUP Evaluations

Low correlation factors were found for the far to near transducer configuration when using a shear receiving transducer and the near to far transducer configurations. Thus, these figures are not shown.

When using a longitudinal receiving transducer and AUP analysis procedures, NDT results appear to show reasonable correlations with the specimen interfacial shear bond strengths. The correlation is a little larger when the stress waves travel shorter distances (approximately 3.5 inches) as with the near to near transducer configuration; however, reasonable correlation is still observed at distances up to 6.25 inches, the far to near transducer configuration.

When using a shear receiving transducer and AUP analysis procedures, NDT results also appear to correlate to specimen interfacial shear bond strengths when transducer separation distances are small. For small distances, the shear stress wave 
correlation is not as strong with the longitudinal stress wave correlations. Shear wave evaluations performed when the transducers were located in the far to near positions showed low correlation. It appears that the distance travelled by the propagating stress waves affects shear waves more than longitudinal waves.

Rao and Daniels (1999) presented correlation factors of 0.80 and above when comparing AUP test results to interfacial shear strengths for their investigation of composite patches bonded to aluminum plates. A correlation of 0.88 was found by Tanary et al. (1992) when they compared AUP test results to interfacial shear strengths of two bonded graphite/epoxy test specimens. These correlation factors are higher than those calculated from the current investigation. It is believed that the higher correlations can be attributed to the material differences. Aluminum and epoxy are relatively homogeneous materials in comparison to concrete. Therefore, we expected more variability in the concrete and FRP test data; thus, lower $\mathrm{R}^{2}$ values.

Using a longitudinal receiving transducer to collect propagating stress waves and analyzing the data with the AUP procedure appears to provide fairly good correlation to specimen interfacial shear strengths; however, additional testing should be performed to fine tune and improve the procedures.

\section{E. Energy vs. CFRP Test Specimen Shear Bond Capacity}

\section{Longitudinal Receiving Transducer}

Figure 57 shows the correlation between the interfacial shear load and total energy test results using a shear receiving transducer in the near to near transducer 
configuration. This figure includes test specimens which exhibited moment failures prior to concrete/FRP interfacial shearing.

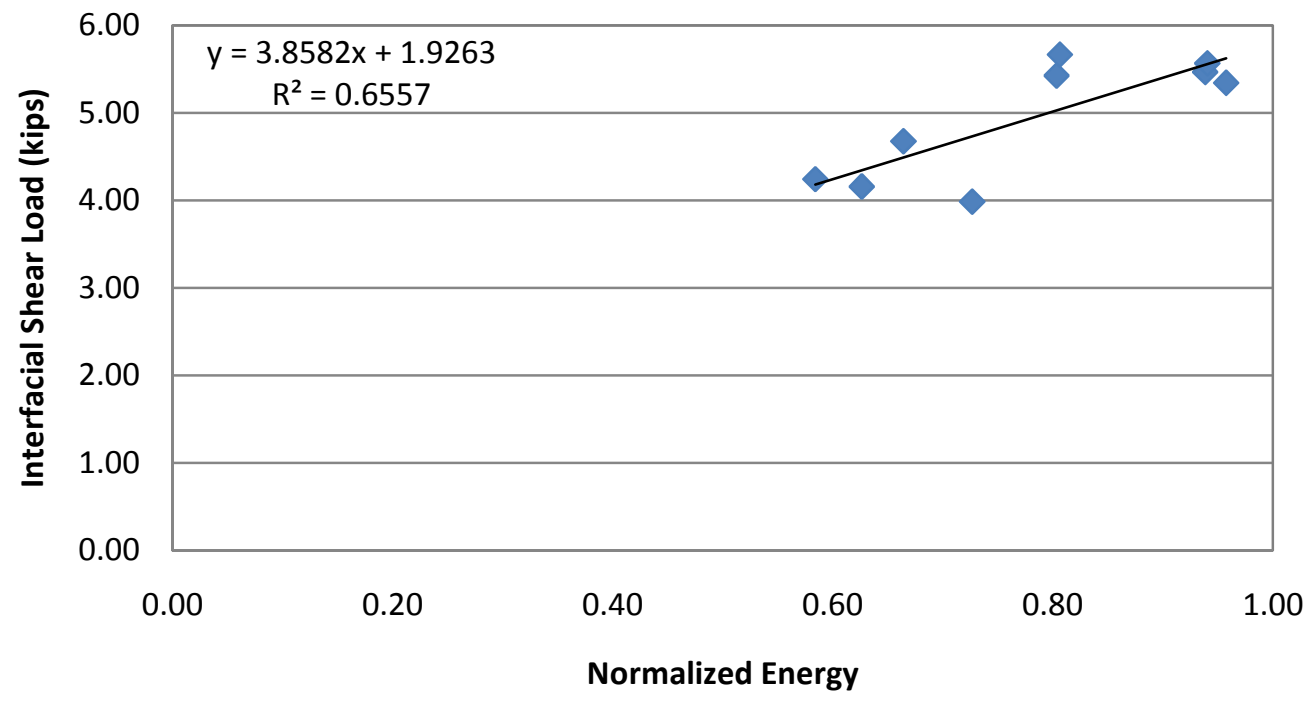

FIGURE 57 - Interfacial Shear Load of Carbon Reinforced Test Specimen (Including Moment Failures) vs. Near to Near Longitudinal Normalized Energy Evaluations

Figure 58 shows the correlation between the interfacial shear load and total energy test results using a longitudinal receiving transducer in the near to near transducer configuration. This figure does not include test specimens which exhibited moment failures prior to concrete/FRP interfacial shearing. Removal of the data from tests with moment failures decreased the correlation coefficient by about 10 percent. 


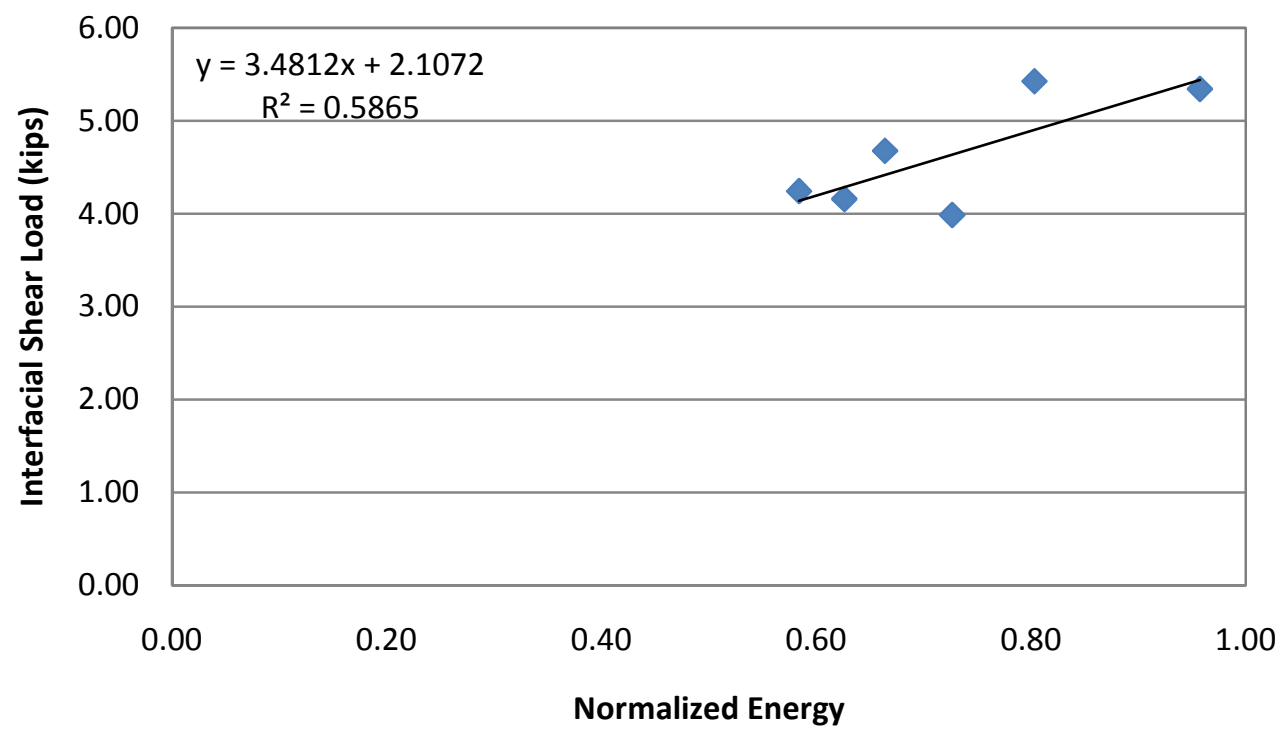

FIGURE 58 - Interfacial Shear Load of Carbon Reinforced Test Specimen (Excluding Moment Failures) vs. Near to Near Longitudinal Normalized Energy Evaluations

Figure 59 shows the correlation between the interfacial shear loads and the total energy test results using a longitudinal receiving transducer in the far to near transducer configuration without the data from test specimens which exhibited moment failures prior to concrete/FRP interfacial shearing. There is a very poor correlation between shear strength and AUP values for this configuration. 


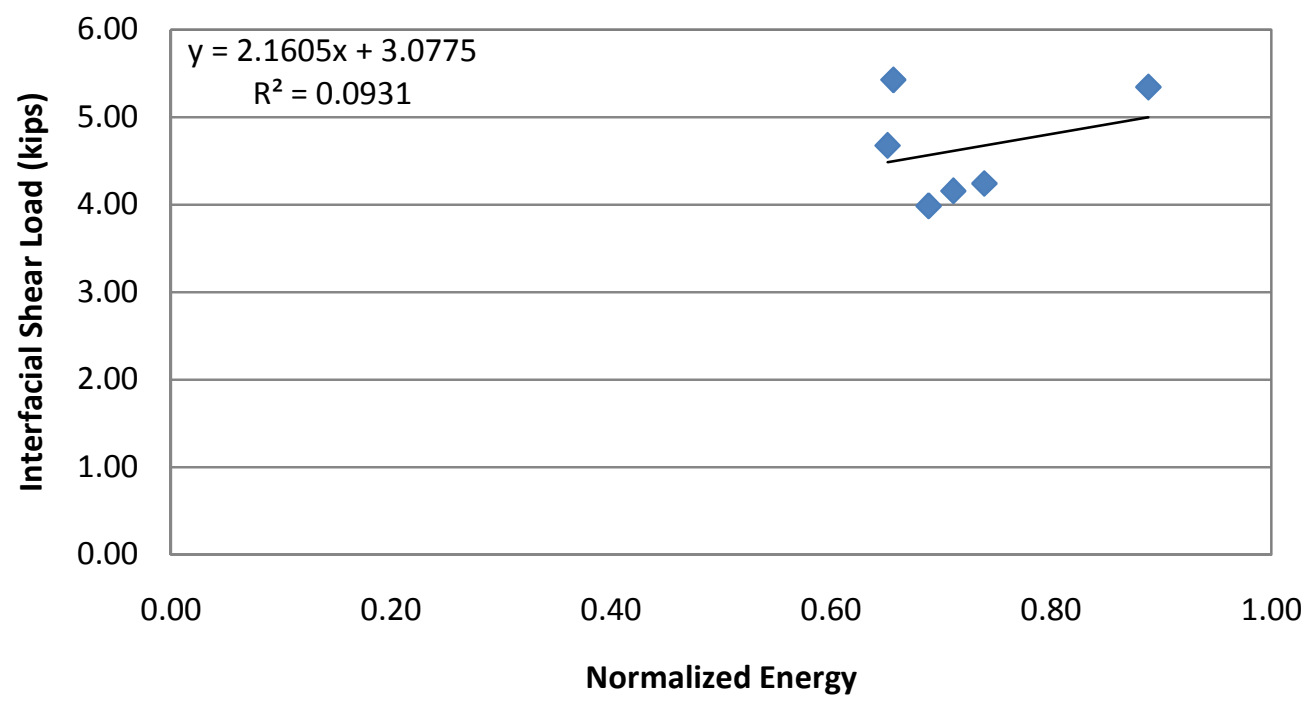

FIGURE 59 - Interfacial Shear Load of Carbon Reinforced Test Specimen (Excluding Moment Failures) vs. Far to Near Longitudinal Normalized Energy Evaluations

\section{Shear Receiving Transducer}

Figure 60 shows the correlation between the interfacial shear load and total energy test results using a shear receiving transducer in the near to near transducer configuration. This figure includes test specimens with moment failures. 


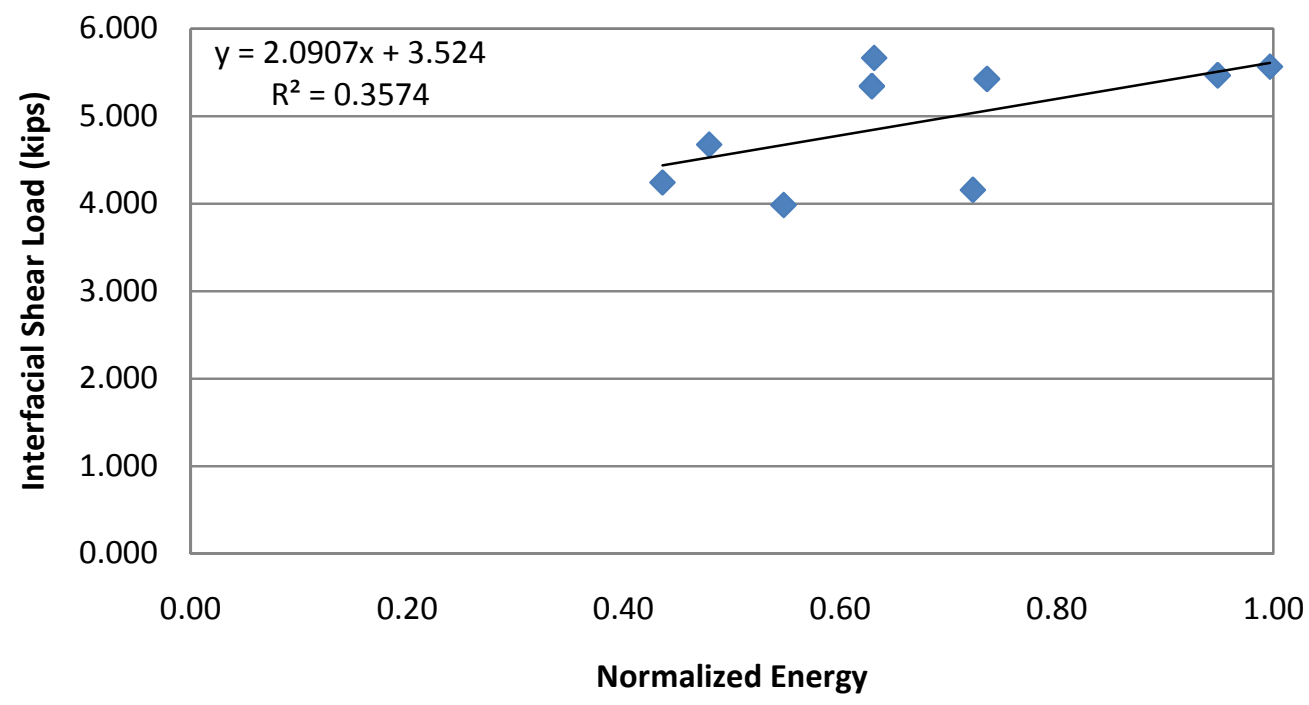

FIGURE 60 - Interfacial Shear Load of Carbon Reinforced Test Specimen (Including Moment Failures) vs. Near to Near Shear Normalized Energy Evaluations

A similar comparison of the interfacial shear load and total energy test results using a shear receiving transducer in the near to near transducer configuration without moment failures and far to near transducer configurations also show poor correlation. These correlation coefficients ranged from 0.001 to 0.176 for far to near and near to near, respectively.

When using a longitudinal receiving transducer and the total energy analysis procedure, NDT results appear to correlate reasonably well to the specimen interfacial shear bond strengths, but not as well as the AUP analyses. However, reasonable correlations were only established for the near to near transducer configurations, indicating that this method may only work for transducer separation distances up to about 3.25 inches. 
Significant correlation between the total signal energy and the interfacial shear bond strength was not observed for the shear transducer configuration.

Using a longitudinal receiving transducer to collect propagating stress waves and analyzing the data with the total energy methodology appears to provide fairly good correlation to specimen interfacial shear strengths, provided the transducer separation distance is small. However, additional testing should be performed to fine tune the procedure.

\section{F. AUP vs. GFRP Test Specimen Bond Capacity}

\section{Longitudinal Receiving Transducer}

Figure 61 shows the correlation between the GFRP interfacial shear load and the AUP test results using a longitudinal receiving transducer in the near to near transducer configuration. This figure includes all specimen data. The estimated interfacial shear strength was determined for the weaker side of the test specimen and coupled with the AUP value for that side. The estimated shear strength and AUP values do not correlate well. 


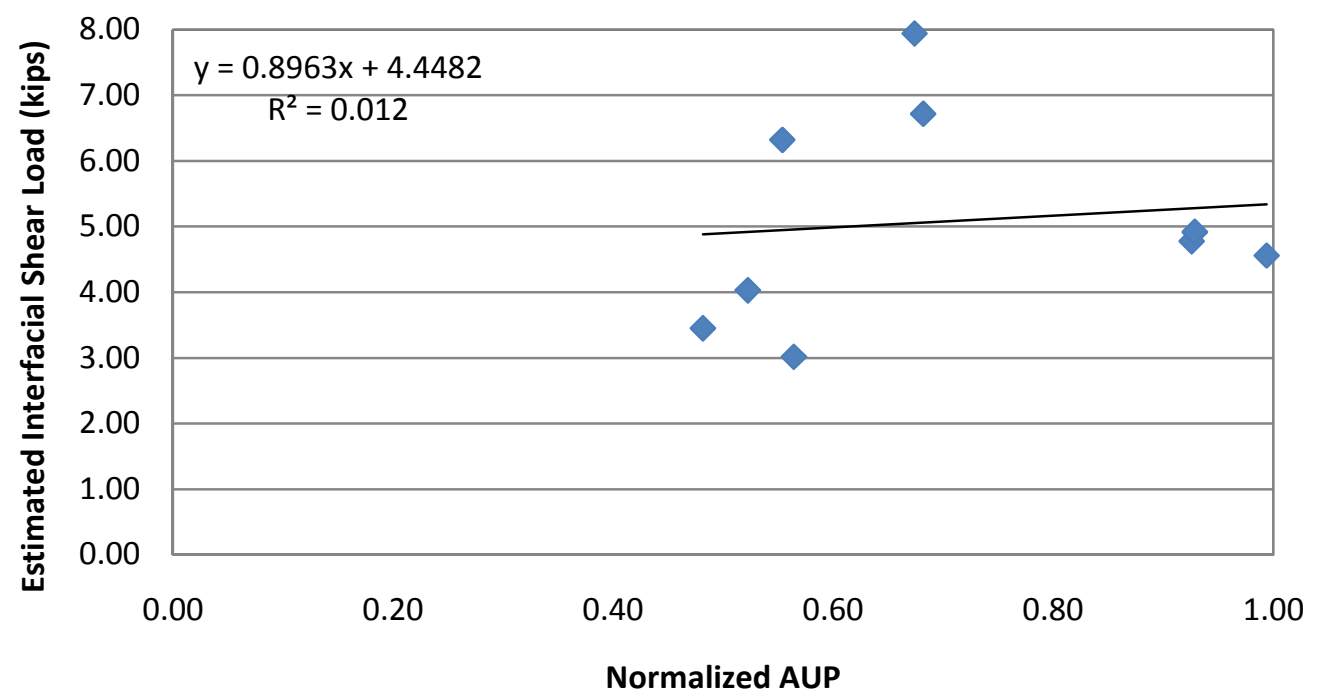

FIGURE 61 - Interfacial Shear Load of Glass Reinforced Test Specimen (All Data) vs. Near to Near Longitudinal Normalized AUP Evaluations

Figure 62 shows the correlation between the GFRP interfacial shear load and the AUP test results using a longitudinal receiving transducer in the near to near transducer configuration, but excluding tests with an estimated interfacial shear force larger than 5.0 kips. By removing this data, the correlation factor between interfacial shear force and AUP increased to 0.724 . 


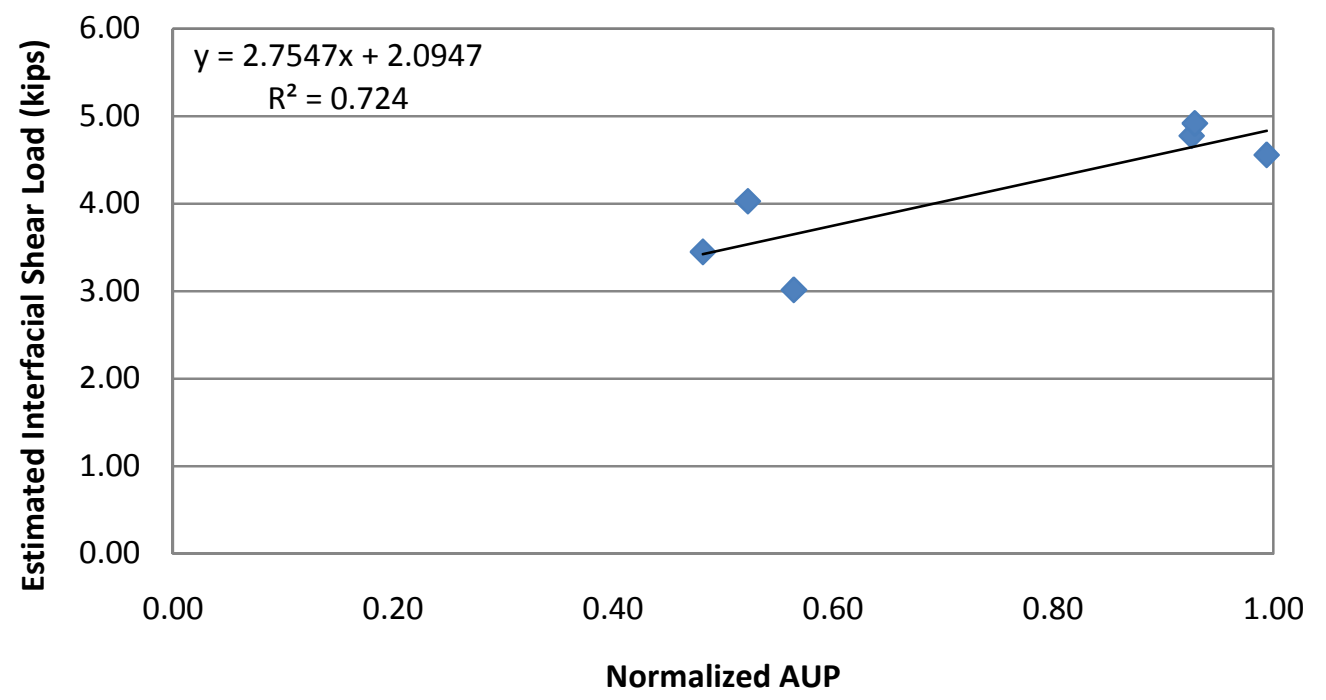

FIGURE 62 - Interfacial Shear Load of Glass Reinforced Test Specimen (Excluding Interfacial Shear Loads Above 5.0 kips) vs. Near to Near Longitudinal Normalized AUP Evaluations

Figure 63 shows the correlation between the GFRP interfacial shear load and the AUP analysis results using a longitudinal receiving transducer in the far to near transducer configuration excluding data with estimated shear capacities larger than 5.0 kips. 


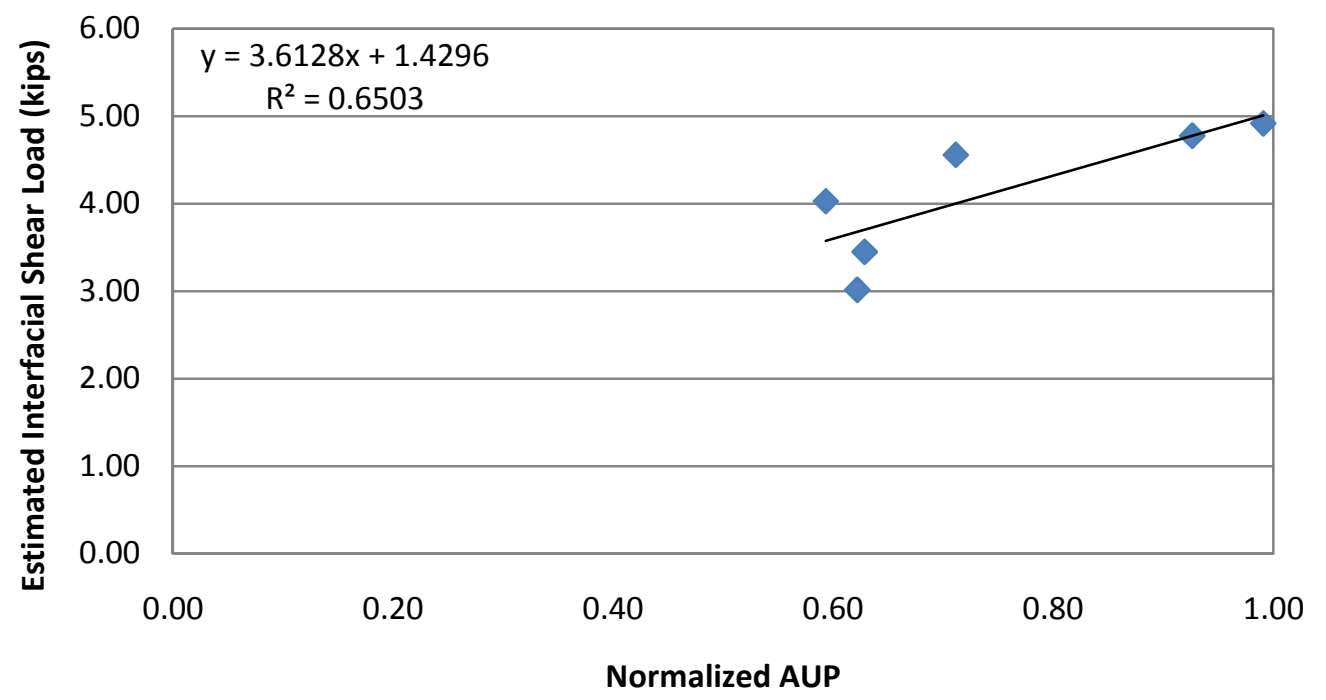

FIGURE 63 - Interfacial Shear Load of Glass Reinforced Test Specimen (Excluding Interfacial Shear Loads Above 5.0 kips) vs. Far to Near Longitudinal Normalized AUP Evaluations

When using a longitudinal receiving transducer and the AUP analysis procedures, the NDT methodology appears to correlate fairly well to the interfacial shear bond strength if the estimates of the shear capacity are correct. This correlation is a little larger when performed on GFRP specimens as opposed to CFRP, and may be due to the surface of the glass being smoother than the carbon, allowing more energy transfer through the couplant and into the receiving transducer. Similar to the CFRP specimens, correlations were a little lower when the far to near transducer configuration was used.

Unlike the CFRP specimens, when GFRP specimens were evaluated using a shear receiving transducer and the AUP analysis procedures, NDT results did not provide a significant correlation to specimen interfacial shear strengths.

Using a longitudinal receiving transducer to collect propagating stress waves and analyzing the data with the AUP analysis procedure appears to, again, provide fairly good 
to specimen interfacial shear strengths. However, additional testing should be performed to fine tune the procedure and confirm the results since the correlation is based on estimated shear strengths.

\section{G. Energy vs. GFRP Test Specimen Bond Capacity}

\section{$\underline{1 .}$ Longitudinal Receiving Transducer}

Figure 64 shows the correlation between the GFRP interfacial shear load and the signal energy using a longitudinal receiving transducer in the near to near transducer configuration, excluding specimens with estimated interfacial shear forces larger than 5.0 kips. As shown previously, the removal of this data resulted in a significant correlation between interfacial shear force and normalized energy.

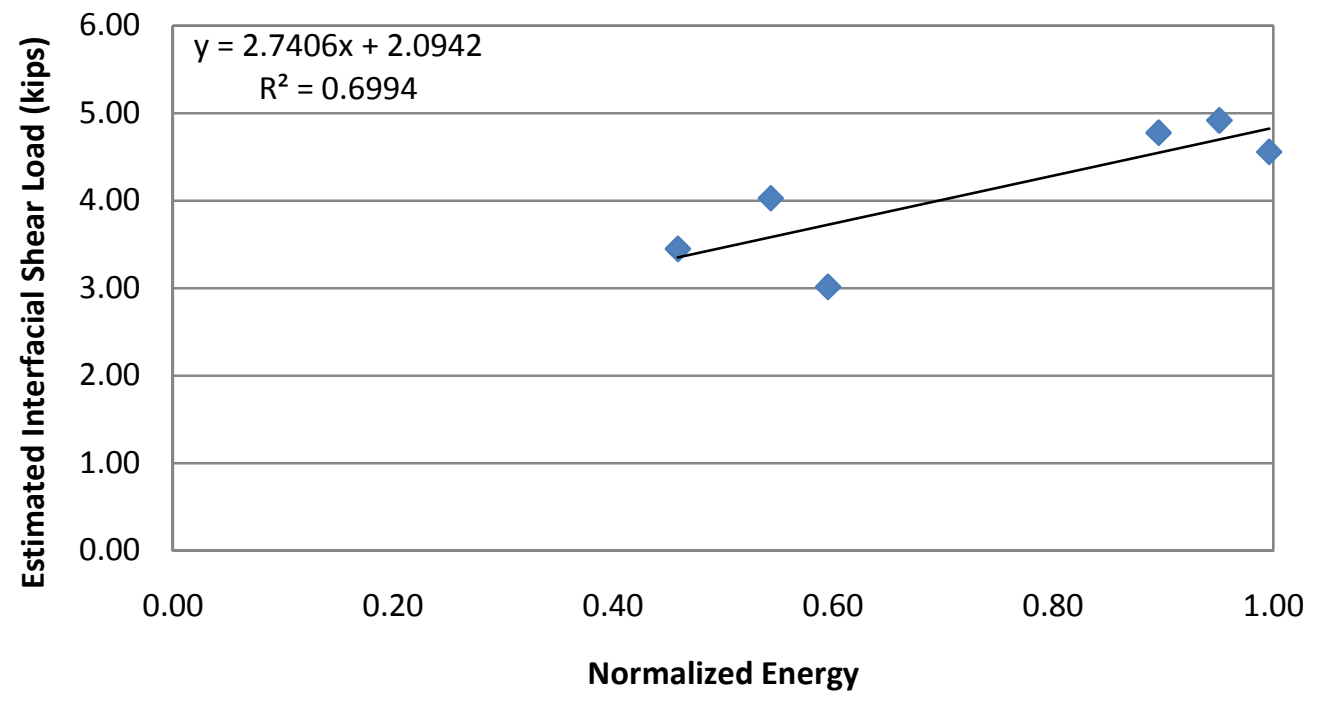

FIGURE 64 - Interfacial Shear Load of Glass Reinforced Test Specimen (Excluding Shear Loads Above 5.0kips) vs. Near to Near Longitudinal Normalized Energy Evaluations 
Figure 65 shows the correlation between the GFRP interfacial shear loads and the signal energy using a longitudinal receiving transducer in the far to near transducer configuration, excluding data from test specimens with estimated interfacial shear forces larger than 5.0 kips.

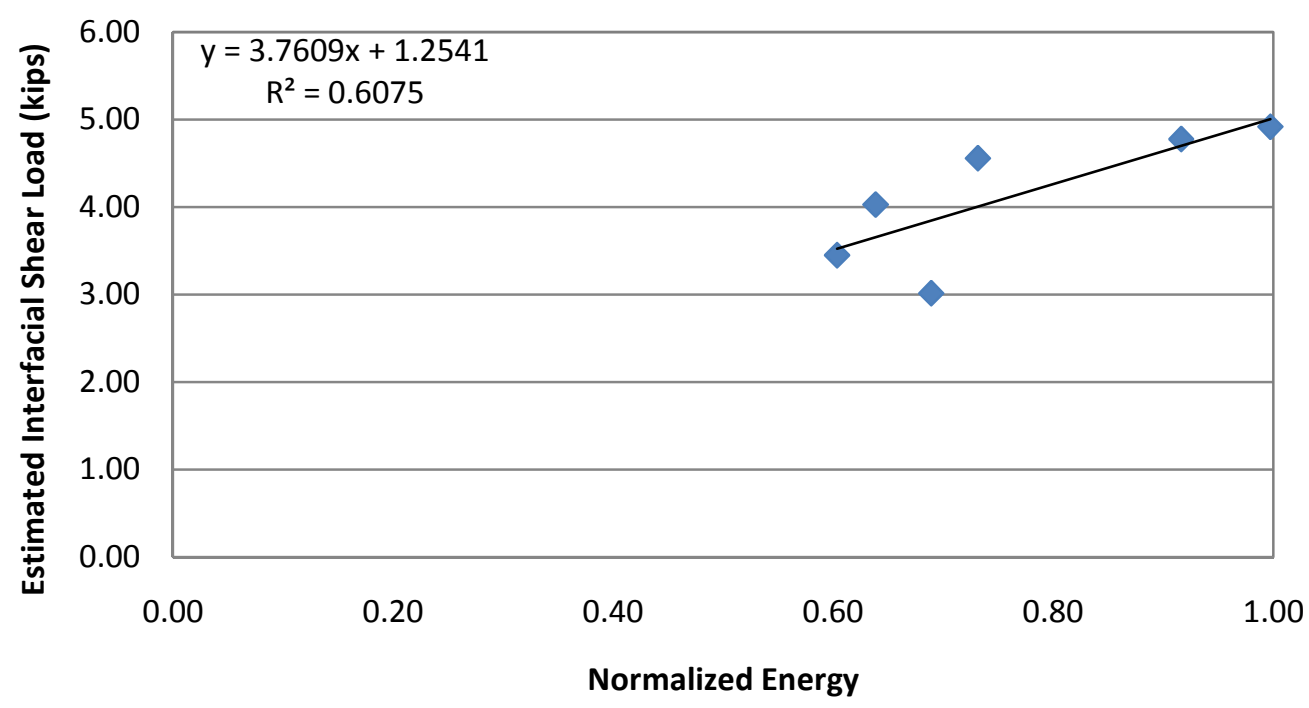

FIGURE 65 - Interfacial Shear Load of Glass Reinforced Test Specimen (Excluding Shear Loads Above 5.0 kips) vs. Far to Near Longitudinal Normalized Energy Evaluations

\section{Shear Receiving Transducer}

No significant correlations between interfacial shear load and total energy calculations could be established for the GFRP test specimens with any of the shear receiving transducer testing configurations.

When using a longitudinal receiving transducer and the total energy analysis procedures, NDT results appear to correlate fairly well to specimen interfacial shear bond strengths for the GFRP specimens. The correlation factors are slightly higher for the GFRP specimens, but definitive conclusions as to why they are slightly higher are not 
possible due to the approximate nature of this comparison. The method does appear to show a reasonable correlation for specific transducer configurations using the AUP NDT procedure.

Use of the shear receiving transducer and using total energy analysis procedures, do not correlate to specimen interfacial shear strengths.

\section{$\underline{\text { H. AUP and Energy Transducer Distance Correlations }}$}

Previous analysis on the CFRP specimens indicated that there was little difference between near to near and far to near AUP test results when a longitudinal receiving transducer is used. Figure 66 shows the correlation obtained by averaging the near to near and far to near transducer configuration AUP analysis results and the carbon specimen interfacial shear strengths. This figure contains test data with moment failures. 


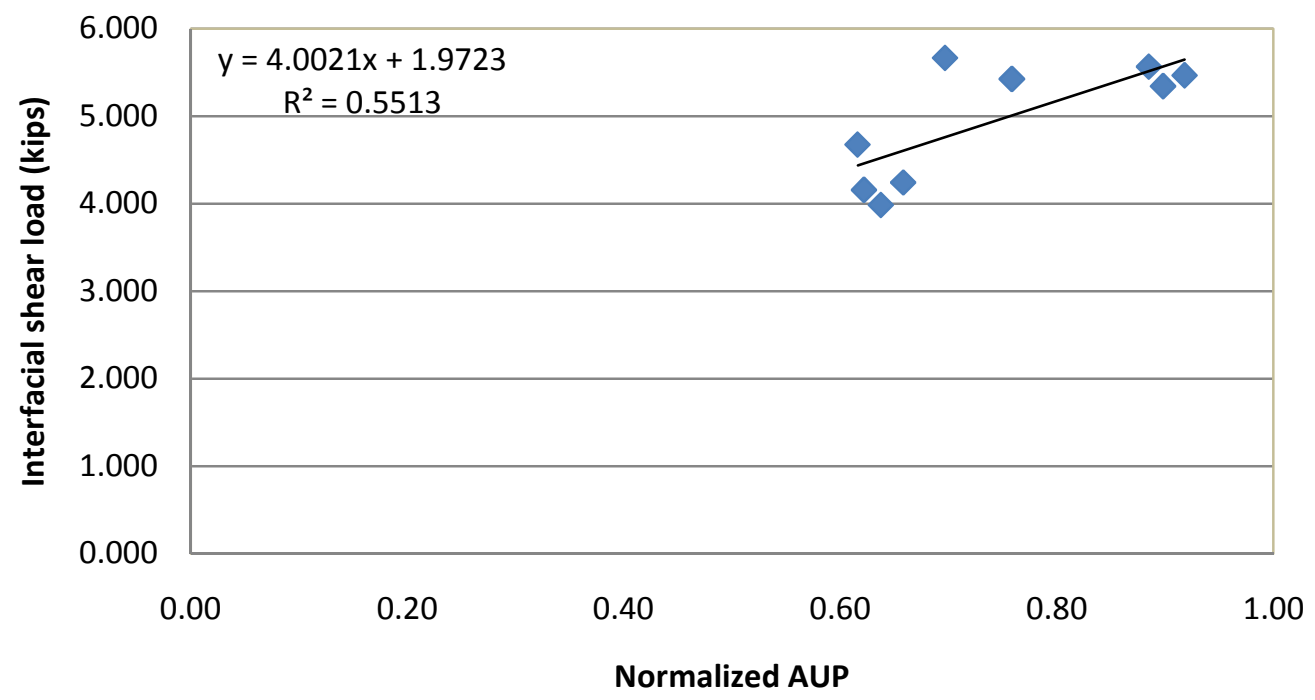

FIGURE 66 - Interfacial Shear Load of Carbon Reinforced Test Specimen (Including Moment Failures) vs. Averaged Near to Near and Far to Near Longitudinal Normalized AUP Evaluations

Figure 67 contains the same information as Figure 66, except it excludes data with moment failures. Comparison of these results with the previous analysis suggests that transducer separation distances do not significantly affect the correlation between AUP and interfacial shear strength. However, it was shown earlier that total energy correlations were significantly affected by transducer separation distances. 


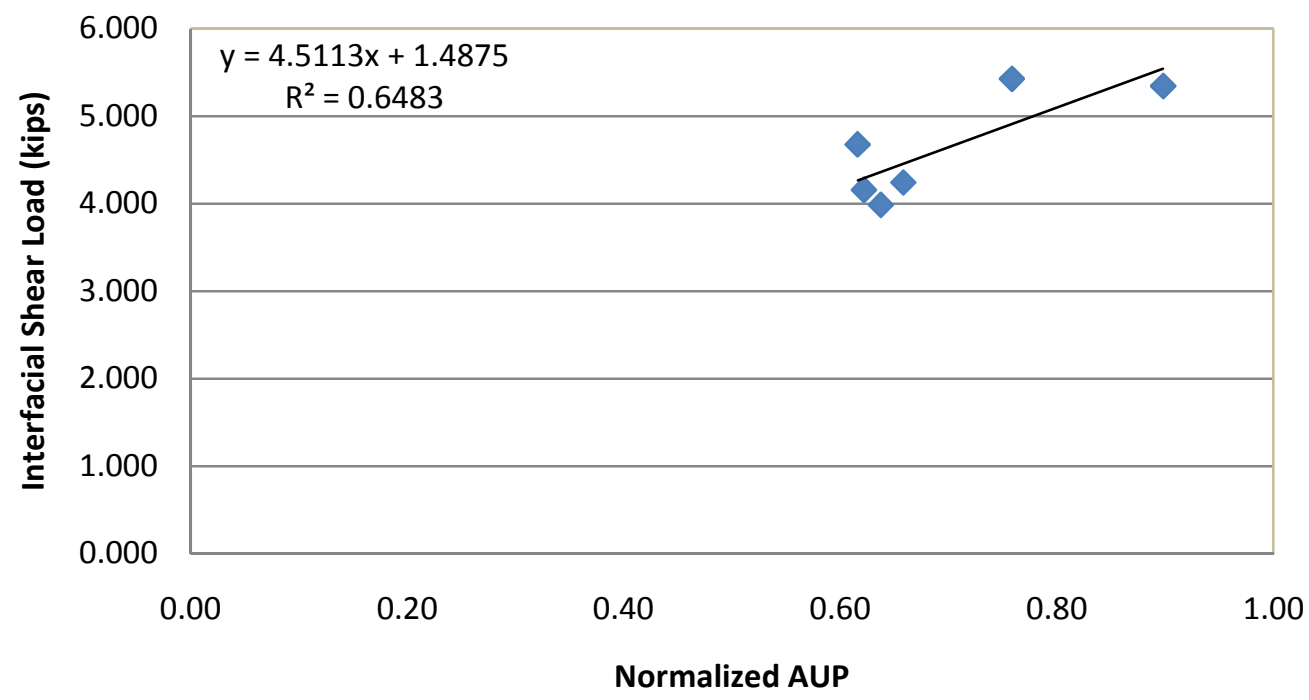

FIGURE 67 - Interfacial Shear Load of Carbon Reinforced Test Specimen (Excluding Moment Failures) vs. Averaged Near to Near and Far to Near Longitudinal Normalized AUP Evaluations

\section{Summary of the Effectiveness of NDT Procedures}

Table X lists all correlations determined between the NDE signal characteristics and measured interfacial FRP shear strengths. In the table, "Fiber Type" denotes "Carbon" for the CFRP overlay test specimens or "Glass" for GFRP overlay test specimens. The "Receiving Transducer Type" distinguishes between either a "Longitudinal" or "Shear" wave receiving transducer. "AUP" or "Energy" defines whether the AUP or total energy analysis procedures were used to evaluate the received waves. Transducer configuration was designated as near to near "NN" or far to near "FN." The "Includes Moment Failure" column distinguishes whether moment failures were included in the data used to determine the correlation. This information is only relevant to the CFRP specimens. The "Includes ISL Above 5.0 kips" column designates 
whether the correlation factors includes test data with interfacial shear loads (ISL) above 5.0 kips.

Examination of Table $\mathrm{X}$ shows the highest correlation factors were for "Glass Shear AUP FN" and "Glass Shear Energy FN" test specimens. This result is somewhat questionable since these values are based on estimates and limited data. This same reasoning places the "Glass Longitudinal AUP NN" and "Glass Longitudinal Energy NN" in some doubt as well. However, it is believed that additional testing would probably show these test configurations would provide a good correlation as well. 
TABLE X

CORRELATION FACTORS BETWEEN NDT AND INTERFACIAL SHEAR LOADS

\begin{tabular}{|c|c|c|c|c|c|c|}
\hline $\begin{array}{l}\text { Fiber } \\
\text { Type }\end{array}$ & $\begin{array}{l}\text { Receiving } \\
\text { Transducer } \\
\text { Type }\end{array}$ & $\begin{array}{l}\text { AUP or } \\
\text { Energy }\end{array}$ & $\begin{array}{c}\text { Transducer } \\
\text { Configuration }\end{array}$ & $\begin{array}{c}\text { Includes } \\
\text { Moment } \\
\text { Failure }\end{array}$ & $\begin{array}{c}\text { Includes } \\
\text { ISL } \\
\text { Above } \\
\text { 5.0kips }\end{array}$ & $\begin{array}{c}\text { Correlation } \\
\text { Factor }\end{array}$ \\
\hline Carbon & Longitudinal & AUP & NN & Yes & & 0.626 \\
\hline Carbon & Longitudinal & AUP & $\mathrm{NN}$ & No & & 0.659 \\
\hline Carbon & Longitudinal & AUP & FN & No & & 0.484 \\
\hline Carbon & Shear & AUP & $\mathrm{NN}$ & Yes & & 0.513 \\
\hline Carbon & Shear & AUP & $\mathrm{NN}$ & No & & 0.439 \\
\hline Carbon & Shear & AUP & FN & No & & 0.030 \\
\hline Carbon & Longitudinal & Energy & $\mathrm{NN}$ & Yes & & 0.656 \\
\hline Carbon & Longitudinal & Energy & $\mathrm{NN}$ & No & & 0.587 \\
\hline Carbon & Longitudinal & Energy & FN & No & & 0.093 \\
\hline Carbon & Shear & Energy & $\mathrm{NN}$ & Yes & & 0.357 \\
\hline Carbon & Shear & Energy & $\mathrm{NN}$ & No & & 0.176 \\
\hline Carbon & Shear & Energy & FN & No & & 0.000 \\
\hline Glass & Longitudinal & AUP & NN & & Yes & 0.011 \\
\hline Glass & Longitudinal & AUP & $\mathrm{NN}$ & & No & 0.724 \\
\hline Glass & Longitudinal & AUP & FN & & No & 0.650 \\
\hline Glass & Shear & AUP & $\mathrm{NN}$ & & Yes & 0.244 \\
\hline Glass & Shear & AUP & $\mathrm{NN}$ & & No & 0.026 \\
\hline Glass & Shear & AUP & FN & & No & 0.869 \\
\hline Glass & Longitudinal & Energy & $\mathrm{NN}$ & & Yes & 0.015 \\
\hline
\end{tabular}


TABLE X (CONTINUED)

CORRELATION FACTORS BETWEEN NDT AND INTERFACIAL SHEAR LOADS

\begin{tabular}{|c|c|c|c|c|c|c|}
\hline \multirow[b]{2}{*}{$\begin{array}{l}\text { Fiber } \\
\text { Type }\end{array}$} & \multirow[b]{2}{*}{$\begin{array}{c}\text { Receiving } \\
\text { Transducer } \\
\text { Type }\end{array}$} & \multirow[b]{2}{*}{$\begin{array}{l}\text { AUP or } \\
\text { Energy }\end{array}$} & \multirow[b]{2}{*}{$\begin{array}{l}\text { Transducer } \\
\text { Configuration }\end{array}$} & \multicolumn{3}{|c|}{ Includes } \\
\hline & & & & $\begin{array}{l}\text { Includes } \\
\text { Moment } \\
\text { Failure }\end{array}$ & $\begin{array}{c}\text { ISL } \\
\text { Above } \\
\text { 5.0kips }\end{array}$ & $\begin{array}{l}\text { Correlation } \\
\text { Factor }\end{array}$ \\
\hline Glass & Longitudinal & Energy & $\mathrm{NN}$ & & No & 0.699 \\
\hline Glass & Longitudinal & Energy & $\mathrm{FN}$ & & No & 0.607 \\
\hline Glass & Shear & Energy & $\mathrm{NN}$ & & Yes & 0.241 \\
\hline Glass & Shear & Energy & NN & & No & 0.350 \\
\hline Glass & Shear & Energy & FN & & No & 0.702 \\
\hline
\end{tabular}

CFRP test specimen data were limited because three test specimens reached moment failures prior to concrete/FRP interfacial shearing and most of the GFRP specimens failed by fiber rupture. However, since it is typically assumed that a correlation factor above 0.50 indicates a reasonably good correlation between variables, it can be seen that reasonably good correlations between the NDT results and the interfacial shear bond strengths were observed when using longitudinal transducers and both AUP and total energy methodologies. The AUP analysis appears to provide a better correlation to interfacial shear strength when compared to the total energy analysis procedures. It was also shown that variation in the transducer separation distance did not significantly affect the AUP results for the configuration tested.

The current NDT procedure appears to be capable of determining interfacial shear bond strengths for both CFRP and GFRP reinforced concrete beams; however, more test 
data are needed to validate the methodology over a greater range of characteristics and confirm the estimated data on the GFRP specimens. Further, transducer distances and the direction of the propagating stress waves in relationship to fiber orientation should be investigated and optimized.

Evaluation of additional test specimens will require the specimen configuration be changed to force interfacial shearing of the fiber. GFRP specimen fiber rupture failures can be reduced by using a glass fiber with a larger tensile strength, such as Sika Hex 100G. To address the CFRP test specimen premature moment failures, either the width of the CFRP will need to be reduced or flexural steel reinforcement will need to be added to the specimens. 


\section{CONCLUSIONS AND RECOMMENDATIONS}

The goal of this investigation was to determine whether a non-destructive testing procedure could be used to predict the magnitude of the shear bond strength developed between the composite FRP and concrete systems. Specifically, the acousto-ultrasonic parameter (AUP) methodology was investigated as a means of evaluating the shear bond interface strength between carbon fiber reinforced polymer (CFRP) overlays, or glass fiber reinforced polymer (GFRP) overlays, and concrete substrates. This investigation attempted to find a reliable non-destructive testing method used to directly determine the concrete/FRP interface shear bond strength.

\section{A. Conclusions}

The investigation evaluated nine plain concrete beams flexurally strengthened with CFRP and nine plain concrete beams flexurally strengthened with GFRP. Based on the results of these investigations, the following conclusions can be made:

1) The acousto-ultrasonic parameter (AUP) analysis procedure appears to correlate reasonably well between the shear bond strength of both glass and carbon reinforced overlays and concrete substrates with in the conditions evaluated by this investigation. Best results were found when a longitudinal transducer was used to receive the propagating stress waves. 
2) The AUP analysis procedure and longitudinal receiving transducer was only marginally affected by the transducer separation distance, up to the maximum tested separation distance of 6.25 inches.

3) The total signal energy analysis procedure showed reasonable correlations between the shear bond strength between both glass and carbon overlays applied to concrete substrates, as long as the transducer separation distance is less than 3.25inches.

4) Both the total energy and the AUP analysis procedures did not appear to correlate consistently to the shear bond strength of overlays and concrete substrates when a shear wave transducer was used to receive the propagating stress waves.

\section{B. Recommendations}

1) Additional evaluations should be performed to determine the effects of propagating stress wave direction in relationship to fiber orientation on the NDT parameters.

2) Large FRP overlays should be examined to determine the effective testing surface area when only one transducer configuration is used. These large overlay areas will provide information as to how often a surface area must be tested to ensure completeness. 
3) Additional testing should be performed to determine the effects of steel reinforcement and variations in concrete strength on the NDT results.

4) Additional testing should be conducted to confirm the correlation coefficients for the GFRP specimens. Test configuration modifications need to be made to ensure that fiber rupture does not occur prior to interfacial shearing.

5) Additional testing should be conducted on reconfigured CFRP beam specimens designed to avoid moment failures and confirm these NDT results as well.

6) Perform additional evaluations to determine the effectiveness of the procedure when both the sending and receiving transducers are placed on top of the FRP material.

7) The methodology needs to be evaluated to determine the effectiveness when small void areas are present between the FRP and concrete substrate. This effort should also evaluate the effect of void configuration on any stress concentrations in the FRP. 


\section{REFERENCES}

ACI Committee 318, "Building Code Requirements for Structural Concrete (ACI 318-08) and Commentary”, ACI 318-08, American Concrete Institute, 2008.

ACI Committee 440, "Guide for the Design and Construction of External Bonded FRP System for Strengthening Concrete Structures", ACI 440.2R-02, American Concrete Institute, 2002.

ACI Committee 503R, "Use of Epoxy Compounds with Concrete", ACI 503R, American Concrete Institute, 1998.

Alkhrdaji, T. and Thomas J. 2004. Techniques for successful structural repair and strengthening of concrete facilities. Concrete Engineering International 8(3):5153.

ASTM C39 / C39M - 05e2 Standard Test Method for Compressive Strength of Cylindrical Concrete Specimens, ASTM International, 100 Barr Harbor Drive, PO Box C700, West Conshohocken, PA, 19428-2959 USA, 2005.

ASTM C78 - 08 Standard Test Method for Flexural Strength of Concrete ( Using Simple Beam with Third-Point Loading), ASTM International, 100 Barr Harbor Drive, PO Box C700, West Conshohocken, PA, 19428-2959 USA, 2008.

ASTM C215 - 02 Standard Test Method for Fundamental Transverse, Longitudinal, and Torsional Frequencies of Concrete Specimens, ASTM International, 100 Barr Harbor Drive, PO Box C700, West Conshohocken, PA, 19428-2959 USA, 2002.

ASTM C1383-04 Standard Test Method for Measuring the P-Wave Speed and the Thickness of Concrete Plates Using the Impact-Echo Method, ASTM International, 100 Barr Harbor Drive, PO Box C700, West Conshohocken, PA, 19428-2959 USA, 2004.

ASTM C1583 / C1583M - 04e1 Standard Test Method for Tensile Strength of Concrete Surfaces and the Bond Strength or Tensile Strength of Concrete Repair and Overlay Materials by Direct Tension (Pull-off Method), ASTM International, 100 Barr Harbor Drive, PO Box C700, West Conshohocken, PA, 19428-2959 USA, 2004. 
ASTM D1002 - 05 Standard Test Method for Apparent Shear Strength of Single-LapJoint Adhesively Bonded Metal Specimens by Tension Loading (Metal-to-Metal), ASTM International, 100 Barr Harbor Drive, PO Box C700, West Conshohocken, PA, 19428-2959 USA, 2005.

Bastianini F., Di Tommaso A., and Pascale G. 2001. Ultrasonic Non-Destructive Assessment of Bonding Defects in Composite Structural Strengthening's. Journal of Composite Structure 53:463-467.

Carino, N. J. 2001. The Impact Echo Method: An Overview. Proceedings of the 2001 Structural Congress \& Exposition (Reston, Virgina), May 21-23.

Ekenel, M., Galati, N., Meyers, J., Nanni, A., \& Godinez, V. 2005. Acousto-Ultrasonic Technology for Non-destructive Evaluation of Concrete. Bridge Members Strengthened by Carbon Fiber-Reinforced Polymer. Transportation Research Record 245-251.

Fahr, A., Lee, S., Tanary, S., and Haddad, Y. 1989. Estimation of Strength in Adhesively Bonded Steel Specimens by Acousto-ultrasonic Technique. Journal of Materials Evaluation 47(2):233-240.

Lorenzis, L.A., Miller, B., and Nanni, A. 2001. Bond of Fiber-Reinforced Polymer Laminates to Concrete. ACI Materials Journal 98(3):256-264.

Malhotra, V. M. and Carino, N. J. Editors, 2004. Handbook on Nondestructive Testing of Concrete: Second Edition, CRC PRESS/ASTM International, 100 Barr Harbor Drive, PO Box C700, West Conshohocken, PA, 19428-2959 USA.

McCormac, Jack.C. and Brown, Russel. H. 2009. Design of Reinforced Concrete: Eighth Edition ACI 318-08 Code Edition. USA: John Wiley and Sons, Inc.

Rao, S. \& Daniel, I.M. 1999. Application of Acousto-ultrasonic Technique in Evaluation of Bond Strength and Adhesive Degradation in Composite Repair Patch, 31st International SAMPLE Technical Conference.

Tanary, S., Haddad, Y.M., Fahr, A. \& Lee, S. 1992. Non-destructive Evaluation of Adhesively Bonded Joints in Graphite/Epoxy Composites Using Acoustoultrasonics, Transaction of the ASME 114:344-352.

Vary, A. 1982. Acousto-Ultrasonic Characterization of Fiber Reinforced Composites. Materials Evaluation 40(6):650-662.

Vary, A., and Bowles, K. J. 1979. An Ultrasonic-Acoustic Technique for Nondestructive Evaluation of Fiber Composite Quality. Polymer Engineering and Science 19(5):373-376. 
Vary, A., and Lark, R. F. 1979. Correlation of Fiber Composite Tensile Strength with the Ultrasonic Stress Wave Factor. Journal of Testing and Evaluation. 7(4):185-191.

Weston-Bartholomew, W. 1981. Using Ultrasonic Surface Waves to Predict Fatigue Failure (the Corner Reflector Method). International Advances in Non-destructive Testing 7:31-55.

Williams, J. H., Jr., and Lampert, N. R. 1980. Ultrasonic Evaluation of Impact-Damaged Graphite Fiber Composite. Materials Evaluation 38(12):68-72. 


\section{APPENDIX}

\section{AUP AND ENERGY TEST RESULTS}

These tables contain specific test specimen information such as: beam designation, percentage of constructed void area and beam testing side designation. The corresponding AUP and signal energy results are also listed in the tables, respectively. As described in Chapter III, both sides of the test specimen were evaluated nondestructively five times and the average values for AUP and signal energy also shown. These values are listed in an adjacent column in the first row of each individual test. The tables also show the maximum received signal amplitude for each test. 
Table XI summarizes both the AUP and signal energy results for tests performed on carbon reinforced beam specimens using a longitudinal receiving transducer in the near to near configuration.

TABLE XI

CARBON SPECIMENS TESTED IN THE NEAR TO NEAR CONFIGURATION WITH LONGITUDINAL RECEIVING TRANSDUCER

\begin{tabular}{|c|c|c|c|c|c|c|c|}
\hline Beam & $\begin{array}{c}\text { Void } \\
\text { Area } \\
(\%) \\
\end{array}$ & $\begin{array}{c}\text { Sending } \\
\text { Transducer } \\
\text { Location } \\
\text { (side of } \\
\text { beam) } \\
\end{array}$ & $\begin{array}{c}\text { AUP } \\
\text { Results } \\
\text { (V) }\end{array}$ & $\begin{array}{c}\text { Average } \\
\text { Test } \\
\text { AUP } \\
\text { Results } \\
\text { (V) } \\
\end{array}$ & $\begin{array}{c}\text { Total } \\
\text { Energy } \\
\left(V^{*} \mathbf{s}\right) \\
\end{array}$ & $\begin{array}{c}\text { Average } \\
\text { Test } \\
\text { Energy } \\
\text { Results } \\
(\mathrm{V} * \mathbf{s}) \\
\end{array}$ & $\begin{array}{c}\text { Max } \\
\text { Received } \\
\text { Amplitude } \\
(\mathrm{V}) \\
\end{array}$ \\
\hline A-1 & 0 & $\mathrm{~A}$ & 54.33 & 55.82 & 140.53 & 143.47 & 3.52 \\
\hline A-1 & 0 & A & 55.45 & & 142.45 & & 3.6 \\
\hline A-1 & 0 & A & 56.57 & & 143.89 & & 3.68 \\
\hline A-1 & 0 & $\mathrm{~A}$ & 56.18 & & 145.38 & & 3.68 \\
\hline A-1 & 0 & A & 56.58 & & 145.11 & & 3.76 \\
\hline A-1 & 0 & B & 58.98 & 59.22 & 166.68 & 167.92 & 3.12 \\
\hline A-1 & 0 & B & 59.06 & & 167.74 & & 3.2 \\
\hline A-1 & 0 & B & 59.45 & & 168.66 & & 3.2 \\
\hline A-1 & 0 & B & 60.49 & & 168.13 & & 3.28 \\
\hline A-1 & 0 & B & 58.10 & & 168.38 & & 3.28 \\
\hline A-5 & 25 & A & 39.96 & 40.79 & 102.14 & 104.54 & 2.24 \\
\hline A-5 & 25 & A & 41.32 & & 104.36 & & 2.24 \\
\hline$A-5$ & 25 & A & 40.76 & & 105.23 & & 2.24 \\
\hline A-5 & 25 & A & 41.08 & & 105.60 & & 2.24 \\
\hline$A-5$ & 25 & A & 40.84 & & 105.36 & & 2.24 \\
\hline A-5 & 25 & B & 42.92 & 43.14 & 120.32 & 121.01 & 2.40 \\
\hline$A-5$ & 25 & B & 42.68 & & 121.12 & & 2.40 \\
\hline A-5 & 25 & B & 43.16 & & 121.23 & & 2.40 \\
\hline$A-5$ & 25 & B & 43.72 & & 121.06 & & 2.40 \\
\hline$A-5$ & 25 & B & 43.24 & & 121.32 & & 2.40 \\
\hline A-6 & 50 & A & 40.91 & 41.42 & 115.68 & 118.85 & 2.08 \\
\hline A-6 & 50 & A & 41.63 & & 118.78 & & 2.16 \\
\hline A-6 & 50 & A & 41.39 & & 118.92 & & 2.08 \\
\hline A-6 & 50 & A & 41.62 & & 120.66 & & 2.16 \\
\hline
\end{tabular}




\begin{tabular}{|c|c|c|c|c|c|c|c|}
\hline A-6 & 50 & A & 41.56 & & 120.18 & & 2.08 \\
\hline A-6 & 50 & B & 20.70 & 22.46 & 57.68 & 61.82 & 1.12 \\
\hline A-6 & 50 & B & 22.46 & & 60.32 & & 1.20 \\
\hline A-6 & 50 & B & 23.02 & & 62.46 & & 1.12 \\
\hline A-6 & 50 & B & 23.50 & & 64.24 & & 1.20 \\
\hline A-6 & 50 & B & 22.62 & & 64.38 & & 1.20 \\
\hline B-1 & 0 & A & 60.25 & 59.43 & 167.49 & 168.26 & 3.92 \\
\hline B-1 & 0 & A & 60.34 & & 167.70 & & 3.92 \\
\hline B-1 & 0 & A & 60.82 & & 168.53 & & 3.84 \\
\hline B-1 & 0 & A & 56.26 & & 168.88 & & 4.00 \\
\hline B-1 & 0 & A & 59.46 & & 168.70 & & 3.92 \\
\hline B-1 & 0 & B & 67.13 & 66.91 & 177.70 & 177.97 & 3.28 \\
\hline B-1 & 0 & B & 66.65 & & 177.32 & & 3.28 \\
\hline B-1 & 0 & B & 67.05 & & 177.56 & & 3.28 \\
\hline B-1 & 0 & B & 66.58 & & 178.32 & & 3.36 \\
\hline B-1 & 0 & B & 67.14 & & 178.96 & & 3.28 \\
\hline B-3 & 25 & A & 52.81 & 55.34 & 143.10 & 150.61 & 3.20 \\
\hline B-3 & 25 & A & 54.81 & & 150.64 & & 3.28 \\
\hline B-3 & 25 & A & 55.77 & & 152.34 & & 3.36 \\
\hline B-3 & 25 & A & 56.17 & & 153.17 & & 3.44 \\
\hline B-3 & 25 & A & 57.13 & & 153.81 & & 3.44 \\
\hline B-3 & 25 & B & 59.38 & 61.15 & 168.10 & 171.31 & 3.20 \\
\hline B-3 & 25 & B & 62.49 & & 170.90 & & 3.44 \\
\hline B-3 & 25 & B & 60.10 & & 171.45 & & 3.36 \\
\hline B-3 & 25 & B & 62.33 & & 172.68 & & 3.44 \\
\hline B-3 & 25 & B & 61.46 & & 173.43 & & 3.36 \\
\hline B-5 & 50 & A & 40.60 & 41.72 & 115.82 & 120.35 & 2.08 \\
\hline B-5 & 50 & A & 41.48 & & 119.55 & & 2.16 \\
\hline B-5 & 50 & A & 42.60 & & 121.94 & & 2.16 \\
\hline B-5 & 50 & A & 42.12 & & 122.03 & & 2.16 \\
\hline B-5 & 50 & A & 41.80 & & 122.42 & & 2.16 \\
\hline B-5 & 50 & B & 45.95 & 46.17 & 128.66 & 130.04 & 2.56 \\
\hline B-5 & 50 & B & 46.19 & & 129.79 & & 2.64 \\
\hline B-5 & 50 & B & 46.19 & & 130.54 & & 2.64 \\
\hline B-5 & 50 & B & 46.83 & & 131.05 & & 2.64 \\
\hline B-5 & 50 & B & 45.71 & & 130.17 & & 2.64 \\
\hline C-1 & 0 & A & 44.74 & 48.13 & 110.33 & 115.95 & 2.56 \\
\hline $\mathrm{C}-1$ & 0 & A & 47.78 & & 114.32 & & 2.64 \\
\hline $\mathrm{C}-1$ & 0 & A & 48.90 & & 116.72 & & 2.72 \\
\hline $\mathrm{C}-1$ & 0 & A & 49.13 & & 118.61 & & 2.72 \\
\hline $\mathrm{C}-1$ & 0 & A & 50.10 & & 119.75 & & 2.72 \\
\hline $\mathrm{C}-1$ & 0 & B & 52.59 & 54.00 & 139.07 & 143.75 & 3.04 \\
\hline $\mathrm{C}-1$ & 0 & $\mathrm{~B}$ & 53.79 & & 144.35 & & 3.12 \\
\hline
\end{tabular}




\begin{tabular}{|c|c|c|c|c|c|c|c|}
\hline $\mathrm{C}-1$ & 0 & B & 53.95 & & 143.66 & & 3.2 \\
\hline C-1 & 0 & B & 54.83 & & 145.28 & & 3.2 \\
\hline C-1 & 0 & B & 54.83 & & 146.36 & & 3.2 \\
\hline C-3 & 25 & A & 46.74 & 48.74 & 128.96 & 131.80 & 2.88 \\
\hline C-3 & 25 & A & 49.46 & & 130.63 & & 2.96 \\
\hline C-3 & 25 & A & 49.14 & & 133.14 & & 2.8 \\
\hline C-3 & 25 & A & 49.06 & & 133.05 & & 2.96 \\
\hline$C-3$ & 25 & A & 49.30 & & 133.25 & & 2.96 \\
\hline C-3 & 25 & B & 48.04 & 49.09 & 140.32 & 144.28 & 2.4 \\
\hline C-3 & 25 & B & 48.68 & & 143.98 & & 2.48 \\
\hline C-3 & 25 & B & 49.14 & & 145.60 & & 2.56 \\
\hline C-3 & 25 & B & 49.78 & & 145.59 & & 2.56 \\
\hline$C-3$ & 25 & B & 49.80 & & 145.93 & & 2.48 \\
\hline$C-5$ & 50 & A & 39.41 & 39.62 & 110.14 & 112.08 & 1.92 \\
\hline C-5 & 50 & A & 39.89 & & 110.94 & & 1.92 \\
\hline$C-5$ & 50 & A & 39.33 & & 113.18 & & 2 \\
\hline$C-5$ & 50 & A & 38.61 & & 112.62 & & 2 \\
\hline$C-5$ & 50 & A & 40.85 & & 113.54 & & 1.92 \\
\hline$C-5$ & 50 & B & 44.59 & 45.57 & 124.02 & 125.99 & 2.24 \\
\hline$C-5$ & 50 & B & 45.55 & & 126.02 & & 2.32 \\
\hline$C-5$ & 50 & B & 45.32 & & 126.79 & & 2.32 \\
\hline C-5 & 50 & B & 46.75 & & 126.36 & & 2.4 \\
\hline $\mathrm{C}-5$ & 50 & B & 45.64 & & 126.74 & & 2.32 \\
\hline
\end{tabular}


Table XII summarizes the results for tests performed on the glass reinforced beam specimens using a longitudinal receiving transducer in the near to near configuration.

TABLE XII

GLASS SPECIMENS TESTED IN THE NEAR TO NEAR CONFIGURATION WITH LONGITUDINAL RECEIVING TRANSDUCER

\begin{tabular}{|c|c|c|c|c|c|c|c|}
\hline Beam & $\begin{array}{c}\text { Void } \\
\text { Area } \\
(\%) \\
\end{array}$ & $\begin{array}{c}\text { Sending } \\
\text { Transducer } \\
\text { Location } \\
\text { (side of } \\
\text { beam) } \\
\end{array}$ & $\begin{array}{c}\mathbf{A U P} \\
(\mathbf{V})\end{array}$ & $\begin{array}{c}\text { Average } \\
\text { Test } \\
\text { AUP } \\
\text { Results } \\
\text { (V) } \\
\end{array}$ & $\begin{array}{c}\text { Total } \\
\text { Energy } \\
(\mathbf{V} * \mathbf{s})\end{array}$ & $\begin{array}{c}\text { Average } \\
\text { Test } \\
\text { Energy } \\
\text { Results } \\
\left(V^{*} \mathbf{s}\right) \\
\end{array}$ & $\begin{array}{c}\text { Max } \\
\text { Received } \\
\text { Amplitude } \\
\text { (V) }\end{array}$ \\
\hline A-2 & 0 & $\mathrm{~A}$ & 57.69 & 57.67 & 145.94 & 147.98 & 3.84 \\
\hline A-2 & 0 & A & 57.77 & & 146.86 & & 3.92 \\
\hline$A-2$ & 0 & A & 57.21 & & 148.95 & & 3.92 \\
\hline A-2 & 0 & A & 58.09 & & 148.57 & & 3.92 \\
\hline$A-2$ & 0 & A & 57.61 & & 149.56 & & 3.84 \\
\hline A-2 & 0 & B & 80.62 & 81.82 & 223.27 & 223.05 & 5.52 \\
\hline$A-2$ & 0 & B & 82.14 & & 222.14 & & 5.68 \\
\hline A-2 & 0 & B & 81.74 & & 222.88 & & 5.6 \\
\hline$A-2$ & 0 & B & 83.02 & & 223.74 & & 5.52 \\
\hline A-2 & 0 & B & 81.59 & & 223.24 & & 5.6 \\
\hline$A-3$ & 50 & A & 50.50 & 49.85 & 146.29 & 148.22 & 2.64 \\
\hline A-3 & 50 & A & 48.91 & & 147.05 & & 2.72 \\
\hline$A-3$ & 50 & A & 49.23 & & 148.49 & & 2.72 \\
\hline A-3 & 50 & A & 50.11 & & 149.31 & & 2.72 \\
\hline$A-3$ & 50 & A & 50.51 & & 149.98 & & 2.72 \\
\hline A-3 & 50 & B & 45.30 & 45.39 & 132.91 & 134.47 & 2.72 \\
\hline A-3 & 50 & B & 45.68 & & 135.20 & & 2.72 \\
\hline A-3 & 50 & B & 44.82 & & 134.63 & & 2.72 \\
\hline A-3 & 50 & $\mathrm{~B}$ & 45.62 & & 134.80 & & 2.8 \\
\hline A-3 & 50 & B & 45.54 & & 134.82 & & 2.72 \\
\hline A-4 & 25 & A & 58.97 & 59.55 & 170.40 & 172.25 & 3.68 \\
\hline A-4 & 25 & A & 58.62 & & 171.78 & & 3.76 \\
\hline A-4 & 25 & $\mathrm{~A}$ & 60.41 & & 171.84 & & 3.72 \\
\hline A-4 & 25 & A & 60.17 & & 174.10 & & 3.72 \\
\hline A-4 & 25 & A & 59.61 & & 173.12 & & 3.76 \\
\hline A-4 & 25 & B & 45.30 & 47.22 & 138.81 & 144.88 & 3.48 \\
\hline A-4 & 25 & B & 47.29 & & 142.38 & & 3.56 \\
\hline A-4 & 25 & B & 46.53 & & 144.67 & & 3.68 \\
\hline
\end{tabular}




\begin{tabular}{|c|c|c|c|c|c|c|c|}
\hline A-4 & 25 & B & 48.34 & & 149.11 & & 3.68 \\
\hline A-4 & 25 & B & 48.66 & & 149.44 & & 3.76 \\
\hline B-2 & 0 & A & 74.28 & 74.37 & 209.53 & 212.08 & 5.04 \\
\hline B-2 & 0 & A & 74.35 & & 211.73 & & 5.04 \\
\hline B-2 & 0 & A & 74.04 & & 213.21 & & 5.04 \\
\hline B-2 & 0 & A & 74.91 & & 212.50 & & 5.12 \\
\hline B-2 & 0 & A & 74.28 & & 213.43 & & 5.04 \\
\hline B-2 & 0 & B & 87.36 & 87.84 & 247.10 & 248.05 & 4.88 \\
\hline B-2 & 0 & B & 87.57 & & 247.14 & & 5.04 \\
\hline B-2 & 0 & B & 87.88 & & 247.98 & & 5.04 \\
\hline B-2 & 0 & B & 88.00 & & 249.06 & & 4.96 \\
\hline B-2 & 0 & B & 88.40 & & 248.98 & & 4.96 \\
\hline B-4 & 25 & A & 72.97 & 73.43 & 203.15 & 204.53 & 3.84 \\
\hline B-4 & 25 & A & 72.25 & & 204.24 & & 3.92 \\
\hline B-4 & 25 & A & 73.85 & & 205.18 & & 3.84 \\
\hline B-4 & 25 & A & 74.17 & & 204.90 & & 3.92 \\
\hline B-4 & 25 & A & 73.93 & & 205.18 & & 3.92 \\
\hline B-4 & 25 & B & 59.77 & 60.25 & 164.26 & 165.62 & 3.84 \\
\hline B-4 & 25 & B & 60.65 & & 164.62 & & 3.76 \\
\hline B-4 & 25 & B & 60.40 & & 165.34 & & 3.84 \\
\hline B-4 & 25 & B & 60.56 & & 166.86 & & 3.76 \\
\hline B-4 & 25 & B & 59.85 & & 167.01 & & 3.84 \\
\hline B-6 & 50 & A & 44.36 & 46.15 & 132.44 & 135.26 & 2.40 \\
\hline B-6 & 50 & A & 46.28 & & 135.05 & & 2.48 \\
\hline B-6 & 50 & A & 46.91 & & 136.04 & & 2.48 \\
\hline B-6 & 50 & A & 46.59 & & 136.45 & & 2.48 \\
\hline B-6 & 50 & A & 46.59 & & 136.31 & & 2.48 \\
\hline B-6 & 50 & B & 45.88 & 47.44 & 140.56 & 141.91 & 2.4 \\
\hline B-6 & 50 & B & 47.31 & & 141.58 & & 2.4 \\
\hline B-6 & 50 & B & 46.83 & & 141.99 & & 2.48 \\
\hline B-6 & 50 & B & 47.95 & & 142.62 & & 2.48 \\
\hline B-6 & 50 & B & 49.23 & & 142.82 & & 2.48 \\
\hline C-2 & 0 & A & 82.43 & 82.07 & 235.36 & 236.79 & 5.2 \\
\hline $\mathrm{C}-2$ & 0 & A & 81.48 & & 236.10 & & 5.2 \\
\hline $\mathrm{C}-2$ & 0 & A & 81.32 & & 236.80 & & 5.12 \\
\hline C-2 & 0 & A & 82.12 & & 237.57 & & 5.28 \\
\hline C-2 & 0 & A & 82.99 & & 238.14 & & 5.2 \\
\hline C-2 & 0 & B & 76.00 & 77.94 & 222.34 & 223.66 & 4.8 \\
\hline C-2 & 0 & B & 77.03 & & 223.68 & & 4.88 \\
\hline C-2 & 0 & B & 79.02 & & 223.91 & & 4.96 \\
\hline C-2 & 0 & B & 77.51 & & 223.81 & & 4.88 \\
\hline C-2 & 0 & B & 80.15 & & 224.57 & & 4.96 \\
\hline C-4 & 25 & A & 67.37 & 67.35 & 176.36 & 179.20 & 3.52 \\
\hline
\end{tabular}




\begin{tabular}{|c|c|c|c|c|c|c|c|}
\hline C-4 & 25 & A & 67.21 & & 179.27 & & 3.68 \\
\hline C-4 & 25 & A & 66.73 & & 179.77 & & 3.68 \\
\hline C-4 & 25 & A & 67.45 & & 180.06 & & 3.68 \\
\hline C-4 & 25 & A & 68.01 & & 180.54 & & 3.68 \\
\hline C-4 & 25 & B & 41.15 & 42.55 & 112.62 & 114.26 & 2.16 \\
\hline C-4 & 25 & B & 44.03 & & 113.90 & & 2.24 \\
\hline $\mathrm{C}-4$ & 25 & B & 42.99 & & 114.20 & & 2.24 \\
\hline$C-4$ & 25 & B & 42.27 & & 114.74 & & 2.24 \\
\hline C-4 & 25 & B & 42.28 & & 115.84 & & 2.24 \\
\hline C-6 & 50 & A & 48.75 & 48.93 & 145.70 & 147.92 & 2.48 \\
\hline C-6 & 50 & A & 49.40 & & 147.95 & & 2.48 \\
\hline C-6 & 50 & A & 48.92 & & 148.42 & & 2.40 \\
\hline$C-6$ & 50 & A & 49.55 & & 148.70 & & 2.56 \\
\hline$C-6$ & 50 & A & 48.03 & & 148.84 & & 2.56 \\
\hline$C-6$ & 50 & B & 56.36 & 56.50 & 174.02 & 174.34 & 2.48 \\
\hline C-6 & 50 & B & 57.28 & & 174.43 & & 2.56 \\
\hline C-6 & 50 & B & 56.26 & & 173.42 & & 2.64 \\
\hline$C-6$ & 50 & B & 55.87 & & 175.26 & & 2.48 \\
\hline C-6 & 50 & B & 56.75 & & 174.57 & & 2.56 \\
\hline
\end{tabular}


Table XIII summarizes the AUP and energy results for tests performed on carbon reinforced beam specimens using a longitudinal receiving transducer in the far to near configuration.

TABLE XIII

CARBON SPECIMENS TESTED IN THE FAR TO NEAR CONFIGURATION WITH LONGITUDINAL RECEIVING TRANSDUCER

\begin{tabular}{|c|c|c|c|c|c|c|c|}
\hline Beam & $\begin{array}{c}\text { Void } \\
\text { Area } \\
(\%)\end{array}$ & $\begin{array}{c}\text { Sending } \\
\text { Transducer } \\
\text { Location } \\
\text { (side of } \\
\text { beam) }\end{array}$ & $\begin{array}{c} \\
\text { AUP } \\
\text { Results } \\
\text { (V) }\end{array}$ & $\begin{array}{c}\text { Average } \\
\text { Test } \\
\text { AUP } \\
\text { Results } \\
\text { (V) }\end{array}$ & $\begin{array}{c}\text { Total } \\
\text { Energy } \\
(\mathbf{V} * \mathbf{s})\end{array}$ & $\begin{array}{c}\text { Average } \\
\text { Test } \\
\text { Energy } \\
\text { Results } \\
(\mathbf{V} * \mathbf{s})\end{array}$ & $\begin{array}{c}\text { Max } \\
\text { Received } \\
\text { Amplitude } \\
\text { (V) }\end{array}$ \\
\hline A-1 & 0 & $\mathrm{~A}$ & 61.54 & 63.06 & 189.17 & 191.97 & 3.68 \\
\hline A-1 & 0 & A & 63.62 & & 191.82 & & 3.84 \\
\hline A-1 & 0 & A & 62.82 & & 192.21 & & 3.84 \\
\hline A-1 & 0 & A & 63.78 & & 193.83 & & 3.84 \\
\hline A-1 & 0 & A & 63.54 & & 192.81 & & 3.84 \\
\hline A-1 & 0 & B & 62.58 & 66.36 & 202.22 & 207.84 & 4.00 \\
\hline A-1 & 0 & B & 64.73 & & 207.21 & & 4.00 \\
\hline A-1 & 0 & B & 65.54 & & 208.53 & & 4.00 \\
\hline A-1 & 0 & B & 69.35 & & 210.24 & & 4.08 \\
\hline A-1 & 0 & B & 69.59 & & 211.02 & & 4.08 \\
\hline$A-5$ & 25 & A & 48.25 & 49.33 & 152.54 & 155.93 & 3.04 \\
\hline$A-5$ & 25 & A & 50.42 & & 155.56 & & 3.04 \\
\hline$A-5$ & 25 & A & 49.14 & & 156.66 & & 3.04 \\
\hline$A-5$ & 25 & A & 49.44 & & 157.89 & & 3.04 \\
\hline$A-5$ & 25 & A & 49.38 & & 157.02 & & 3.12 \\
\hline$A-5$ & 25 & B & 38.42 & 38.83 & 122.80 & 123.67 & 2.88 \\
\hline$A-5$ & 25 & B & 37.87 & & 122.62 & & 2.80 \\
\hline$A-5$ & 25 & B & 38.99 & & 124.70 & & 2.88 \\
\hline$A-5$ & 25 & B & 39.46 & & 123.61 & & 2.96 \\
\hline$A-5$ & 25 & B & 39.39 & & 124.62 & & 2.96 \\
\hline A-6 & 50 & A & 42.59 & 42.80 & 134.99 & 137.38 & 2.16 \\
\hline A-6 & 50 & A & 43.23 & & 137.08 & & 2.16 \\
\hline A-6 & 50 & A & 41.88 & & 137.25 & & 2.16 \\
\hline A-6 & 50 & A & 42.83 & & 139.16 & & 2.16 \\
\hline A-6 & 50 & $\mathrm{~A}$ & 43.48 & & 138.40 & & 2.16 \\
\hline A-6 & 50 & $\mathrm{~B}$ & 31.73 & 32.23 & 93.78 & 97.42 & 1.36 \\
\hline
\end{tabular}




\begin{tabular}{|c|c|c|c|c|c|c|c|}
\hline A-6 & 50 & B & 31.50 & & 97.15 & & 1.36 \\
\hline A-6 & 50 & B & 32.69 & & 97.75 & & 1.44 \\
\hline A-6 & 50 & B & 32.53 & & 98.98 & & 1.44 \\
\hline A-6 & 50 & B & 32.70 & & 99.41 & & 1.44 \\
\hline B-1 & 0 & A & 61.53 & 61.56 & 207.18 & 207.72 & 4.72 \\
\hline B-1 & 0 & A & 62.49 & & 207.21 & & 4.64 \\
\hline B-1 & 0 & A & 61.37 & & 207.33 & & 4.64 \\
\hline B-1 & 0 & A & 60.81 & & 208.24 & & 4.64 \\
\hline B-1 & 0 & A & 61.61 & & 208.64 & & 4.72 \\
\hline B-1 & 0 & B & 51.70 & 52.02 & 169.29 & 169.27 & 3.12 \\
\hline B-1 & 0 & B & 52.35 & & 169.61 & & 3.12 \\
\hline B-1 & 0 & B & 51.79 & & 169.48 & & 3.04 \\
\hline B-1 & 0 & B & 52.50 & & 169.84 & & 3.04 \\
\hline B-1 & 0 & B & 51.78 & & 168.14 & & 2.96 \\
\hline B-3 & 25 & A & 60.58 & 60.58 & 190.56 & 193.06 & 3.20 \\
\hline B-3 & 25 & A & 60.18 & & 191.29 & & 3.28 \\
\hline B-3 & 25 & A & 59.94 & & 193.71 & & 3.28 \\
\hline B-3 & 25 & A & 61.14 & & 193.82 & & 3.28 \\
\hline B-3 & 25 & A & 61.06 & & 195.94 & & 3.28 \\
\hline B-3 & 25 & B & 61.22 & 61.60 & 184.96 & 187.39 & 3.04 \\
\hline B-3 & 25 & B & 61.46 & & 186.79 & & 2.96 \\
\hline B-3 & 25 & B & 61.70 & & 188.43 & & 3.04 \\
\hline B-3 & 25 & B & 61.46 & & 188.14 & & 3.04 \\
\hline B-3 & 25 & B & 62.18 & & 188.61 & & 2.96 \\
\hline B-5 & 50 & A & 38.68 & 39.24 & 122.32 & 125.25 & 2.08 \\
\hline B-5 & 50 & A & 38.84 & & 124.85 & & 2.08 \\
\hline B-5 & 50 & A & 39.06 & & 126.13 & & 2.16 \\
\hline B-5 & 50 & A & 40.28 & & 126.60 & & 2.16 \\
\hline B-5 & 50 & A & 39.32 & & 126.37 & & 2.16 \\
\hline B-5 & 50 & B & 39.95 & 40.86 & 142.94 & 145.24 & 2.72 \\
\hline B-5 & 50 & B & 42.02 & & 144.66 & & 2.72 \\
\hline B-5 & 50 & B & 40.75 & & 145.21 & & 2.72 \\
\hline B-5 & 50 & B & 40.91 & & 147.36 & & 2.72 \\
\hline B-5 & 50 & B & 40.67 & & 146.03 & & 2.72 \\
\hline C-1 & 0 & A & 48.66 & 50.29 & 149.89 & 152.28 & 3.2 \\
\hline C-1 & 0 & A & 51.46 & & 152.63 & & 3.28 \\
\hline C-1 & 0 & A & 50.02 & & 152.34 & & 3.28 \\
\hline C-1 & 0 & A & 50.66 & & 152.78 & & 3.28 \\
\hline C-1 & 0 & A & 50.67 & & 153.75 & & 3.28 \\
\hline C-1 & 0 & B & 46.57 & 49.60 & 129.69 & 138.47 & 2.64 \\
\hline C-1 & 0 & B & 48.17 & & 134.79 & & 2.88 \\
\hline C-1 & 0 & B & 50.09 & & 140.73 & & 3.04 \\
\hline C-1 & 0 & $\mathrm{~B}$ & 51.21 & & 143.10 & & 3.12 \\
\hline
\end{tabular}




\begin{tabular}{lccccccc}
\hline C-1 & 0 & B & 51.94 & & 144.03 & & 3.12 \\
C-3 & 25 & A & 48.03 & 50.38 & 155.69 & 160.18 & 2.96 \\
C-3 & 25 & A & 50.90 & & 159.76 & & 2.96 \\
C-3 & 25 & A & 50.50 & & 160.90 & & 3.04 \\
C-3 & 25 & A & 51.30 & & 161.79 & & 3.12 \\
C-3 & 25 & A & 51.15 & & 162.76 & & 3.04 \\
C-3 & 25 & B & 46.03 & 46.08 & 138.21 & 141.13 & 2.4 \\
C-3 & 25 & B & 45.00 & & 139.45 & & 2.4 \\
C-3 & 25 & B & 45.72 & & 142.01 & & 2.48 \\
C-3 & 25 & B & 46.76 & & 142.17 & & 2.48 \\
C-3 & 25 & B & 46.92 & & 143.83 & & 2.48 \\
C-5 & 50 & A & 45.54 & 45.49 & 145.94 & 150.00 & 3.2 \\
C-5 & 50 & A & 44.58 & & 149.26 & & 3.2 \\
C-5 & 50 & A & 45.46 & & 150.32 & & 3.2 \\
C-5 & 50 & A & 45.94 & & 151.94 & & 3.28 \\
C-5 & 50 & A & 45.94 & & 152.53 & & 3.28 \\
C-5 & 50 & B & 44.52 & 45.31 & 152.22 & 154.25 & 2.32 \\
C-5 & 50 & B & 45.00 & & 154.00 & & 2.32 \\
C-5 & 50 & B & 45.08 & & 154.26 & & 2.32 \\
C-5 & 50 & B & 45.77 & & 155.90 & & 2.4 \\
C-5 & 50 & B & 46.20 & & 154.89 & & 2.32 \\
\hline
\end{tabular}


Table XIV summarizes the results for tests performed on glass reinforced beam specimens using a longitudinal receiving transducer in the far to near configuration.

TABLE XIV

GLASS SPECIMENS TESTED IN THE FAR TO NEAR CONFIGURATION WITH LONGITUDINAL RECEIVING TRANSDUCER

\begin{tabular}{|c|c|c|c|c|c|c|c|}
\hline Beam & $\begin{array}{c}\text { Void } \\
\text { Area } \\
(\%) \\
\end{array}$ & $\begin{array}{c}\text { Sending } \\
\text { Transducer } \\
\text { Location } \\
\text { (side of } \\
\text { beam) } \\
\end{array}$ & $\begin{array}{c}\text { AUP } \\
\text { Results } \\
(\mathbf{V})\end{array}$ & $\begin{array}{c}\text { Average } \\
\text { Test AUP } \\
\text { Results } \\
(\text { V) }\end{array}$ & $\begin{array}{c}\text { Total } \\
\text { Energy } \\
(\mathrm{V} * \mathbf{s})\end{array}$ & $\begin{array}{c}\text { Average } \\
\text { Test } \\
\text { Energy } \\
\text { Results } \\
\left(V^{*} \mathbf{s}\right) \\
\end{array}$ & $\begin{array}{c}\text { Max } \\
\text { Received } \\
\text { Amplitude } \\
(\mathrm{V})\end{array}$ \\
\hline A-2 & 0 & $\mathrm{~A}$ & 62.97 & 63.64 & 201.63 & 203.20 & 4 \\
\hline A-2 & 0 & A & 62.01 & & 203.15 & & 4 \\
\hline$A-2$ & 0 & A & 62.17 & & 203.48 & & 4 \\
\hline A-2 & 0 & A & 65.11 & & 203.57 & & 4.08 \\
\hline A-2 & 0 & A & 65.92 & & 204.16 & & 4.08 \\
\hline A-2 & 0 & $\mathrm{~B}$ & 82.24 & 83.34 & 255.11 & 255.07 & 4.48 \\
\hline$A-2$ & 0 & B & 84.07 & & 254.78 & & 4.4 \\
\hline A-2 & 0 & B & 83.43 & & 255.17 & & 4.48 \\
\hline A-2 & 0 & B & 83.27 & & 255.48 & & 4.48 \\
\hline A-2 & 0 & B & 83.67 & & 254.82 & & 4.48 \\
\hline$A-3$ & 50 & $\mathrm{~A}$ & 56.26 & 55.95 & 190.34 & 191.76 & 3.44 \\
\hline A-3 & 50 & A & 54.98 & & 191.47 & & 3.44 \\
\hline A-3 & 50 & A & 55.86 & & 191.62 & & 3.44 \\
\hline A-3 & 50 & A & 56.97 & & 192.86 & & 3.52 \\
\hline A-3 & 50 & A & 55.70 & & 192.49 & & 3.44 \\
\hline A-3 & 50 & B & 46.97 & 47.27 & 154.47 & 156.43 & 3.28 \\
\hline A-3 & 50 & B & 47.06 & & 156.07 & & 3.28 \\
\hline A-3 & 50 & B & 47.22 & & 156.50 & & 3.36 \\
\hline A-3 & 50 & $\mathrm{~B}$ & 47.14 & & 157.38 & & 3.28 \\
\hline A-3 & 50 & B & 47.94 & & 157.70 & & 3.36 \\
\hline A-4 & 25 & A & 60.41 & 61.34 & 201.48 & 202.45 & 4.12 \\
\hline A-4 & 25 & A & 61.40 & & 202.20 & & 4.12 \\
\hline A-4 & 25 & A & 62.00 & & 202.70 & & 4.08 \\
\hline A-4 & 25 & A & 61.71 & & 202.42 & & 4.12 \\
\hline A-4 & 25 & A & 61.17 & & 203.46 & & 4.16 \\
\hline A-4 & 25 & B & 46.99 & 47.91 & 156.42 & 160.74 & 2.40 \\
\hline A-4 & 25 & B & 49.31 & & 162.25 & & 2.48 \\
\hline A-4 & 25 & $\mathrm{~B}$ & 47.83 & & 161.12 & & 2.52 \\
\hline
\end{tabular}




\begin{tabular}{|c|c|c|c|c|c|c|c|}
\hline A-4 & 25 & B & 47.56 & & 161.92 & & 2.52 \\
\hline A-4 & 25 & B & 47.88 & & 161.99 & & 2.48 \\
\hline B-2 & 0 & A & 78.17 & 79.08 & 235.58 & 235.78 & 4.72 \\
\hline B-2 & 0 & A & 79.36 & & 235.39 & & 4.72 \\
\hline B-2 & 0 & A & 78.41 & & 236.21 & & 4.80 \\
\hline B-2 & 0 & A & 79.44 & & 236.16 & & 4.80 \\
\hline B-2 & 0 & A & 80.00 & & 235.54 & & 4.72 \\
\hline B-2 & 0 & B & 64.08 & 64.01 & 200.74 & 203.60 & 4.40 \\
\hline B-2 & 0 & B & 63.35 & & 202.52 & & 4.48 \\
\hline B-2 & 0 & B & 64.55 & & 204.53 & & 4.48 \\
\hline B-2 & 0 & B & 63.76 & & 205.54 & & 4.48 \\
\hline B-2 & 0 & B & 64.32 & & 204.67 & & 4.56 \\
\hline B-4 & 25 & A & 66.89 & 66.55 & 210.54 & 211.04 & 4.08 \\
\hline B-4 & 25 & A & 66.96 & & 211.22 & & 4.16 \\
\hline B-4 & 25 & A & 66.09 & & 211.19 & & 4.16 \\
\hline B-4 & 25 & A & 65.93 & & 210.58 & & 4.16 \\
\hline B-4 & 25 & A & 66.88 & & 211.66 & & 4.16 \\
\hline B-4 & 25 & B & 60.18 & 61.00 & 188.68 & 193.11 & 3.60 \\
\hline B-4 & 25 & B & 60.34 & & 193.02 & & 3.68 \\
\hline B-4 & 25 & B & 61.14 & & 194.02 & & 3.68 \\
\hline B-4 & 25 & B & 61.22 & & 194.75 & & 3.68 \\
\hline B-4 & 25 & B & 62.10 & & 195.08 & & 3.76 \\
\hline B-6 & 50 & A & 52.50 & 53.38 & 176.28 & 177.70 & 3.20 \\
\hline B-6 & 50 & A & 52.02 & & 177.17 & & 3.20 \\
\hline B-6 & 50 & A & 53.78 & & 178.22 & & 3.28 \\
\hline B-6 & 50 & A & 53.15 & & 179.05 & & 3.20 \\
\hline B-6 & 50 & A & 55.46 & & 177.78 & & 3.20 \\
\hline B-6 & 50 & B & 49.45 & 48.04 & 177.04 & 178.17 & 4.72 \\
\hline B-6 & 50 & B & 47.05 & & 177.75 & & 4.64 \\
\hline B-6 & 50 & B & 47.53 & & 178.29 & & 4.64 \\
\hline B-6 & 50 & B & 47.93 & & 178.56 & & 4.64 \\
\hline B-6 & 50 & B & 48.25 & & 179.20 & & 4.64 \\
\hline C-2 & 0 & A & 88.67 & 89.14 & 276.86 & 277.63 & 5.44 \\
\hline $\mathrm{C}-2$ & 0 & A & 89.55 & & 277.22 & & 5.44 \\
\hline $\mathrm{C}-2$ & 0 & A & 89.75 & & 277.78 & & 5.52 \\
\hline $\mathrm{C}-2$ & 0 & A & 89.99 & & 277.90 & & 5.52 \\
\hline C-2 & 0 & A & 87.75 & & 278.40 & & 5.52 \\
\hline C-2 & 0 & B & 76.64 & 76.99 & 241.17 & 241.46 & 4.8 \\
\hline C-2 & 0 & B & 77.12 & & 242.03 & & 4.88 \\
\hline C-2 & 0 & B & 77.27 & & 241.18 & & 4.88 \\
\hline C-2 & 0 & B & 75.99 & & 241.34 & & 4.88 \\
\hline C-2 & 0 & B & 77.92 & & 241.57 & & 4.88 \\
\hline C-4 & 25 & A & 62.32 & 63.53 & 208.12 & 209.25 & 4.24 \\
\hline
\end{tabular}




\begin{tabular}{|c|c|c|c|c|c|c|c|}
\hline C-4 & 25 & A & 63.44 & & 209.24 & & 4.24 \\
\hline C-4 & 25 & A & 64.24 & & 209.33 & & 4.24 \\
\hline C-4 & 25 & A & 64.24 & & 209.85 & & 4.24 \\
\hline C-4 & 25 & A & 63.44 & & 209.71 & & 4.32 \\
\hline C-4 & 25 & B & 55.38 & 56.55 & 166.12 & 167.95 & 3.20 \\
\hline C-4 & 25 & B & 56.82 & & 167.62 & & 3.28 \\
\hline C-4 & 25 & B & 54.90 & & 168.22 & & 3.20 \\
\hline C-4 & 25 & B & 57.78 & & 168.47 & & 3.20 \\
\hline C-4 & 25 & B & 57.86 & & 169.33 & & 3.28 \\
\hline C-6 & 50 & A & 49.79 & 51.99 & 167.60 & 172.14 & 3.28 \\
\hline C-6 & 50 & A & 53.47 & & 171.22 & & 3.28 \\
\hline C-6 & 50 & A & 52.59 & & 173.39 & & 3.36 \\
\hline C-6 & 50 & A & 51.70 & & 174.34 & & 3.36 \\
\hline C-6 & 50 & A & 52.42 & & 174.15 & & 3.36 \\
\hline C-6 & 50 & B & 50.42 & 51.11 & 182.37 & 183.64 & 3.36 \\
\hline C-6 & 50 & B & 50.75 & & 184.02 & & 3.36 \\
\hline C-6 & 50 & B & 52.10 & & 183.62 & & 3.44 \\
\hline C-6 & 50 & B & 50.51 & & 184.35 & & 3.36 \\
\hline C-6 & 50 & B & 51.78 & & 183.86 & & 3.44 \\
\hline
\end{tabular}


Table XV summarizes both the AUP and signal energy results for tests performed on carbon reinforced beam specimens using a longitudinal receiving transducer in the near to far configuration with two gain settings.

TABLE XV

CARBON SPECIMENS TESTED IN THE NEAR TO FAR CONFIGURATION WITH LONGITUDINAL RECEIVING TRANSDUCER

\begin{tabular}{|c|c|c|c|c|c|c|c|c|}
\hline Beam & $\begin{array}{c}\text { Void } \\
\text { Area } \\
(\%) \\
\end{array}$ & $\begin{array}{l}\text { Gain } \\
\text { (dB) }\end{array}$ & $\begin{array}{c}\text { Sending } \\
\text { Transducer } \\
\text { Location } \\
\text { (side of } \\
\text { beam) } \\
\end{array}$ & $\begin{array}{c}\text { AUP } \\
\text { Results } \\
(\mathrm{V})\end{array}$ & $\begin{array}{c}\text { Average } \\
\text { Test AUP } \\
\text { Results } \\
(\text { V) }\end{array}$ & $\begin{array}{c}\text { Total } \\
\text { Energy } \\
(\mathbf{V} * \mathbf{s}) \\
\end{array}$ & $\begin{array}{c}\text { Average } \\
\text { Test } \\
\text { Energy } \\
\text { Results } \\
(\mathbf{V} * \mathbf{s}) \\
\end{array}$ & $\begin{array}{c}\text { Max } \\
\text { Received } \\
\text { Amplitude } \\
(\mathrm{V}) \\
\end{array}$ \\
\hline A-1 & 0 & 40 & A & 244.14 & 246.21 & 819.18 & 825.12 & 9.44 \\
\hline A-1 & 0 & 40 & A & 245.43 & & 821.73 & & 9.44 \\
\hline A-1 & 0 & 40 & A & 246.14 & & 824.22 & & 9.44 \\
\hline A-1 & 0 & 40 & A & 247.40 & & 830.12 & & 9.52 \\
\hline A-1 & 0 & 40 & A & 247.92 & & 830.34 & & 9.6 \\
\hline A-1 & 0 & 40 & B & 312.22 & 310.22 & 1126.71 & 1129.51 & 10.32 \\
\hline A-1 & 0 & 40 & B & 306.85 & & 1128.02 & & 10.32 \\
\hline A-1 & 0 & 40 & B & 312.14 & & 1130.07 & & 10.32 \\
\hline A-1 & 0 & 40 & B & 307.03 & & 1130.18 & & 10.32 \\
\hline A-1 & 0 & 40 & B & 312.87 & & 1132.59 & & 10.32 \\
\hline A-6 & 50 & 40 & A & 157.42 & 159.22 & 588.73 & 591.43 & 6.00 \\
\hline A-6 & 50 & 40 & A & 156.63 & & 589.34 & & 6.00 \\
\hline A-6 & 50 & 40 & A & 157.26 & & 592.16 & & 6.00 \\
\hline A-6 & 50 & 40 & A & 167.58 & & 593.88 & & 6.00 \\
\hline A-6 & 50 & 40 & A & 157.19 & & 593.02 & & 6.00 \\
\hline A-6 & 50 & 40 & B & 130.08 & 132.18 & 489.02 & 490.65 & 4.72 \\
\hline A-6 & 50 & 40 & B & 132.65 & & 490.82 & & 4.80 \\
\hline A-6 & 50 & 40 & B & 133.44 & & 490.20 & & 4.88 \\
\hline A-6 & 50 & 40 & B & 132.56 & & 490.84 & & 4.80 \\
\hline A-6 & 50 & 40 & B & 132.17 & & 492.38 & & 4.88 \\
\hline C-1 & 0 & 40 & A & 290.94 & 291.82 & 945.94 & 951.78 & 10.32 \\
\hline C-1 & 0 & 40 & A & 292.53 & & 950.16 & & 10.32 \\
\hline C-1 & 0 & 40 & A & 289.67 & & 951.19 & & 10.32 \\
\hline C-1 & 0 & 40 & A & 291.73 & & 953.96 & & 10.32 \\
\hline C-1 & 0 & 40 & A & 294.21 & & 957.63 & & 10.32 \\
\hline C-1 & 0 & 40 & $\mathrm{~B}$ & 290.67 & 291.03 & 942.90 & 944.79 & 10.32 \\
\hline
\end{tabular}




\begin{tabular}{|c|c|c|c|c|c|c|c|c|}
\hline $\mathrm{C}-1$ & 0 & 40 & B & 291.25 & & 945.41 & & 10.32 \\
\hline C-1 & 0 & 40 & B & 290.28 & & 943.41 & & 10.32 \\
\hline $\mathrm{C}-1$ & 0 & 40 & B & 290.51 & & 945.60 & & 10.32 \\
\hline C-1 & 0 & 40 & B & 292.43 & & 946.62 & & 10.32 \\
\hline C-5 & 50 & 40 & A & 279.60 & 279.06 & 1122.18 & 1126.00 & 10.32 \\
\hline C-5 & 50 & 40 & A & 278.23 & & 1123.33 & & 10.32 \\
\hline C-5 & 50 & 40 & A & 279.34 & & 1126.72 & & 10.32 \\
\hline C-5 & 50 & 40 & A & 278.87 & & 1128.82 & & 10.32 \\
\hline C-5 & 50 & 40 & A & 279.27 & & 1128.94 & & 10.32 \\
\hline C-5 & 50 & 40 & B & 208.45 & 208.71 & 758.28 & 761.82 & 6.64 \\
\hline C-5 & 50 & 40 & B & 205.16 & & 759.65 & & 6.64 \\
\hline C-5 & 50 & 40 & B & 210.52 & & 761.46 & & 6.56 \\
\hline C-5 & 50 & 40 & B & 209.49 & & 764.73 & & 6.64 \\
\hline C-5 & 50 & 40 & B & 209.91 & & 764.99 & & 6.72 \\
\hline A-1 & 0 & 20 & A & 23.43 & 24.78 & 75.96 & 78.26 & 0.88 \\
\hline A-1 & 0 & 20 & A & 23.99 & & 77.70 & & 0.88 \\
\hline A-1 & 0 & 20 & A & 25.58 & & 78.47 & & 0.88 \\
\hline A-1 & 0 & 20 & A & 26.11 & & 79.59 & & 0.88 \\
\hline A-1 & 0 & 20 & A & 24.79 & & 79.58 & & 0.88 \\
\hline A-1 & 0 & 20 & B & 31.34 & 32.01 & 109.43 & 111.06 & 1.44 \\
\hline A-1 & 0 & 20 & B & 31.82 & & 110.85 & & 1.44 \\
\hline A-1 & 0 & 20 & B & 32.94 & & 111.11 & & 1.44 \\
\hline A-1 & 0 & 20 & B & 32.30 & & 111.89 & & 1.44 \\
\hline A-1 & 0 & 20 & B & 31.65 & & 112.04 & & 1.6 \\
\hline A-6 & 50 & 20 & A & 17.59 & 17.45 & 57.28 & 57.59 & 0.64 \\
\hline A-6 & 50 & 20 & A & 16.71 & & 57.59 & & 0.64 \\
\hline A-6 & 50 & 20 & A & 18.15 & & 57.80 & & 0.64 \\
\hline A-6 & 50 & 20 & A & 18.07 & & 57.76 & & 0.64 \\
\hline A-6 & 50 & 20 & A & 16.71 & & 57.54 & & 0.64 \\
\hline A-6 & 50 & 20 & B & 12.47 & 13.22 & 46.83 & 48.03 & 0.48 \\
\hline A-6 & 50 & 20 & B & 13.59 & & 47.82 & & 0.48 \\
\hline A-6 & 50 & 20 & B & 13.03 & & 48.22 & & 0.48 \\
\hline A-6 & 50 & 20 & B & 13.03 & & 48.06 & & 0.48 \\
\hline A-6 & 50 & 20 & B & 13.99 & & 49.22 & & 0.56 \\
\hline C-1 & 0 & 20 & A & 27.25 & 28.82 & 84.81 & 89.08 & 1.04 \\
\hline C-1 & 0 & 20 & A & 28.45 & & 87.70 & & 1.12 \\
\hline C-1 & 0 & 20 & A & 29.66 & & 89.88 & & 1.12 \\
\hline C-1 & 0 & 20 & A & 28.93 & & 91.22 & & 1.12 \\
\hline C-1 & 0 & 20 & A & 29.81 & & 91.81 & & 1.12 \\
\hline C-1 & 0 & 20 & B & 29.57 & 29.83 & 89.95 & 91.28 & 1.04 \\
\hline C-1 & 0 & 20 & B & 29.74 & & 90.50 & & 0.96 \\
\hline C-1 & 0 & 20 & B & 29.42 & & 91.59 & & 1.04 \\
\hline $\mathrm{C}-1$ & 0 & 20 & $\mathrm{~B}$ & 30.14 & & 92.07 & & 1.04 \\
\hline
\end{tabular}




\begin{tabular}{|c|c|c|c|c|c|c|c|c|}
\hline C-1 & 0 & 20 & B & 30.30 & & 92.30 & & 1.04 \\
\hline C-5 & 50 & 20 & A & 29.34 & 29.61 & 108.42 & 108.83 & 1.12 \\
\hline C-5 & 50 & 20 & A & 29.42 & & 108.42 & & 1.12 \\
\hline C-5 & 50 & 20 & A & 29.82 & & 108.86 & & 1.2 \\
\hline C-5 & 50 & 20 & A & 29.81 & & 109.22 & & 1.2 \\
\hline C-5 & 50 & 20 & A & 29.66 & & 109.21 & & 1.2 \\
\hline C-5 & 50 & 20 & B & 20.55 & 21.37 & 71.86 & 73.49 & 0.64 \\
\hline C-5 & 50 & 20 & B & 21.67 & & 73.30 & & 0.64 \\
\hline C-5 & 50 & 20 & B & 21.51 & & 73.40 & & 0.72 \\
\hline C-5 & 50 & 20 & B & 21.74 & & 74.82 & & 0.64 \\
\hline C-5 & 50 & 20 & B & 21.42 & & 74.05 & & 0.72 \\
\hline
\end{tabular}


Table XVI summarizes both the AUP and signal energy results for tests

performed on carbon reinforced beam specimens using a shear receiving transducer in the near to near configuration.

TABLE XVI

CARBON SPECIMENS TESTED IN THE NEAR TO NEAR CONFIGURATION WITH SHEAR RECEIVING TRANSDUCER

\begin{tabular}{|c|c|c|c|c|c|c|c|}
\hline $\begin{array}{c}\text { Bea } \\
\text { m } \\
\end{array}$ & $\begin{array}{c}\text { Void } \\
\text { Area } \\
(\%) \\
\end{array}$ & $\begin{array}{c}\text { Sending } \\
\text { Transducer } \\
\text { Location } \\
\text { (side of } \\
\text { beam) } \\
\end{array}$ & $\begin{array}{c}\text { AUP } \\
\text { Results } \\
(\mathbf{V}) \\
\end{array}$ & $\begin{array}{c}\text { Average } \\
\text { Test AUP } \\
\text { Results } \\
\text { (V) } \\
\end{array}$ & $\begin{array}{c}\text { Total } \\
\text { Energy } \\
(\mathrm{V} * \mathbf{s})\end{array}$ & $\begin{array}{c}\text { Average } \\
\text { Test } \\
\text { Energy } \\
\text { Results } \\
(\mathbf{V} * \mathbf{s}) \\
\end{array}$ & $\begin{array}{c}\text { Max } \\
\text { Received } \\
\text { Amplitude } \\
(\mathrm{V}) \\
\end{array}$ \\
\hline A-1 & 0 & $\mathrm{~A}$ & 186.64 & 199.03 & 425.38 & 439.12 & 10 \\
\hline A-1 & 0 & A & 202.09 & & 440.71 & & 10.16 \\
\hline A-1 & 0 & A & 204.01 & & 442.15 & & 10.32 \\
\hline A-1 & 0 & A & 200.96 & & 443.78 & & 10.32 \\
\hline A-1 & 0 & A & 201.44 & & 443.57 & & 10.32 \\
\hline A-1 & 0 & B & 270.69 & 272.69 & 552.54 & 550.23 & 10.32 \\
\hline A-1 & 0 & B & 272.29 & & 547.96 & & 10.32 \\
\hline A-1 & 0 & B & 274.35 & & 548.58 & & 10.32 \\
\hline A-1 & 0 & B & 274.19 & & 550.98 & & 10.32 \\
\hline$A-1$ & 0 & B & 271.96 & & 551.08 & & 10.32 \\
\hline$A-5$ & 75 & A & 127.32 & 129.16 & 246.62 & 252.78 & 6.88 \\
\hline$A-5$ & 75 & A & 126.13 & & 249.30 & & 6.96 \\
\hline$A-5$ & 75 & A & 131.02 & & 255.60 & & 7.04 \\
\hline$A-5$ & 75 & A & 129.28 & & 254.37 & & 7.04 \\
\hline$A-5$ & 75 & A & 132.05 & & 258.02 & & 7.12 \\
\hline$A-5$ & 75 & B & 128.37 & 132.41 & 250.61 & 255.29 & 5.28 \\
\hline$A-5$ & 75 & B & 132.20 & & 253.91 & & 5.60 \\
\hline$A-5$ & 75 & B & 133.39 & & 257.20 & & 5.52 \\
\hline$A-5$ & 75 & B & 133.80 & & 256.98 & & 5.52 \\
\hline$A-5$ & 75 & B & 134.29 & & 257.75 & & 5.6 \\
\hline A-6 & 50 & A & 143.24 & 145.04 & 275.62 & 277.79 & 4.72 \\
\hline A-6 & 50 & A & 145.55 & & 276.02 & & 4.96 \\
\hline$A-6$ & 50 & A & 145.41 & & 276.70 & & 5.04 \\
\hline A-6 & 50 & A & 145.88 & & 280.88 & & 4.96 \\
\hline$A-6$ & 50 & A & 145.11 & & 279.73 & & 5.04 \\
\hline A-6 & 50 & B & 97.41 & 97.43 & 186.39 & 187.56 & 4.32 \\
\hline
\end{tabular}




\begin{tabular}{|c|c|c|c|c|c|c|c|}
\hline$A-6$ & 50 & B & 96.76 & & 186.73 & & 4.32 \\
\hline A-6 & 50 & B & 98.78 & & 189.18 & & 4.32 \\
\hline$A-6$ & 50 & B & 97.41 & & 187.53 & & 4.24 \\
\hline$A-6$ & 50 & B & 96.77 & & 187.98 & & 4.32 \\
\hline B-1 & 0 & A & 261.69 & 258.28 & 576.95 & 578.19 & 10.32 \\
\hline B-1 & 0 & A & 258.98 & & 577.18 & & 10.32 \\
\hline B-1 & 0 & A & 253.37 & & 576.72 & & 10.32 \\
\hline B-1 & 0 & A & 258.96 & & 579.99 & & 10.32 \\
\hline B-1 & 0 & A & 258.42 & & 580.11 & & 10.32 \\
\hline B-1 & 0 & B & 196.77 & 202.07 & 379.92 & 390.00 & 6.72 \\
\hline B-1 & 0 & B & 200.62 & & 387.68 & & 6.96 \\
\hline B-1 & 0 & B & 202.78 & & 393.08 & & 7.12 \\
\hline B-1 & 0 & B & 204.52 & & 393.82 & & 7.20 \\
\hline B-1 & 0 & B & 205.66 & & 395.50 & & 7.20 \\
\hline B-3 & 25 & A & 203.98 & 205.42 & 408.55 & 415.36 & 10.32 \\
\hline B-3 & 25 & A & 204.63 & & 414.16 & & 10.32 \\
\hline B-3 & 25 & A & 205.52 & & 416.40 & & 10.32 \\
\hline B-3 & 25 & A & 207.81 & & 418.74 & & 10.32 \\
\hline B-3 & 25 & A & 205.18 & & 418.95 & & 10.32 \\
\hline B-3 & 25 & B & 189.94 & 191.71 & 360.01 & 364.92 & 8.40 \\
\hline B-3 & 25 & B & 189.20 & & 364.32 & & 8.48 \\
\hline B-3 & 25 & B & 191.28 & & 365.76 & & 8.64 \\
\hline B-3 & 25 & B & 194.65 & & 367.01 & & 8.56 \\
\hline B-3 & 25 & B & 193.50 & & 367.48 & & 8.56 \\
\hline B-5 & 50 & A & 177.35 & 178.50 & 325.25 & 329.07 & 7.68 \\
\hline B-5 & 50 & A & 179.05 & & 328.74 & & 7.84 \\
\hline B-5 & 50 & A & 178.81 & & 329.44 & & 7.84 \\
\hline B-5 & 50 & A & 179.12 & & 329.85 & & 7.84 \\
\hline B-5 & 50 & A & 178.16 & & 332.08 & & 7.76 \\
\hline B-5 & 50 & B & 157.31 & 158.72 & 316.26 & 317.63 & 5.84 \\
\hline B-5 & 50 & B & 157.39 & & 318.24 & & 5.68 \\
\hline B-5 & 50 & B & 159.79 & & 317.20 & & 5.76 \\
\hline B-5 & 50 & B & 157.87 & & 317.28 & & 5.92 \\
\hline B-5 & 50 & B & 161.23 & & 319.16 & & 5.68 \\
\hline C-1 & 0 & A & 253.99 & 254.81 & 504.30 & 516.07 & 10.32 \\
\hline C-1 & 0 & A & 251.76 & & 514.88 & & 10.32 \\
\hline C-1 & 0 & A & 254.95 & & 519.66 & & 10.32 \\
\hline C-1 & 0 & A & 256.35 & & 517.39 & & 10.32 \\
\hline C-1 & 0 & A & 257.00 & & 524.14 & & 10.32 \\
\hline C-1 & 0 & B & 218.57 & 226.74 & 407.46 & 426.57 & 5.76 \\
\hline C-1 & 0 & B & 225.69 & & 429.75 & & 5.84 \\
\hline C-1 & 0 & B & 228.57 & & 430.88 & & 5.84 \\
\hline C-1 & 0 & $\mathrm{~B}$ & 229.76 & & 431.90 & & 5.84 \\
\hline
\end{tabular}




\begin{tabular}{lccccccc}
\hline C-1 & 0 & B & 231.12 & & 432.85 & & 5.92 \\
C-3 & 25 & A & 181.28 & 186.03 & 376.76 & 386.58 & 10.32 \\
C-3 & 25 & A & 186.78 & & 387.10 & & 10.32 \\
C-3 & 25 & A & 188.15 & & 388.97 & & 10.32 \\
C-3 & 25 & A & 186.70 & & 388.78 & & 10.32 \\
C-3 & 25 & A & 187.26 & & 391.27 & & 10.32 \\
C-3 & 25 & B & 185.62 & 191.02 & 360.90 & 366.11 & 6.00 \\
C-3 & 25 & B & 190.53 & & 364.35 & & 6.08 \\
C-3 & 25 & B & 193.72 & & 366.55 & & 6.24 \\
C-3 & 25 & B & 193.34 & & 368.79 & & 6.24 \\
C-3 & 25 & B & 191.90 & & 369.98 & & 6.24 \\
C-5 & 50 & A & 183.89 & 188.58 & 415.02 & 419.10 & 7.76 \\
C-5 & 50 & A & 188.45 & & 417.34 & & 7.6 \\
C-5 & 50 & A & 189.27 & & 419.32 & & 7.76 \\
C-5 & 50 & A & 190.38 & & 420.02 & & 7.76 \\
C-5 & 50 & A & 190.93 & & 423.82 & & 7.92 \\
C-5 & 50 & B & 137.24 & 145.43 & 264.72 & 278.71 & 4.56 \\
C-5 & 50 & B & 147.40 & & 282.82 & & 4.88 \\
C-5 & 50 & B & 148.43 & & 282.99 & & 4.96 \\
C-5 & 50 & B & 147.71 & & 281.44 & & 4.96 \\
C-5 & 50 & B & 146.35 & & 281.57 & & 4.88 \\
\hline
\end{tabular}


Table XVII summarizes the AUP and signal energy test results for glass

reinforced specimens evaluated in the near to near configuration using shear receiving transducers.

TABLE XVII

GLASS SPECIMENS TESTED IN THE NEAR TO NEAR CONFIGURATION WITH SHEAR RECEIVING TRANSDUCER

\begin{tabular}{|c|c|c|c|c|c|c|c|}
\hline Beam & $\begin{array}{c}\text { Void } \\
\text { Area } \\
(\%) \\
\end{array}$ & $\begin{array}{c}\text { Sending } \\
\text { Transducer } \\
\text { Location } \\
\text { (side of } \\
\text { beam) } \\
\end{array}$ & $\begin{array}{c}\text { AUP } \\
\text { Results } \\
(\mathrm{V}) \\
\end{array}$ & $\begin{array}{c}\text { Average } \\
\text { Test } \\
\text { AUP } \\
\text { Results } \\
\text { (V) } \\
\end{array}$ & $\begin{array}{c}\text { Total } \\
\text { Energy } \\
(\mathbf{V} * \mathbf{s}) \\
\end{array}$ & $\begin{array}{c}\text { Average } \\
\text { Test } \\
\text { Energy } \\
\text { Results } \\
(\mathbf{V} * \mathbf{s}) \\
\end{array}$ & $\begin{array}{c}\text { Max } \\
\text { Received } \\
\text { Amplitude } \\
(\mathrm{V}) \\
\end{array}$ \\
\hline B-2 & 0 & A & 331.41 & 338.17 & 692.14 & 706.96 & 10.32 \\
\hline B-2 & 0 & A & 330.78 & & 707.66 & & 10.32 \\
\hline B-2 & 0 & A & 342.38 & & 709.33 & & 10.32 \\
\hline B-2 & 0 & A & 342.31 & & 712.21 & & 10.32 \\
\hline B-2 & 0 & A & 343.99 & & 713.45 & & 10.32 \\
\hline B-2 & 0 & B & 278.92 & 313.69 & 507.53 & 580.53 & 9.68 \\
\hline B-2 & 0 & B & 310.29 & & 577.13 & & 10.32 \\
\hline B-2 & 0 & B & 324.43 & & 603.47 & & 10.32 \\
\hline B-2 & 0 & B & 328.45 & & 605.84 & & 10.32 \\
\hline B-2 & 0 & B & 326.36 & & 608.70 & & 10.32 \\
\hline B-6 & 50 & A & 230.47 & 252.91 & 482.64 & 530.70 & 9.52 \\
\hline B-6 & 50 & A & 248.72 & & 527.00 & & 10.08 \\
\hline B-6 & 50 & A & 254.67 & & 538.65 & & 10.24 \\
\hline B-6 & 50 & A & 265.29 & & 550.64 & & 10.32 \\
\hline B-6 & 50 & A & 265.38 & & 554.58 & & 10.32 \\
\hline B-6 & 50 & B & 190.08 & 213.96 & 367.11 & 422.51 & 7.28 \\
\hline B-6 & 50 & B & 214.40 & & 417.10 & & 7.28 \\
\hline B-6 & 50 & B & 214.17 & & 433.42 & & 7.68 \\
\hline B-6 & 50 & B & 221.55 & & 443.87 & & 7.92 \\
\hline B-6 & 50 & B & 229.62 & & 451.04 & & 8.08 \\
\hline $\mathrm{C}-2$ & 0 & A & 222.57 & 229.77 & 398.76 & 418.08 & 10.32 \\
\hline $\mathrm{C}-2$ & 0 & A & 227.56 & & 412.40 & & 10.32 \\
\hline C-2 & 0 & A & 231.55 & & 420.88 & & 10.32 \\
\hline C-2 & 0 & A & 231.80 & & 426.22 & & 10.32 \\
\hline $\mathrm{C}-2$ & 0 & A & 235.37 & & 432.16 & & 10.32 \\
\hline $\mathrm{C}-2$ & 0 & $\mathrm{~B}$ & 332.25 & 341.04 & 674.38 & 698.90 & 10.32 \\
\hline
\end{tabular}




\begin{tabular}{|c|c|c|c|c|c|c|c|}
\hline $\mathrm{C}-2$ & 0 & B & 339.96 & & 697.16 & & 10.32 \\
\hline C-2 & 0 & B & 343.90 & & 706.56 & & 10.32 \\
\hline C-2 & 0 & B & 345.18 & & 707.40 & & 10.32 \\
\hline C-2 & 0 & B & 343.90 & & 709.01 & & 10.32 \\
\hline C-6 & 50 & A & 225.89 & 227.11 & 462.93 & 466.56 & 10.32 \\
\hline C-6 & 50 & A & 227.00 & & 464.10 & & 10.32 \\
\hline C-6 & 50 & A & 227.24 & & 467.13 & & 10.32 \\
\hline C-6 & 50 & A & 228.30 & & 468.44 & & 10.32 \\
\hline C-6 & 50 & A & 227.09 & & 470.18 & & 10.32 \\
\hline C-6 & 50 & B & 223.67 & 234.84 & 408.50 & 423.92 & 8.72 \\
\hline C-6 & 50 & B & 235.58 & & 422.58 & & 9.04 \\
\hline C-6 & 50 & B & 234.87 & & 426.18 & & 8.88 \\
\hline C-6 & 50 & B & 241.04 & & 430.05 & & 8.72 \\
\hline C-6 & 50 & B & 239.03 & & 432.30 & & 8.64 \\
\hline
\end{tabular}


Table XVIII summarizes both the AUP and signal energy results for tests

performed on carbon reinforced beam specimens using a shear receiving transducer in the far to near configuration.

\section{TABLE XVIII}

CARBON SPECIMENS TESTED IN THE FAR TO NEAR CONFIGURATION WITH SHEAR RECEIVING TRANSDUCER

\begin{tabular}{|c|c|c|c|c|c|c|c|}
\hline Beam & $\begin{array}{c}\text { Void } \\
\text { Area } \\
(\%) \\
\end{array}$ & $\begin{array}{c}\text { Sending } \\
\text { Transducer } \\
\text { Location } \\
\text { (side of } \\
\text { beam) } \\
\end{array}$ & $\begin{array}{c}\text { AUP } \\
\text { Results } \\
\text { (V) } \\
\end{array}$ & $\begin{array}{c}\text { Average } \\
\text { Test } \\
\text { AUP } \\
\text { Results } \\
\text { (V) } \\
\end{array}$ & $\begin{array}{c}\text { Total } \\
\text { Energy } \\
\left(V^{*} \mathbf{s}\right) \\
\end{array}$ & $\begin{array}{c}\text { Average } \\
\text { Test } \\
\text { Energy } \\
\text { Results } \\
(\mathbf{V} * \mathbf{s}) \\
\end{array}$ & $\begin{array}{c}\text { Max } \\
\text { Received } \\
\text { Amplitude } \\
(\mathrm{V}) \\
\end{array}$ \\
\hline A-1 & 0 & $\mathrm{~A}$ & 244.79 & 251.67 & 533.03 & 538.53 & 10.32 \\
\hline A-1 & 0 & A & 251.12 & & 535.56 & & 10.32 \\
\hline A-1 & 0 & A & 252.40 & & 536.15 & & 10.32 \\
\hline A-1 & 0 & A & 254.30 & & 542.97 & & 10.32 \\
\hline A-1 & 0 & A & 255.75 & & 544.92 & & 10.32 \\
\hline A-1 & 0 & B & 224.80 & 223.86 & 488.77 & 488.42 & 9.36 \\
\hline A-1 & 0 & B & 223.30 & & 490.37 & & 9.04 \\
\hline A-1 & 0 & B & 221.75 & & 487.94 & & 9.04 \\
\hline A-1 & 0 & B & 225.21 & & 488.66 & & 8.96 \\
\hline A-1 & 0 & $\mathrm{~B}$ & 224.27 & & 486.36 & & 8.80 \\
\hline$A-5$ & 75 & A & 215.51 & 219.31 & 452.07 & 459.41 & 10.32 \\
\hline$A-5$ & 75 & A & 219.19 & & 457.62 & & 10.32 \\
\hline$A-5$ & 75 & A & 220.09 & & 461.19 & & 10.32 \\
\hline$A-5$ & 75 & A & 221.03 & & 463.06 & & 10.32 \\
\hline$A-5$ & 75 & A & 220.74 & & 463.09 & & 10.32 \\
\hline$A-5$ & 75 & $\mathrm{~B}$ & 94.84 & 96.15 & 202.94 & 206.18 & 4.32 \\
\hline A-5 & 75 & B & 96.13 & & 206.15 & & 4.48 \\
\hline$A-5$ & 75 & $\mathrm{~B}$ & 96.76 & & 206.13 & & 4.48 \\
\hline A-5 & 75 & $\mathrm{~B}$ & 95.56 & & 207.70 & & 4.48 \\
\hline$A-5$ & 75 & B & 97.49 & & 208.00 & & 4.4 \\
\hline A-6 & 50 & A & 184.96 & 185.94 & 398.99 & 400.70 & 9.28 \\
\hline A-6 & 50 & A & 186.55 & & 401.06 & & 9.52 \\
\hline A-6 & 50 & A & 186.48 & & 401.02 & & 9.76 \\
\hline A-6 & 50 & A & 184.56 & & 400.10 & & 9.44 \\
\hline A-6 & 50 & A & 187.14 & & 402.33 & & 9.44 \\
\hline A-6 & 50 & B & 85.60 & 95.73 & 165.73 & 188.03 & 3.60 \\
\hline
\end{tabular}




\begin{tabular}{|c|c|c|c|c|c|c|c|}
\hline A-6 & 50 & B & 98.61 & & 190.78 & & 4.16 \\
\hline A-6 & 50 & B & 97.89 & & 191.73 & & 4.16 \\
\hline$A-6$ & 50 & B & 98.78 & & 195.37 & & 4.08 \\
\hline A-6 & 50 & B & 97.77 & & 196.56 & & 4.08 \\
\hline B-1 & 0 & A & 245.04 & 233.91 & 515.10 & 487.34 & 10.32 \\
\hline B-1 & 0 & A & 232.33 & & 478.82 & & 10.32 \\
\hline B-1 & 0 & A & 231.36 & & 479.34 & & 10.32 \\
\hline B-1 & 0 & A & 229.69 & & 480.23 & & 10.32 \\
\hline B-1 & 0 & A & 231.12 & & 483.20 & & 10.32 \\
\hline B-1 & 0 & B & 296.24 & 295.74 & 592.93 & 597.43 & 10.32 \\
\hline B-1 & 0 & B & 293.29 & & 596.02 & & 10.32 \\
\hline B-1 & 0 & B & 298.25 & & 597.98 & & 10.32 \\
\hline B-1 & 0 & B & 294.17 & & 599.93 & & 10.32 \\
\hline B-1 & 0 & B & 296.74 & & 600.30 & & 10.32 \\
\hline B-3 & 25 & A & 247.51 & 247.71 & 483.00 & 484.43 & 10.32 \\
\hline B-3 & 25 & A & 248.25 & & 483.35 & & 10.32 \\
\hline B-3 & 25 & A & 248.29 & & 484.33 & & 10.32 \\
\hline B-3 & 25 & A & 246.76 & & 485.26 & & 10.32 \\
\hline B-3 & 25 & A & 247.73 & & 486.21 & & 10.32 \\
\hline B-3 & 25 & B & 183.63 & 185.76 & 353.53 & 356.16 & 6.96 \\
\hline B-3 & 25 & B & 185.30 & & 355.91 & & 7.04 \\
\hline B-3 & 25 & B & 186.35 & & 355.98 & & 6.96 \\
\hline B-3 & 25 & B & 185.23 & & 357.14 & & 6.96 \\
\hline B-3 & 25 & B & 188.29 & & 358.26 & & 7.20 \\
\hline B-5 & 50 & A & 174.88 & 176.09 & 353.06 & 354.75 & 10.24 \\
\hline B-5 & 50 & A & 176.17 & & 354.66 & & 10.16 \\
\hline B-5 & 50 & A & 177.57 & & 354.73 & & 10.32 \\
\hline B-5 & 50 & A & 175.50 & & 356.74 & & 10.16 \\
\hline B-5 & 50 & A & 176.32 & & 354.57 & & 10.24 \\
\hline B-5 & 50 & B & 168.51 & 169.83 & 315.77 & 316.73 & 6.72 \\
\hline B-5 & 50 & B & 169.55 & & 316.28 & & 6.72 \\
\hline B-5 & 50 & B & 170.66 & & 316.14 & & 6.80 \\
\hline B-5 & 50 & B & 170.90 & & 318.05 & & 6.64 \\
\hline B-5 & 50 & B & 169.55 & & 317.39 & & 6.80 \\
\hline C-1 & 0 & A & 246.65 & 248.21 & 489.48 & 493.08 & 10.32 \\
\hline C-1 & 0 & A & 247.22 & & 491.38 & & 10.32 \\
\hline C-1 & 0 & A & 248.27 & & 493.90 & & 10.32 \\
\hline C-1 & 0 & A & 247.29 & & 494.79 & & 10.32 \\
\hline C-1 & 0 & A & 251.62 & & 495.85 & & 10.32 \\
\hline C-1 & 0 & B & 231.07 & 234.10 & 459.61 & 465.40 & 9.28 \\
\hline C-1 & 0 & B & 233.65 & & 465.33 & & 9.20 \\
\hline C-1 & 0 & B & 235.88 & & 466.97 & & 9.20 \\
\hline $\mathrm{C}-1$ & 0 & $\mathrm{~B}$ & 234.87 & & 466.28 & & 9.44 \\
\hline
\end{tabular}




\begin{tabular}{lccccccc}
\hline C-1 & 0 & B & 235.01 & & 468.81 & & 9.28 \\
C-3 & 25 & A & 250.06 & 249.68 & 535.46 & 535.51 & 10.32 \\
C-3 & 25 & A & 249.03 & & 534.42 & & 10.32 \\
C-3 & 25 & A & 249.59 & & 535.53 & & 10.32 \\
C-3 & 25 & A & 250.07 & & 536.10 & & 10.32 \\
C-3 & 25 & A & 249.67 & & 536.02 & & 10.32 \\
C-3 & 25 & B & 184.09 & 185.25 & 358.04 & 358.77 & 7.52 \\
C-3 & 25 & B & 185.24 & & 357.59 & & 7.36 \\
C-3 & 25 & B & 186.04 & & 358.21 & & 7.36 \\
C-3 & 25 & B & 184.94 & & 361.23 & & 7.68 \\
C-3 & 25 & B & 185.93 & & 358.76 & & 7.60 \\
C-5 & 50 & A & 220.80 & 226.39 & 478.78 & 494.26 & 10.32 \\
C-5 & 50 & A & 225.54 & & 494.85 & & 10.32 \\
C-5 & 50 & A & 227.77 & & 497.86 & & 10.32 \\
C-5 & 50 & A & 229.04 & & 499.79 & & 10.32 \\
C-5 & 50 & A & 228.81 & & 500.02 & & 10.32 \\
C-5 & 50 & B & 152.98 & 158.55 & 300.44 & 309.42 & 5.76 \\
C-5 & 50 & B & 159.72 & & 310.84 & & 6.24 \\
C-5 & 50 & B & 159.17 & & 310.93 & & 6.08 \\
C-5 & 50 & B & 160.91 & & 312.95 & & 6.24 \\
C-5 & 50 & B & 159.96 & & 311.95 & & 6.08 \\
\hline
\end{tabular}


Table XIX summarizes the AUP and signal energy test results for specimens

tested in the far to near transducer configuration using a shear wave receiving transducer.

TABLE XIX

GLASS SPECIMENS TESTED IN THE FAR TO NEAR CONFIGURATION WITH SHEAR RECEIVING TRANSDUCER

\begin{tabular}{|c|c|c|c|c|c|c|c|}
\hline Beam & $\begin{array}{c}\text { Void } \\
\text { Area } \\
(\%)\end{array}$ & $\begin{array}{c}\text { Sending } \\
\text { Transducer } \\
\text { Location } \\
\text { (side of } \\
\text { beam) }\end{array}$ & $\begin{array}{c}\text { AUP } \\
\text { Results } \\
\text { (V) }\end{array}$ & $\begin{array}{c}\text { Average } \\
\text { Test } \\
\text { AUP } \\
\text { Results } \\
\text { (V) }\end{array}$ & $\begin{array}{c}\text { Total } \\
\text { Energy } \\
(\mathrm{V} * \mathbf{s})\end{array}$ & $\begin{array}{c}\text { Average } \\
\text { Test } \\
\text { Energy } \\
\text { Results } \\
(\mathbf{V} * \mathbf{s})\end{array}$ & $\begin{array}{c}\text { Max } \\
\text { Received } \\
\text { Amplitude } \\
\text { (V) }\end{array}$ \\
\hline B-2 & 0 & $\mathrm{~A}$ & 302.70 & 355.48 & 654.06 & 795.71 & 10.32 \\
\hline B-2 & 0 & A & 364.38 & & 811.15 & & 10.32 \\
\hline B-2 & 0 & $\mathrm{~A}$ & 369.61 & & 834.94 & & 10.32 \\
\hline B-2 & 0 & $\mathrm{~A}$ & 369.66 & & 838.71 & & 10.32 \\
\hline B-2 & 0 & $\mathrm{~A}$ & 371.04 & & 839.69 & & 10.32 \\
\hline B-2 & 0 & B & 251.95 & 303.89 & 481.07 & 578.35 & 9.84 \\
\hline B-2 & 0 & $\mathrm{~B}$ & 303.09 & & 570.05 & & 10.32 \\
\hline B-2 & 0 & B & 320.20 & & 603.25 & & 10.32 \\
\hline B-2 & 0 & $\mathrm{~B}$ & 324.83 & & 613.74 & & 10.32 \\
\hline B-2 & 0 & B & 319.38 & & 623.65 & & 10.32 \\
\hline B-6 & 50 & A & 251.50 & 253.79 & 538.69 & 542.15 & 10.32 \\
\hline B-6 & 50 & A & 251.61 & & 540.12 & & 10.32 \\
\hline B-6 & 50 & $\mathrm{~A}$ & 251.27 & & 541.98 & & 10.32 \\
\hline B-6 & 50 & A & 255.51 & & 543.59 & & 10.32 \\
\hline B-6 & 50 & $\mathrm{~A}$ & 259.04 & & 546.39 & & 10.32 \\
\hline B-6 & 50 & B & 237.33 & 238.08 & 463.02 & 464.33 & 10.32 \\
\hline B-6 & 50 & $\mathrm{~B}$ & 237.08 & & 464.04 & & 10.32 \\
\hline B-6 & 50 & B & 239.25 & & 465.05 & & 10.32 \\
\hline B-6 & 50 & B & 238.27 & & 464.72 & & 10.32 \\
\hline B-6 & 50 & B & 238.49 & & 464.82 & & 10.32 \\
\hline C-2 & 0 & A & 441.17 & 440.39 & 1110.14 & 1119.75 & 10.32 \\
\hline $\mathrm{C}-2$ & 0 & A & 437.43 & & 1117.06 & & 10.32 \\
\hline C-2 & 0 & A & 439.02 & & 1120.99 & & 10.32 \\
\hline $\mathrm{C}-2$ & 0 & A & 443.42 & & 1123.76 & & 10.32 \\
\hline C-2 & 0 & A & 440.92 & & 1126.80 & & 10.32 \\
\hline C-2 & 0 & B & 318.71 & 319.90 & 655.56 & 658.14 & 10.32 \\
\hline C-2 & 0 & B & 319.34 & & 657.02 & & 10.32 \\
\hline C-2 & 0 & B & 319.91 & & 658.56 & & 10.32 \\
\hline
\end{tabular}




\begin{tabular}{|c|c|c|c|c|c|c|c|}
\hline C-2 & 0 & B & 320.38 & & 658.73 & & 10.32 \\
\hline C-2 & 0 & B & 321.17 & & 660.82 & & 10.32 \\
\hline C-6 & 50 & A & 235.11 & 234.77 & 500.94 & 501.43 & 10.32 \\
\hline C-6 & 50 & A & 234.23 & & 500.42 & & 10.32 \\
\hline C-6 & 50 & A & 234.24 & & 501.23 & & 10.32 \\
\hline C-6 & 50 & A & 233.52 & & 502.18 & & 10.32 \\
\hline C-6 & 50 & A & 236.77 & & 502.38 & & 10.32 \\
\hline C-6 & 50 & B & 210.86 & 209.82 & 389.38 & 389.57 & 10.32 \\
\hline C-6 & 50 & B & 208.54 & & 389.14 & & 10.32 \\
\hline C-6 & 50 & B & 211.40 & & 389.14 & & 10.32 \\
\hline C-6 & 50 & B & 209.10 & & 389.90 & & 10.32 \\
\hline C-6 & 50 & B & 209.19 & & 390.28 & & 10.32 \\
\hline
\end{tabular}




\section{VITA}

Stanley C. Stoll graduated high school in 1999 from Montrose High School in

Montrose, Colorado. He performed a tour duty with the United States Army from 1999

to 2003. Mr. Stoll received his Bachelor of Science in Civil and Environmental

Engineering from the University of Louisville in 2009. 